Revue de l'Institut des langues et cultures

d'Europe, Amérique, Afrique, Asie et Australie

$29 \mid 2017$

Les femmes en Russie : parcours, mythes et représentations

\title{
ЧАСТНОЕ И ПУБЛИЧНОЕ В ЖИЗНИ ПЕРВЫХ РОССИЙСКИХ ЖЕНЩИН-ИСТОРИКОВ
}

Private and Public Aspects of Daily Life of the First Russian Women Historians

[by Natalia Pushkareva]

\section{Наталья Львовна Пушкарёва}

\section{OpenEdition}

\section{Journals}

Édition électronique

URL : http://journals.openedition.org/ilcea/4318

DOI : 10.4000/ilcea.4318

ISSN : 2101-0609

Éditeur

UGA Éditions/Université Grenoble Alpes

Édition imprimée

ISBN : 978-2-37747-007-5

ISSN : $1639-6073$

Référence électronique

Наталья Львовна Пушкарёва, « Частное и публичное в жизни первых российских женщинисториков », ILCEA [Онлайн], 29 | 2017, Выложить онлайн 30 јuin 2017, Наводить справки в 19 avril 2019. URL : http://journals.openedition.org/ilcea/4318 ; DOI : 10.4000/ilcea.4318

Ce document a été généré automatiquement le 19 avril 2019

(C) ILCEA 


\section{ЧАСТНОЕ И ПУБЛИЧНОЕ В ЖИЗНИ ПЕРВЫХ РОССИЙСКИХ ЖЕНЩИН- ИСТОРИКОВ}

Private and Public Aspects of Daily Life of the First Russian Women Historians

[by Natalia Pushkareva]

Наталья Львовна Пушкарёва

«МОГУЧИМ СТИМУЛОМ ТВОРЧЕСТВА ЯВЛЯЕТСЯ ОГОНЬ чУЖИХ МЫСЛЕЙ И ЗВУКИ чУЖИХ

гОлосов.»

О. А. ДОБИАШ-РОЖДЕСТВЕНСКАЯ

(ПЕРВАЯ ЖЕНЩИНА-ИСТОРИК, ИЗБРАННАЯ

ЧЛЕНОМ-КОРРЕСПОНДЕНТОМ АН СССР) ${ }^{1}$.

\section{Введение}

ИМЕНА ПЕРВЫХ РОССИЙСКИХ ЖЕНЩИН-ИСТОРИКОВ ПОЧТИ ЗАБЫТЫ. ДАННЫЙ ТЕКСТ СТАВИТ ЦЕЛЬЮ НАПОМНИТЬ ИХ, РАВНО КАК ЗАДУМАТЬСЯ НАД ГЕНДЕРНОЙ СОСТАВЛЯЮЩЕЙ ПРОБЛЕМЫ - СВОЕОБРАЗИИ СПОСОБОВ СОЦИАЛЬНОГО ВЫЖИВАНИЯ, ЖИЗНЕННЫХ СТРАТЕГИЙ, ОБРАЗОВ ЖИЗНИ МУЖЧИН И ЖЕНЩИН В ИСТОРИЧЕСКОЙ НАУКЕ, ИХ СОЦИАЛЬНЫХ НАСТРОЕНИЙ, АКСИОСФЕРЫ, БЮДЖЕТА ВРЕМЕНИ, МОДЕЛЕЙ МЕЖЛИЧНОСТНОГО И МЕЖГРУППОВОГО ВЗАИМОДЕЙСТВИЯ. ТЕМАТИЗАЦИЯ ИСТОРИИ ГЕНДЕРНЫХ ДИСКРИМИНАЦИЙ - ЦЕНТРАЛЬНАЯ ПРОБЛЕМА ПРОЕКТА, КОТОРЫМ Я ЗАНИМАЮСЬ УЖЕ МНОГО ЛЕТ И СОСТАВНОЙ ЧАСТЬЮ КОТОРОГО ЯВЛЯЕТСЯ ДАННЫЙ ТЕКСТ. К СОЖАЛЕНИЮ, ЖЕНЩИНЫ-ИСТОРИКИ (ЗА ИСКЛЮЧЕНИЕМ В. Н. ХАРУЗИНОЙ) НЕ ОСТАВИЛИ АВТОБИОГРАФИЙ, ПОЭТОМУ ОБ ИХ ПУТИ В НАУКУ И НАУЧНОЙ УСПЕШНОСТИ МОЖНО СУДИТЬ ЛИШЬ ПО КОСВЕННЫМ ЗАМЕЧАНИЯМ О НИХ ДРУГИХ, ПРЕЖДЕ ВСЕГО мУжчин. 
МНЕ ХОТЕЛОСЬ БЫ РАССКАЗАТЬ О НЕСКОЛЬКИХ СУДЬБАХ, КАЖДАЯ ИЗ КОТОРЫХ БУДУЧИ ЧАСТНОЙ БИОГРАФИЕЙ, СОДЕРЖИТ В СЕБЕ ЧЕРТЫ, ОБЩИЕ ДЛЯ СУЩЕСТВОВАНИЯ ЖЕНЩИНЫ-АВТОРА В ТУ ЭПОХУ, ТИПИЧЕСКИЕ ДЛЯ ВРЕМЕНИ, КОГДА «АКАДЕМИКИ В ЧЕПЦЕ» (ВЫРАЖЕНИЕ АЛЕКСАНДРА ПУШКИНА) ВЫГЛЯДЕЛИ СКОРЕЕ НЕЛЕПО, НЕЖЕЛИ МОГЛИ СТАТЬ ОБРАЗЦОМ ДЛЯ ПОДРАЖАНИЯ.

ЕСЛИ РОДОНАЧАЛЬНИКОМ РОССИЙСКОГО ИСТОРИОПИСАНИЯ ТРАДИЦИОННО СЧИТАЕТСЯ В.Н. ТАТИЩЕВ, ВПЕРВЫЕ ОБОБЩИВШИЙ ЗНАЧИТЕЛЬНЫЙ КРУГ ИСТОЧНИКОВ ДЛЯ ВОССОЗДАНИЯ КАРТИНЫ ОТЕЧЕСТВЕННОГО ПРОШЛОГО, ТО ПЕРВУЮ РУССКУЮ ЖЕНЩИНУИСТОРИКА НАЙТИ КУДА СЛОЖНЕЕ. ВОЗМОЖНО, РЕЧЬ ДОЛЖНА ИДТИ ОБ АЛЕКСАНДРЕ ОСИПОВНЕ ИШИМОВОЙ - АВТОРЕ ПЕРВОГО РОССИЙСКОГО УЧЕБНИКА ИСТОРИИ (18051881) - «ИСТОРИИ РОССИИ В РАССКАЗАХ ДЛЯ ДЕТЕЙ». ПЕРВЫЕ ЕЕ ОБОБЩЕНИЯ (ПЕРЕСКАЗЫ ПЕРВОИСТОЧНИКОВ И ТРУДОВ ИСТОРИКОВ XVIII В.) В ВИДЕ ОТДЕЛЬНЫХ ТЕКСТОВ УВИДЕЛИ СВЕТ В 1830-ЕГГ. РУКОПИСЬ РАССКАЗОВ ВИДЕЛ И ОДОБРИЛ А.С. ПУШКИН, А ВЫШЕДШЕЕ В 1838-1841 ГОДАХ СВОДНОЕ ДВУХТОМНОЕ ИЗДАНИЕ БЫЛО УДОСТОЕНО ДЕМИДОВСКОЙ ПРЕМИИ АКАДЕМИИ НАУК - НАИБОЛЕЕ ПОЧЕТНОЙ НАУЧНОЙ НАГРАДЫ РОССИИ СЕРЕДИНЫ ХІХ В. ВЫСОКО ОЦЕНИЛА СОЧИНЕНИЕ ПИСАТЕЛЬНИЦЫ И РУССКАЯ КРИТИКА.

РАССКАЗ Г-ЖИ ИШИМОВОЙ ДО ТОГО КАРТИНЕН, ЖИВ, УВЛЕКАТЕЛЕН, ЯЗЫК ТАК ПРЕКРАСЕН, ЧТО ЧТЕНИЕ ЕЁ ИСТОРИИ ЕСТЬ ИСТИННОЕ НАСЛАЖДЕНИЕ... ДЛЯ МОЛОДЫХ, ВЗРОСЛЫХ И ДАЖЕ СТАРЫХ ЛЮДЕЙ... [ЭТО] ВАЖНОЕ ПРИОБРЕТЕНИЕ ДЛЯ РУССКОЙ ЛИТЕРАТУРЫ: ТАК БОГАТО СОЧИНЕНИЕ ЕЁ ДРУГИМИ ДОСТОИНСТВАМИ, МЕЖДУ КОТОРЫМИ ПЕРВОЕ МЕСТО ЗАНИМАЕТ ПРЕВОСХОДНЫЙ РАССКАЗ И ПРЕКРАСНЫЙ ЯЗЫК, ОБЛИЧАЮЩИЕ РУКУ ТВЕРДУЮ, ОПЫТНОСТЬ ЛИТЕРАТУРНУЮ, ОСНОВАТЕЛЬНОЕ ИЗУЧЕНИЕ ПРЕДМЕТА, НЕУТОМИМОЕ ТРУДОЛЮБИЕ 2 .

ЭТО БЫЛИ ИМЕННО РАССКАЗЫ ПО ИСТОРИИ, «СОЕДИНЯЮЩИЕ ЗАНИМАТЕЛЬНОСТЬ АНЕКДОТА С ДОСТОВЕРНОСТЬЮ И ВАЖНОСТЬЮ ИСТОРИИ», АДРЕСОВАННЫЕ ДЕТЯМ (НО ТОТ ЖЕ В.Г. БЕЛИНСКИЙ СЧИТАЛ, ЧТО ДЛЯ ДЕТЕЙ ИСТОРИЮ РОССИИ ИЗЛОЖИТЬ НЕВОЗМОЖНО, «И НЕ У ДИТЯТИ ЗАКРУЖИТСЯ ГОЛОВА ОТ НЕПРОХОДИМОЙ ЧАЩИ РОСТИСЛАВОВ И МСТИСЛАВОВ» $)^{3}$.

ВАЖНО, ЧТО ЭТО БЫЛИ ПЕРВЫЕ ТЕКСТЫ ПО ИСТОРИИ, НАПИСАННЫЕ РОССИЯНКОЙ И ПОРУССКИ, ОНА РЕКОНСТРУИРОВАЛА ПРОШЛОЕ И ПЫТАЛАСЬ В ХОДЕ ЭТОЙ РЕКОНСТРУКЦИИ ПЕРЕДАТЬ СВОЕ ОТНОШЕНИЕ К ПРЕДМЕТУ. О САМОЙ А. О. ИШИМОВОЙ МОГЛИ БЫ БЫТЬ УЖЕ НАПИСАНЫ КНИГИ, СУДЬБА ЕЕ БЫЛА ЯРКА, ЖИЗНЬ ПРОДОЛЖИТЕЛЬНА, ВСТРЕЧИ СО ЗВЕЗДАМИ РУССКОЙ ЛИТЕРАТУРЫ НА ПРОТЯЖЕНИИ ВСЕГО ХІХ В. ЛЮБОПЫТНЫ, ДА И О СЕБЕ ОНА ОСТАВИЛА ПОДРОБНУЮ АВТОБИОГРАФИЮ, НО ЕДИНСТВЕННАЯ ПУБЛИКАЦИЯ О НЕЙ — НЕБОЛЬШАЯ СТАТЬЯ НАУЧНО-ПОПУЛЯРНОГО ХАРАКТЕРА СОВСЕМ НЕДАВНЕГО ВРЕМЕНИ, НАПИСАННАЯ К ЕЕ 200-ЛЕТНЕМУ ЮБИЛЕЮ ${ }^{4}$.

6 КОНЕЧНО, А. О. ИШИМОВА БЫЛА СКОРЕЕ ПИСАТЕЛЬНИЦЕЙ, НЕЖЕЛИ УЧЕНЫМ, СИСТЕМАТИЧЕСКИ РАБОТАЮЩИМ С ПЕРВОИСТОЧНИКАМИ, ТЕМ НЕ МЕНЕЕ, СПИСОК ЖЕНЩИН-ИСТОРИКОВ, РОДИВШИХСЯ В «ЦАРСКОЙ РОССИИ», ОТКРЫВАЕТ ИМЕННО ОНА, А ПРОДОЛЖАЕТ ЕЕ МЛАДШАЯ СОВРЕМЕННИЦА ЕЛЕНА ИОСИФОВНА ЛИХАЧЕВА (1836-1904) ОБЩЕСТВЕННАЯ ДЕЯТЕЛЬНИЦА И ПЕРЕВОДЧИЦА, УЧАСТНИЦА ЖЕНСКОГО ДВИЖЕНИЯ ВТОРОЙ ПОЛОВИНЫ ХІХ В., ЖЕНА ЛИБЕРАЛА В. И. ЛИХАЧЕВА, БЫВШЕГО ПЕТЕРБУРГСКИМ ГОРОДСКИМ ГОЛОВОЙ В 1885-1889 ГГ. ЕЕ ПЕРУ ПРИНАДЛЕЖИТ КНИГА, НЕ ПОТЕРЯВШАЯ ЗНАЧЕНИЯ ДО СИХ ПОР (В СИЛУ СКРУПУЛЕЗНОСТИ ПРОДЕЛАННОЙ ЕЮ РАБОТЫ) ЧЕТЫРЕХТОМНИК ПО ИСТОРИИ ЖЕНСКОГО ОБРАЗОВАНИЯ В РОССИИ 
ИТОГОМ ЕЕ МНОГОЛЕТНЕЙ ПРИНАДЛЕЖНОСТИ К ЗАЩИТНИКАМ ЖЕНСКОГО РАВНОПРАВИЯ, ЕЕ АКТИВНОГО СОТРУДНИЧЕСТВА С ЖУРНАЛОМ «ОТЕЧЕСТВЕННЫЕ ЗАПИСКИ», ЕЕ СВЯЗЕЙ С ЛИБЕРАЛЬНО-МЫСЛЯЩЕЙ ЧАСТЬЮ РОССИЙСКОГО ОБЩЕСТВА. ИССЛЕДОВАТЕЛЬСКАЯ РАБОТА ДОПОЛНЯЛАСЬ У ПРЕДСЕДАТЕЛЬНИЦЕЙ КОМИТЕТА ПО ДОСТАВЛЕНИЮ СРЕДСТВ ВЫСШИМ ЖЕНСКИМ КУРСАМ (ВЖК), НАЛАДИЛА СОТРУДНИЧЕСТВО С ПРОФЕССУРОЙ НАУКИ ОНА, КОНЕЧНО ЖЕ, ВОШЛА БЛАГОДАРЯ СВОЕМУ ЧЕТЫРЕХТОМНИКУ, УДОСТОЕННОМУ НАГРАДЫ ИМПЕРАТОРСКОЙ АКАДЕМИИ НАУК. ВЫСОКО ОЦЕНИВАЯ ДОСТОИНСТВА КНИГИ, РЕЦЕНЗЕНТ (АКАДЕМИК С. Ф. ОЛЬДЕНБУРГ) СОЖАЛЕЛ, ЧТО АВТОР «НЕ ЗАДАЕТСЯ ЦЕЛЬЮ УКАЗЫВАТЬ НА ПРИЧИНЫ И СЛЕДСТВИЯ ТЕХ ИЛИ ДРУГИХ ЯВЛЕНИЙ В ИСТОРИИ ЖЕНСКОГО ОБРАЗОВАНИЯ, НЕ СТАВИТ ИХ В СВЯЗЬ С СООТВЕТСТВУЮЩИМИ ЯВЛЕНИЯМИ ОБЩЕСТВЕННОЙ ЖИЗНИ И ИСТОРИИ МУЖСКИХ УЧЕБНЫХ ЗАВЕДЕНИЙ ${ }^{7}$. СПРАВЕДЛИВ ЛИ ЭТОТ УПРЕК, ЕСЛИ И СЕГОДНЯ ЖЕНСКОЕ ОБРАЗОВАНИЕ И ПРОБЛЕМЫ РАВНОПРАВИЯ К ЕГО ДОСТУПУ ОСТАЮТСЯ НАИМЕНЕЕ ИЗУЧЕННОЙ ГЛАВОЙ ИСТОРИИ ОТЕЧЕСТВЕННОГО ОБРАЗОВАНИЯ? МНОГО ЛИ БЫЛО В ПОЗАПРОШЛОМ И ПРОШЛОМ ВЕКЕ ПОДОБНЫХ Е. И. ЛИХАЧЕВОЙ? ПРОСТОЙ ПОДСЧЕТ УКАЗЫВАЕТ, ЧТО ТЕХ, ЧЬИ ЖЕНСКИЕ ИМЕНА ПРОЧНО И ПРИЗНАННО ЗАПИСАНЫ НАВЕКИ НА СКРИЖАЛЯХ РОССИЙСКОГО ИСТОРИОПИСАНИЯ ДО РЕВОЛЮЦИОННЫХ ПОТРЯСЕНИЙ В РОССИИ, СТРОГО ГОВОРЯ, МЕНЕЕ 20 (СМ. ТАБЛИЦУ, КОЛОНКИ 1 и 2).

\begin{tabular}{|c|c|c|}
\hline $\begin{array}{l}1 . \\
\text { ТРУДИВШИЕСЯ В } 1800-1900 \\
\text { ГГ., ПОЛУЧИВШИЕ } \\
\text { ДОМАШНЕЕ ОБРАЗОВАНИЕ И } \\
\text { ЗАНИМАВШИЕСЯ НАУЧНОЙ } \\
\text { РАБОТОЙ ДОМА }\end{array}$ & $\begin{array}{l}2 . \\
\text { ТРУДИВШИЕСЯ И ДО } \\
\text { РЕВОЛЮЦИИ, И ПРИ СОВЕТСКОЙ } \\
\text { ВЛАСТИ ИССЛЕДОВАТЕЛЬНИЦЫ } \\
\text { И ПРЕПОДАВАТЕЛЬНИЦЫ }\end{array}$ & \begin{tabular}{|lr}
3. & \\
СОВЕТСКИЕ & ЖЕНЩИНЫ- \\
ИСТОРИКИ, \\
ЗВАНИЯ \\
КОРРЕСПОНДЕНТОВ \\
АКАДЕМИКОВ АН СССР И РАН ПО \\
ИСТОРИИ
\end{tabular} \\
\hline $\begin{array}{l}\text { А. о. ИшИМОВА (1805-1881) } \\
\text { П. Я. ЛИТВИНОВА } \\
\text { 1904) } \\
\text { Е. И. ЛИХАЧЕВА (1836-1904) } \\
\text { Н. А. БЕЛОЗЕРСКАЯ }(1838- \\
\text { 1912) } \\
\text { П. с. УВАРОВА (1840-1924) } \\
\text { С. К. БРЮЛЛОВА }(1851-1877)\end{array}$ & $\begin{array}{l}\text { А. Я. ЕФИМЕНКО (1848-1918) } \\
\text { Е. Н. ЩЕПКИНА (1854-1938) } \\
\text { В. Н. ХАРУЗИНА (1866-1931) } \\
\text { О. А. } \\
\text { РОЖДЕСТВЕНСКАЯ (1874-1939) } \\
\text { С. И. ПРОТАСОВА (1878-1946) } \\
\text { И. И. ЛЮБИМЕНКО (1878-1959) } \\
\text { Л. И. ОЛАВСКАЯ (1879-1975) } \\
\text { Н. И. СПРЫГИНА (1880-1953) } \\
\text { В. А. КРАЧКОВСКАЯ (1884-1974) } \\
\text { М. А. ОСТРОВСКАЯ (1884-1927) } \\
\text { М. И. МАКСИМОВА (1885-1973) } \\
\text { А. В. ПРУССАК (1887-1956) } \\
\text { Н. В. БРЮЛЛОВА-ШАСКОЛЬСКАЯ } \\
\text { (1889-19З7) } \\
\text { Г. М. ВАСИЛЕВИЧ (1895-1971) }\end{array}$ & $\begin{array}{l}\text { В. П. АДРИАНОВА-ПЕРЕТЦ } \\
(1888-1972) \\
\text { Н. В. ПИГУЛЕВСКАЯ (1894-1970) } \\
\text { А. М. ПАНКРАТОВА (1897-1957) } \\
\text { М. В. НЕЧКИНА (1901-1985) } \\
\text { З. В. УДАЛЬЦОВА (1918-1987) } \\
\text { Т. И. АЛЕКСЕЕВА (1928-2007) } \\
\text { Л. П. РЕПИНА (1947-?) } \\
\text { А. П. БУЖИЛОВА (1960-?) }\end{array}$ \\
\hline
\end{tabular}


ОДНАКО ТЕМ ВАЖНЕЕ СКАЗАТЬ НЕСКОЛЬКО СЛОВ О КАЖДОЙ. ЛИШЬ СОБРАВ ПЕРВИЧНЫЕ БИОГРАФИЧЕСКИЕ ДАННЫЕ О ПЕРВЫХ РУССКИХ ЖЕНЩИНАХ-ИСТОРИКАХ, МОЖНО СОЗДАТЬ ПРЕДПОСЫЛКИ ДЛЯ ИЗУЧЕНИЯ И ТИПИЗАЦИИ ИХ ЖИЗНЕННЫХ СТРАТЕГИЙ. ОДНАКО ТАКАЯ ЗАДАЧА - ТЕМА ОТДЕЛЬНОЙ ИССЛЕДОВАТЕЛЬСКОЙ РАБОТЫ, КОТОРУЮ АВТОР ДАННОГО ТЕКСТА ПЕРЕД СОБОЙ НЕ СТАВИТ.

\section{Трудившиеся в 1800-1900 гг., получившие домашнее образование и занимавшиеся научной работой дома}

9 С НЕКОТОРОЙ УСЛОВНОСТЬЮ В ЧИСЛО ЖЕНЩИН-ИСТОРИКОВ, ПЕРВЫМИ ВСТУПИВШИХ НА ПУТЬ САМОСТОЯТЕЛЬНОГО СОСТАВЛЕНИЯ ИСТОРИЧЕСКИХ СОЧИНЕНИЙ, МОЖНО ВКЛЮЧИТЬ Н.А. БЕЛОЗЕРСКУЮ (1838-1912) - УРОЖДЕННУЮ ГЕН, ДОЧЬ ПРОСТОГО ЛЕСНИЧЕГО, ВЫШЕДШУЮ ЗАМУЖ ЗА КНЯЗЯ В. М. БЕЛОЗЕРСКОГО. ЕЕ ТАЛАНТ РАСЦВЕЛ УЖЕ В 1850-Е ГГ. ПРАВДА, ПРОФЕССИОНАЛЬНО СФОРМИРОВАЛАСЬ ОНА БЛИЖЕ К РУБЕЖУ ХІХ$\mathrm{XX}$ BB. ${ }^{9}$.

МУЖ ПОЗНАКОМИЛ НАДЕЖДУ С Н. И. КОСТОМАРОВЫМ, ОНА УВЛЕКАЛАСЬ И ИМ САМИМ, И ЕГО ИДЕЯМИ, ВПОСЛЕДСТВИИ - ОТКАЗАЛАСЬ ОТ СОВМЕСТНОГО ПРОЖИВАНИЯ С МУЖЕМ, ПО СУТИ РАЗВЕЛАСЬ С НИМ. КОГДА ЭТОТ ИЗВЕСТНЫЙ ИСТОРИК, СТАВШИЙ ЕЕ КУМИРОМ, ВЫНУЖДЕН БЫЛ ОТОЙТИ ОТ ДЕЛ В СВЯЗИ С ОФТАЛЬМОЛОГИЧЕСКИМИ ПРОБЛЕМАМИ, НАДЕЖДА СТАЛА «ЕГО ГЛАЗАМИ». ОНА НАЧИТЫВАЛА ЕМУ ТЕКСТЫ, РАБОТАЛА В АРХИВАХ, РЕДАКТИРОВАЛА, ВЫПОЛНЯЛА ОБЯЗАННОСТИ СЕКРЕТАРЯ. «РУССКИЙ БИОГРАФИЧЕСКИЙ СЛОВАРЬ» И ДРУГИЕ ЭНЦИКЛОПЕДИЧЕСКИЕ ИЗДАНИЯ УПОМИНАЮТ ЕЕ КАК ПЕРЕВОДЧИЦУ ИНОСТРАННЫХ ИСТОРИЧЕСКИХ СОЧИНЕНИЙ, А ТАКЖЕ АВТОРШУ, СОТРУДНИЧАВШУЮ В «ИСТОРИЧЕСКОМ ВЕСТНИКЕ», «РУССКОЙ МЫСЛИ», «РУССКОЙ СТАРИНЕ», НАПИСАВШУЮ НЕМАЛО ПОСЛЕ СМЕРТИ ЕЕ КУМИРА ${ }^{10}$. СКОЛЬКО БЫЛО ВОКРУГ НЕЕ ТАКИХ ЖЕ ВЕРНО СЛУЖИВШИХ МУЖЬЯМ-ИСТОРИКАМ! МОЖНО УПОМЯНУТЬ, СКАЖЕМ, С. А. КАРЕЕВУ (18631926) - ЖЕНУ ЗНАМЕНИТОГО РОССИЙСКОГО ИСТОРИКА Н.И. КАРЕЕВА, ЭТО ОНА ЗАНИМАЛАСЬ ТЕХНИЧЕСКОЙ РАБОТОЙ ПО СОСТАВЛЕНИЮ «ШКОЛЬНОГО ИСТОРИЧЕСКОГО СЛОВАРЯ», КОТОРЫЙ ВЫШЕЛ ПОТОМ ПОД РЕДАКЦИЕЙ ЕЕ МУЖА ${ }^{11}$. ИЗ-ЗА СХОЖЕСТИ ЗВУЧАНИЯ ФАМИЛИЕЙ, Ее ИНОЙ РАЗ ПУТАЮТ С ЖЕНОЙ ИСТОРИКА Н. П. КОРЕЛИНА (1854ПОСЛЕ 1940); СВОЮ ПОМОЩЬ МУЖУ И СОВМЕСТНУЮ РАБОТУ С НИМ ОНА СОХРАНИЛА ДЛЯ ЧИТАТЕЛЯ В НЕОПУБЛИКОВАННЫХ ПОКА ВОСПОМИНАНИЯХ ${ }^{12}$.

ПЕРВУЮ ЖЕНСКУЮ «ВОЛНУ» - РОСТ ЧИСЛА ЖЕНЩИН, ГОТОВЫХ ЗАНЯТЬСЯ ИЗУЧЕНИЕМ ИСТОРИИ ПРОФЕССИОНАЛЬНО - ЛЕГКО РАЗГЛЯДЕТЬ СРЕДИ ТЕХ, КТО ОКАЗАЛСЯ ЗАМЕТЕН В НАУЧНЫХ КРУГАХ СО ВТОРОЙ ПОЛОВИНЫ ХІХ В. С КОНЦА 1850-Х ГГ. В РОССИЙСКОМ ОБЩЕСТВЕ УЖЕ ШИРОКО ОБСУЖДАЛСЯ ВОПРОС О «ДОПУЩЕНИИ ЖЕНЩИН К УНИВЕРСИТЕТСКОМУ ОБРАЗОВАНИЮ ${ }^{13}$. ОН БЫЛ ВОСТРЕБОВАН ВОЗРОСШИМ ЧУВСТВОМ СОБСТВЕННОГО ДОСТОИНСТВА РОССИЯНОК, ИХ СТРЕМЛЕНИЕМ К ИНТЕЛЛЕКТУАЛЬНОЙ НЕЗАВИСИМОСТИ, ЗАИНТЕРЕСОВАННОСТЬЮ В ОБЩЕСТВЕННЫХ ДЕЛАХ ${ }^{14}$. ЭТО «ДОПУЩЕНИЕ» И СТАЛО ВАЖНЕЙШЕЙ ПРЕДПОСЫЛКОЙ ВКЛЮЧЕНИЯ ЖЕНЩИН В НАУЧНУЮ ДЕЯТЕЛЬНОСТЬ.

12 В 1859 Г. ДЛЯ ЖЕНЩИН, СТРЕМЯЩИХСЯ К СИСТЕМАТИЧЕСКИМ ЗАНЯТИЯМ НАУКОЙ, ОТКРЫЛ ДВЕРИ ПЕТЕРБУРГСКИЙ УНИВЕРСИТЕТ. «СОТНИ ДАМ И ДЕВИЦ» ПОЯВИЛИСЬ В 
АУДИТОРИЯХ КИЕВСКОГО И ХАРЬКОВСКОГО УНИВЕРСИТЕТОВ, В ЗАЛАХ ПЕТЕРБУРГСКОЙ «ПУБЛИЧКИ» И РУМЯНЦЕВСКОЙ БИБЛИОТЕКИ В МОСКВЕ ${ }^{15}$. НА УЛИЦАХ КРУПНЫХ ГОРОДОВ КОНЦА 1850-Х ГГ. ПОЯВИЛИСЬ МОЛОДЫЕ ЖЕНЩИНЫ С КНИГАМИ И ТЕТРАДЯМИ В РУКАХ, «НЕКОТОРЫЕ ИЗ НИХ РАБОТАЛИ, НЕ ПЕРЕСТАВАЯ, ОТ 3 ДО 9 ЧАСОВ ВЕЧЕРА» ${ }^{16}$. РАСПРОСТРАНЕННОЙ ФОРМОЙ ОБУЧЕНИЯ ЖЕНЩИН БЫЛИ ТОГДА И «ЛЕТУЧИЕ УНИВЕРСИТЕТЫ» НА ЧАСТНЫХ КВАРТИРАХ: ТАМ ЧИТАЛИСЬ БЕСПЛАТНЫЕ ЛЕКЦИИ ВЕДУЩИМИ ПРОФЕССОРАМИ И ПРЕПОДАВАТЕЛЯМИ, ОНИ ПОМОГАЛИ МОЛОДЫМ УЧЕНЫМ ЖЕНЩИНАМ ОПРЕДЕЛИТЬ СВОЙ ПУТЬ В НАУКУ.

ПОНЯТНО, ЧТО ПЕРВЫЕ ЖЕНЩИНЫ-ИСТОРИКИ ДОЛЖНЫ БЫЛИ БЫТЬ ВЫХОДЦАМИ ИЗ САМОГО ОБРАЗОВАННОГО СОСЛОВИЯ - ДВОРЯНСКОГО: ТОЛЬКО И ИМЕННО ТАМ МОЖНО БЫЛО ПОЛУЧИТЬ ДО НАЧАЛА «ВЕЛИКИХ РЕФОРМ», ДО СЕРЕДИНЫ 1860-Х ГГ., БОЛЕЕ ИЛИ МЕНЕЕ СНОСНОЕ ДОМАШНЕЕ ОБРАЗОВАНИЕ. В ГРАФСКОЙ СЕМЬЕ РОДИЛАСЬ ВЫДАЮЩИЙСЯ ИСТОРИК И АРХЕОЛОГ, МАТЬ ШЕСТЕРЫХ ДЕТЕЙ, ГЛАВА МОСКОВСКОГО АРХЕОЛОГИЧЕСКОГО ОБЩЕСТВА, КОМИССИИ ПО СОХРАНЕНИЮ ДРЕВНИХ ПАМЯТНИКОВ, ОДНА ИЗ ОСНОВАТЕЛЬНИЦ ИСТОРИЧЕСКОГО МУЗЕЯ НА КРАСНОЙ ПЛОЩАДИ В МОСКВЕ, ПЕРВАЯ ЖЕНЩИНА-ПОЧЕТНЫЙ ЧЛЕН РОССИЙСКОЙ АКАДЕМИИ НАУК ПРАСКОВЬЯ СЕРГЕЕВНА УВАРОВА $(1840-1924)^{17}$.

ОНА БЫЛА ВТОРОЙ ПОСЛЕ КНЯГИНИ Е.Р. ДАШКОВОЙ ЖЕНЩИНОЙ, ИЗБРАННОЙ ДЕЙСТВИТЕЛЬНЫМ ПОЛНЫМ ПОЧЕТНЫМ ЧЛЕНОМ ПЕТЕРБУРГСКОЙ АКАДЕМИИ НАУК, И ЭТИ ЗАСЛУГИ Ее БЕССПОРНЫ, ПОСКОЛЬКУ БЫЛА ПЕРВОЙ РУССКОЙ УЧЕНОЙ, СТАВШЕЙ ОРГАНИЗАТОРОМ НАУКИ (П. С. УВАРОВА СУМЕЛА СОЗВАТЬ НЕСКОЛЬКО ВСЕРОССИЙСКИХ АРХЕОЛОГИЧЕСКИХ КОНГРЕССОВ) И, ОДНОВРЕМЕННО, АВТОРОМ ОКОЛО 200 НАУЧНЫХ РАБОТ. В СВОИХ ВОСПОМИНАНИЯХ ОНА, ПРОФЕССОР АРХЕОЛОГИИ ДЕРПТСКОГО УНИВЕРСИТЕТА, ПИСАЛА:

В МАЕ 1885 ГОДА АРХЕОЛОГИЧЕСКОЕ ОБЩЕСТВО ИЗБИРАЕТ МЕНЯ СВОЕЙ ПРЕДСЕДАТЕЛЬНИЦЕЙ. БОЯСЬ ОТВЕТСТВЕННОСТИ ЗА БЕЗДЕЯТЕЛЬНОСТЬ ОБЩЕСТВА И НЕ НАХОДЯ МЕЖДУ СОБОЙ ЧЕЛОВЕКА СВОБОДНОГО И РАБОТОСПОСОБНОГО, ОНИ РЕШИЛИ, ЧТО ‘... ЕСЛИ Я ОКАЖУСЬ НЕСПОСОБНОЙ, ТО ВСЕГДА ЛЕГЧЕ И ДЛЯ НИХ ПОКОЙНЕЕ СВАЛИТЬ ВИНУ НА СЛАБУЮ НЕСПОСОБНУЮ ЖЕНЩИНУ. '... Я ПОБЛАГОДАРИЛА И ПООБЕЩАЛА БЫТЬ ОБЩЕСТВУ ПОСЛУЖНИЦЕЙ ${ }^{18}$.

НА ТОТ МОМЕНТ ЕЙ БЫЛО 45 ЛЕТ. НЕ РАЗ НА СТРАНИЦАХ Ее ВОСПОМИНАНИЙ ПОПАДАЮТСЯ ОПИСАНИЯ ЕЕ ВСТРЕЧ С УЧЕНЫМИ В ДРУГИХ СТРАНАХ, КОТОРЫЕ «НЕ ПРИВЫКЛИ ВИДЕТЬ РУССКУЮ ДАМУ, ЗАНИМАЮЩУЮСЯ НАУКАМИ, А ТЕМ БОЛЕЕ АРХЕОЛОГИЕЙ», НО ОТМЕЧАВШИМИ, ЧТО ОНА «ВЕЛА ДЕЛА С БЛЕСКОМ» ${ }^{19}$. ЛЮБОПЫТНО, ЧТО ВО ВРЕМЯ ПЕРВОЙ МИРОВОЙ ВОЙНЫ, КОГДА РУССКИЕ ВОЙСКА ОКАЗАЛИСЬ ПОД КЕНИГСБЕРГОМ, ИМЯ П.С. УВАРОВОЙ БЫЛО НЕМЕДЛЕННО ВЫЧЕРКНУТО ИЗ СПИСКОВ ДЕЙСТВИТЕЛЬНЫХ ЧЛЕНОВ НЕМЕЦКОЙ АКАДЕМИИ НАУК.

ПОД СТАТЬ ЕЙ РОЖДЕННАЯ В СЕМЬЕ ПОТОМСТВЕННЫХ ДВОРЯН ДОЧЬ ЗНАМЕНИТОГО ИСТОРИКА К. Д. КАВЕЛИНА, С. К. КАВЕЛИНА, В ЗАМУЖЕСТВЕ - БРЮЛЛОВА (1851-1877), БЕЗВРЕМЕННО РАНО, В 26 ЛЕТ, УМЕРШАЯ, КАК ПИСАЛИ О НЕЙ В НЕКРОЛОГЕ, «ОТ ПОСЛЕДСТВИЙ БЕРЕМЕННОСТИ ${ }^{20} »$. ОНА ИЗВЕСТНА СВОИМИ ПЕРЕВОДАМИ, ПУБЛИКАЦИЯМИ ПО ИСТОРИИ РОССИИ ЕКАТЕРИНИНСКОЙ ЭПОХИ «ПРЕКРАСНО ВЛАДЕЯ СЛОВОМ, - ПИСАЛ О НЕЙ И.С. ТУРГЕНЕВ, - ОНА ПРИНИМАЛА САМОЕ ДЕЯТЕЛЬНОЕ УЧАСТИЕ В ДИСПУТАХ ПЕДАГОГИЧЕСКИХ ОБЩЕСТВ, ПРИЧЕМ ВСЕГДА ОБНАРУЖИВАЛА СЕРЬЕЗНОСТЬ ПОЗНАНИЙ, НАХОДЧИВОСТЬ И МЕТКОСТЬ ВОЗРАЖЕНИЙ ${ }^{21}$ ». 
ПРЕДСТАВИТЕЛЬНИЦЫ ПРИВИЛЕГИРОВАННЫХ СЛОЕВ УСТРЕМЛЯЛИСЬ В СФЕРЫ ИНТЕЛЛИГЕНТНОГО ТРУДА ${ }^{22}$, НО ДАВЛЕНИЕ СТЕРЕОТИПОВ БЫЛО ОГРОМНЫМ. ПОПЫТКА ПРОБРАТЬСЯ В ЗАПРЕЩЕННУЮ ДЛЯ ЖЕНЩИН СФЕРУ НАУЧНЫХ ЗАНЯТИЙ, СТРАЩАЛИ КОНСЕРВАТИВНО НАСТРОЕННЫЕ ВОСПИТАТЕЛИ УМОВ, БУДЕТ ИМЕТЬ ПОСЛЕДСТВИЯ ДЛЯ НАРУШИТЕЛЬНИЦ, «УМСТВЕННЫЕ СИЛЫ КОТОРЫХ ОКАЖУТСЯ РАЗВИТЫ В УЩЕРБ ДРУГИМ СПОСОБНОСТЯМ ДУШИ», ПОРОДИВ ПОПУТНО «СТРАННОСТИ ХАРАКТЕРА УЧЕНЫХ ЖЕНЩИН». «УЧЕНАЯ ЖЕНЩИНА НЕ МОЖЕТ БЫТЬ ХОРОШЕЙ ЖЕНОЙ!», «ГОРЕ МИРУ, ЕСЛИ ЖЕНЩИНА БУДЕТ ЗНАЮЩЕЙ ${ }^{23}$ » - ТЕЗИСЫ, ИЗВЕСТНЫЕ СТОРОННИКАМ НЕДОПУЩЕНИЯ ЖЕНСКОГО ПОЛА В НАУКУ ${ }^{24}$, ПОВТОРЯЛИСЬ НА РАЗНЫЕ ЛАДЫ ВО МНОЖЕСТВЕ ПУБЛИКАЦИЙ ВТОРОЙ ПОЛОВИНЫ ХІХ В.

ЗАНЯТИЯ НАУКАМИ И ЧТЕНИЕМ, - УТВЕРЖДАЛОСЬ В ОДНОЙ ИЗ НИХ, - ПАГУБНЫ ДЛЯ ЖЕНЩИН, ПОТОМУ ЧТО ОНИ ОТВЛЕКАЮТ ИХ ЖИЗНЕННЫЕ СИЛЫ К МОЗГУ И ТАКИМ ОБРАЗОМ ЛИШАЮТ ПОЛОВЫЕ ОРГАНЫ ЕСТЕСТВЕННОЙ ИХ СИЛЫ. ПОТОМУ-ТО УЧЕНЫЕ ЖЕНЩИНЫ ОБЫКНОВЕННО БЫВАЮТ ИЛИ БЕСПЛОДНЫ, ИЛИ ПОДВЕРЖЕНЫ ОПАСНЕЙШИМ ПРИПАДКАМ ВО ВРЕМЯ БЕРЕМЕННОСТИ ${ }^{25}$.

31 МАЯ 1861 ГОДА ВРЕМЕННЫЕ ПРАВИЛА, УТВЕРЖДЕННЫЕ ГОСУДАРЕМ, ЗАПРЕТИЛИ ЖЕНЩИНАМ ДОСТУП В РОССИЙСКИЕ УНИВЕРСИТЕТЫ ДАЖЕ ВОЛЬНОСЛУШАТЕЛЬНИЦАМИ . ЧТО ЭТО ЗНАЧИЛО? НОВЫЙ ШАГ В СТОРОНУ ИЛИ ДАЖЕ НАЗАД ОТ ЗАНЯТИЙ НАУЧНОЙ ДЕЯТЕЛЬНОСТЬЮ! УНИВЕРСИТЕТСКИЙ УСТАВ 1863 ГОДА КАТЕГОРИЧЕСКИ ЗАПРЕТИЛ ПРИЕМ ЖЕНЩИН-СТУДЕНТОК В ВЫСШИЕ УЧЕБНЫЕ ЗАВЕДЕНИЯ. К 1864 Г. ЖЕНЩИН В НИХ НЕ ОСТАЛОСЬ ${ }^{27}$. ТАК ВЛАСТИ ОТПЛАТИЛИ СТУДЕНТКАМ-ШЕСТИДЕСЯТНИЦАМ ЗА ИХ УЧАСТИЕ В ВОЛНЕНИЯХ, ЗА ПРОТЕСТ ПРОТИВ ГЕНДЕРНОГО И СОЦИАЛЬНОГО НЕРАВЕНСТВА - ЗА ВСЕ ТО, ЧЕМ БЫЛО ОТМЕЧЕНО ПРЕДЫДУЩЕЕ ДЕСЯТИЛЕТИЕ. ПРОТИВНИКОМ ВЫСШЕГО ЖЕНСКОГО ОБРАЗОВАНИЯ И ТЕМ БОЛЕЕ ДОПУЩЕНИЯ ЖЕНЩИН В НАУКУ БЫЛ ЗНАМЕНИТЫЙ КОНСЕРВАТОР ВТОРОЙ ПОЛОВИНЫ ХІХ В. В.П. МЕЩЕРСКИЙ, ПРИЗЫВАВШИЙ: «УЧИТЕ ТАК, КАК УЧИЛИ ДЕВОЧЕК ВО ДНИ ЕКАТЕРИНЫ II И ВО ДНИ ПУШКИНА, И ТОГДА ВЫ ПОЛУЧИТЕ ЖЕНЩИН ОБРАЗОВАННЫХ, НО НЕ УЧЕНЫХ ${ }^{28}$.»

\section{Исследовательницы и преподавательницы, трудившиеся до революции и при Советской власти}

\section{А. Я. Ефименко}

С СЕРЕДИНЫ ХІХ В. ЧИСЛО ЖЕНЩИН, ПОСВЯТИВШИХ СЕБЯ НАУЧНЫМ ИЗЫСКАНИЯМ НА НИВЕ ИСТОРИИ ВОЗРОСЛО, НО ЗАНЯТИЯ НАУКОЙ В «ДОМАШНИХ УСЛОВИЯХ» И РАБОТА В ОБЩЕСТВЕННЫХ НАУЧНЫХ АССОЦИАЦИЯХ ВСЕ ЭТО ВРЕМЯ ОСТАВАЛИСЬ ПОЧТИ ЕДИНСТВЕННЫМИ ДОСТУПНЫМИ ДЛЯ ЖЕНЩИН ФОРМАМИ ПРИОБЩЕНИЯ К НАУЧНОЙ ДЕЯТЕЛЬНОСТИ, ПРИЧЕМ ЭТНОГРАФИЯ В СИЛУ СВОЕЙ ОПИСАТЕЛЬНОСТИ ПРИВЛЕКАЛА ИХ СКОРЕЕ И ЧАЩЕ, НЕЖЕЛИ ПОЛИТИЧЕСКАЯ ИСТОРИЯ. НЕКОТОРЫЕ ИЗ ПРИОБЩИВШИХСЯ НАУКЕ ЖЕНЩИН ОСТАВИЛИ ВЕСЬМА ИНТЕРЕСНЫЕ ТРУДЫ. ОДНОЙ ИЗ ПЕРВЫХ ИЗ НИХ БЫЛА ПЕЛАГЕЯ ЯКОВЛЕВНА ЛИТВИНОВА (1833-1904)29; ПРОДОЛЖАТЕЛЬНИЦЕЙ ЕЕ ИНТЕРЕСА К ИСТОРИИ ИСКУССТВА, НО УЖЕ НЕ РУССКОГО НАРОДНОГО, А АНТИЧНОГО БЫЛА ЕЕ МЛАДШАЯ СОВРЕМЕННИЦА МАРИЯ ИВАНОВНА МАКСИМОВА (1885-1973) ${ }^{30}$. НО САМУЮ БОЛЬШУЮ ИЗВЕСТНОСТЬ ИМЕЕТ, НЕСОМНЕННО, АЛЕКСАНДРА ЯКОВЛЕВНА ЕФИМЕНКО, УРОЖДЕННАЯ СТАВРОВСКАЯ (1848-1918) ${ }^{31}$. ЕСЛИ В ПЕРВОЙ ПОЛОВИНЕ ХІХ В. 
ОСНОВОЙ ОБРАЗОВАНИЯ ЖЕНЩИН-ИСТОРИКОВ БЫЛО САМООБРАЗОВАНИЕ, КОТОРОЕ МНОГИМ ДВОРЯНКАМ ДАВАЛО ИХ ДВОРЯНСКОЕ ПРОИСХОЖДЕНИЕ - ПРИ ЭТОМ М.А. ОСТРОВСКАЯ, С. К. БРЮЛЛОВА (КАВЕЛИНА), О. А. ДОБИАШ-РОЖДЕСТВЕНСКАЯ БЫЛИ ДАЖЕ ПОТОМСТВЕННЫМИ ДВОРЯНКАМИ, ТО СУДЬБЫ, ПОДОБНЫЕ СУДЬБЕ А. Я. ЕФИМЕНКО, БЫЛИ СКОРЕЕ РЕДКОСТЬЮ. БУДУЩАЯ ИССЛЕДОВАТЕЛЬНИЦА РОДИЛАСЬ В СЕМЬЕ ЧИНОВНИКА АРХАНГЕЛЬСКОЙ ГУБЕРНИИ И НАСТОЯЩИМИ «УНИВЕРСИТЕТАМИ» ДЛЯ НЕЕ СТАЛИ ЕЕ БРАТЬЯ - МИХАИЛ, АЛЕКСЕЙ И НИКОЛАЙ, ОСТАВИВШИЕ БОЛЬШОЙ СЛЕД В ЕСТЕСТВОЗНАНИИ, АНТРОПОЛОГИИ, ЭТНОГРАФИИ ${ }^{32}$. ПОЛУЧИВ ПОСЛЕ ГИМНАЗИИ ДИПЛОМ ДОМАШНЕЙ УЧИТЕЛЬНИЦЫ, АЛЕКСАНДРА СТАВРОВСКАЯ СОВСЕМ ЮНОЙ ВЫШЛА ЗАМУЖ ЗА ПОЛИТИЧЕСКОГО ССЫЛЬНОГО, ФОЛЬКЛОРИСТА НАРОДНИЧЕСКОГО ТОЛКА П. С. ЕФИМЕНКО И С ЭТОГО МОМЕНТА ЕЕ ПУБЛИКАЦИИ В ЭТНОГРАФИЧЕСКИХ И ИСТОРИЧЕСКИХ ЖУРНАЛАХ СТАЛИ ОСНОВНЫМ ИСТОЧНИКОМ ЗАРАБОТКА СЕМЬИ. УКРАИНСКАЯ ФАМИЛИЯ, ПО КОТОРОЙ НЕ ОПРЕДЕЛИТЬ ГЕНДЕРНУЮ ПРИНАДЛЕЖНОСТЬ, ИЗБАВИЛА АЛЕКСАНДРУ ОТ НЕОБХОДИМОСТИ ПУБЛИКОВАТЬСЯ ПОД ЧУЖИМ, МУЖСКИМ ИМЕНЕМ. В ЦЕЛОМ ТАКАЯ ПРАКТИКА ВПЛОТЬ ДО 1920-ХГГ. ВО МНОГИХ СТРАНАХ ЕВРОПЫ БЫЛА ДЛЯ ЖЕНЩИН РАСПРОСТРАНЕННОЙ, ДА И В РОССИИ ТОЖЕ ${ }^{33}$.

СУДЬБУ А. Я. ЕФИМЕНКО ЛЕГКОЙ НЕ НАЗОВЕШЬ. ОНА ПОДНЯЛА ПЯТЕРЫХ ДЕТЕЙ, УХАЖИВАЛА ЗА ПОСТОЯННО БОЛЕЮЩИМ МУЖЕМ, ТАКЖЕ ЭТНОГРАФОМ И ССЫЛЬНЫМ, КОТОРОГО ПЕРЕНАПРАВЛЯЛИ ТО В АРХАНГЕЛЬСКУЮ, ТО В ВОЛОГОДСКУЮ ГУБЕРНИЮ, МЕТАЛАСЬ МЕЖДУ НИМ И МАТЕРЬЮ, ЖИВШЕЙ В СОСЕДНИХ С АРХАНГЕЛЬСКОМ ХОЛМОГОРА ${ }^{34}$. НО ТО, ЧТО СДЕЛАНО ИССЛЕДОВАТЕЛЬНИЦЕЙ КАК УЧЕНЫМ, НЕСЕТ ПЕЧАТЬ ЛЕГКОСТИ ЯЗЫКА И ИЗЛОЖЕНИЯ, ОНА ХОРОШО УМЕЛА ПОПУЛЯРИЗИРОВАТЬ НАУКУ, А НАУЧНЫЕ ИЗЫСКАНИЯ А. Я. ЕФИМЕНКО ВНЕСЛИ БОЛЬШОЙ ВКЛАД В ОБСУЖДЕНИЕ ТЕОРИЙ О ПРОИСХОЖДЕНИИ И ОСОБЕННОСТЯХ РУССКОЙ ОБЩИНЫ, ОБ ОСОБЕННОСТЯХ ЖИЗНИ НА РУССКОМ СЕВЕРЕ, ЕЕ РОДИНЕ. ДАНЬЮ НАРОДНИЧЕСКИМ ИДЕАЛАМ АЛЕКСАНДРЫ СТАЛИ ЕЕ РАБОТЫ ПО ИСТОРИИ «ТРУДОВОГО НАЧАЛА» В РУССКОМ НАРОДНОМ ПРАВЕ.

В НАЧАЛЕ 1900-Х ГГ. СЕМЬЯ ЕФИМЕНКО ПЕРЕЕХАЛА В УКРАИНУ, В ХАРЬКОВ. ТУТ ОНА ВЫСТУПАЛА ПЕРЕД БОЛЬШИМИ АУДИТОРИЯМИ С ЛЕКЦИЯМИ О ЖИЗНИ И ТВОРЧЕСТВЕ Т.Г. ШЕВЧЕНКО, И. П. КОТЛЯРЕВСКОГО, Г. С. СКОВОРОДЫ, КАК И ПРЕЖДЕ, ОКАЗЫВАЛА ПОМОЩЬ В НАУЧНОМ ТВОРЧЕСТВЕ СВОЕМУ МУЖУ 35 . КАК ВСПОМИНАЛ АКАДЕМИК Д. И. БАГАЛЕЙ,

<... ХАРЬКОВСКАЯ ЖИЗНЬ СЕМЬИ ЕФИМЕНКО БЫЛА ОЧЕНЬ ПРОСТОЙ, НАЧИНАЯ С ПОМЕЩЕНИЯ И КОНЧАЯ МЕБЕЛЬЮ (И ТЕПЕРЬ ПРИПОМИНАЮ СКРИПЯЩИЙ ДИВАН В ИХ КОМНАТЕ), ОДЕЖДОЙ (ВОЛЧЬЯ ШУБА П.С. ЕФИМЕНКО). НО ЭТИ КВАРТИРЫ, В КОТОРЫХ ПРОЖИВАЛИ АЛЕКСАНДРА ЯКОВЛЕВНА И ПЕТР САВВИЧ, ПРИВЛЕКАЛИ К СЕБЕ ВСЕХ, КТО ИМЕЛ НАСЛАЖДЕНИЕ ПОЗНАКОМИТЬСЯ С НИМИ ‘... ${ }^{36}$.

ПОСЛЕ СМЕРТИ ДВУХ ДОЧЕРЕЙ, А ПОТОМ МУЖА, ИССЛЕДОВАТЕЛЬНИЦА НЕ ОСТАВИЛА НАУЧНОЙ РАБОТЫ, И ВСКОРЕ ЕЕ НАУЧНЫЙ ПОДВИГ, МНОЖЕСТВО ПУБЛИКАЦИЙ, ЛЕКЦИЙ БЫЛ ОЦЕНЕН ${ }^{37}$. В 1910 Г., В ГОД 40-ЛЕТИЯ НАУЧНОЙ ДЕЯТЕЛЬНОСТИ УЧЕНОЙ, ХАРЬКОВСКИЙ УНИВЕРСИТЕТ ВОЗВЕЛ ЕЕ В СТЕПЕНЬ ДОКТОРА ИСТОРИИ honoris causa (УНИВЕРСИТЕТСКИЙ УСТАВ В ДАННОМ ГОРОДЕ ПОЗВОЛЯЛ ВОЗВОДИТЬ В ЭТУ СТЕПЕНЬ ЖЕНЩИНУ). С ТОГО ЖЕ 1910 ГОДА ЕФИМЕНКО СТАЛА ПРОФЕССОРОМ САНКТПЕТЕРБУРГСКИХ ВЫСШИХ ЖЕНСКИХ КУРСОВ.

БУРНЫЕ СОБЫТИЯ ОКТЯБРЯ 1917 ГОДА ВЫГНАЛИ А. Я. ЕФИМЕНКО, КОТОРОЙ БЫЛО УЖЕ ОКОЛО 70-ТИ, ВМЕСТЕ С ДОЧЕРЬЮ ТАТЬЯНОЙ ИЗ СТОЛИЦЫ ОБРАТНО В ХАРЬКОВ, А ОТТУДА НА НЕБОЛЬШОЙ ХУТОР ЛЮБОЧКА ${ }^{38}$. НА НЕМ, В НОЧЬ С 17 НА 18 ДЕКАБРЯ ОБЕ ТРАГИЧЕСКИ ПОГИБЛИ, РАССТРЕЛЯННЫЕ ВОРВАВШИМИСЯ В МАЛЕНЬКИЙ ДОМИК БАНДИТАМИ ${ }^{39}$. 
ТВОРЧЕСТВО А. Я. ЕФИМЕНКО КАК ИСТОРИКА НЕОДНОКРАТНО ПРИВЛЕКАЛО ВНИМАНИЕ УКРАИНОВЕДОВ, В УКРАИНЕ ИЗДАНЫ НЕСКОЛЬКО БИОГРАФИЧЕСКИХ ОЧЕРКОВ О НЕЙ, РАССКАЗЫВАЮЩИХ В ТОМ ЧИСЛЕ И О ЕЕ ЛЕКТОРСКОЙ ДЕЯТЕЛЬНОСТИ. МЕНЬШЕ ГОВОРИТСЯ О ТОМ, ЧТО ОНА АКТИВНО ВЫСТУПАЛА ЗА ЖЕНСКУЮ ЭМАНСИПАЦИЮ, ПОДДЕРЖИВАЛА ИДЕИ «РАВНОПРАВОК» (СОЮЗА РАВНОПРАВИЯ). ПО СУТИ ДЕЛА, ФИГУРА А. Я. ЕФИМЕНКО ЗАМЫКАЕТ ТОТ НЕБОЛЬШОЙ ПЕРЕЧЕНЬ ЖЕНЩИН-ИСТОРИКОВ, КОТОРЫЕ ТВОРИЛИ В РОССИИ ДО РЕВОЛЮЦИИ. ИХ, КАК МЫ ПОНЯЛИ, ВСЕГО ПЯТЬ.

ДРУГИМ РОВЕСНИЦАМ А. Я. ЕФИМЕНКО, А ОСОБЕННО ЕЕ МЛАДШИМ КОЛЛЕГАМ, ПОВЕЗЛО БОЛЬШЕ: ПОЛУЧИВ ОБРАЗОВАНИЕ, А ЗАЧАСТУЮ И НАЧАВ РАБОТУ ЕЩЕ ДО РЕВОЛЮЦИОННЫХ И ВОЕННЫХ ПОТРЯСЕНИЙ 1910-Х ГГ., ОНИ ПРОДОЛЖИЛИ ЕЕ ПОСЛЕ, В ЛУЧШЕЙ ИЛИ ХУДШЕЙ СТЕПЕНИ ВПИСАВШИСЬ ВО ВНОВЬ СОЗДАВАЕМЫЕ ПОСЛЕ РЕВОЛЮЦИИ НАУЧНЫЕ СТРУКТУРЫ. ТАКОВЫХ - РОДИВШИХСЯ ЕЩЕ В ХІХ СТОЛЕТИИ, НО УСПЕВШИХ ПОРАБОТАТЬ НА НАУЧНОЙ НИВЕ И ДО, И ПОСЛЕ 1917 ГОДА, ТОЖЕ МЕНЕЕ ДЕСЯТКА: Е.Н. ЩЕПКИНА (1854-1938), В. Н. ХАРУЗИНА (1866-1931), О. А. ДОБИАШРОЖДЕСТВЕНСКАЯ (1874-1939), Л. И. ОЛАВСКАЯ (1879-1975), С. И. ПРОТАСОВА (18781946), Н. И. СПРЫГИНА (1880-1953), М. А. ОСТРОВСКАЯ (1884-1927).

\section{Е. Н. Щепкина}

О ПЕРВОЙ ИЗ НАЗВАННЫХ В ЭТОМ СПИСКЕ, ЕКАТЕРИНЕ НИКОЛАЕВНЕ ЩЕПКИНОЙ, СТОИТ СКАЗАТЬ ОСОБО. ЭТО БЫЛА ПЕРВАЯ ЖЕНЩИНА-ИСТОРИК, РЕШИВШАЯ НАПИСАТЬ СПЕЦИАЛЬНЫЕ ИССЛЕДОВАНИЯ, ПОСВЯЩЕННЫЕ ИСТОРИИ РУССКИХ ЖЕНЩИН, А ТАКЖЕ ИСТОРИИ ДВИЖЕНИЯ ЖЕНЩИН ЗА РАВНОПРАВИЕ. ПУБЛИКОВАЛИСЬ ОНИ И В ЖУРНАЛАХ, И ОТДЕЛЬНЫМИ КНИГАМИ, НО ВПЛОТЬ ДО 2000-Х ГГ., КОГДА В СТРАНЕ ВОЗНИК ИНТЕРЕС К ЖЕНСКОЙ ИСТОРИИ КАК ОСОБОМУ НАПРАВЛЕНИЮ ИЗУЧЕНИЯ ОТЕЧЕСТВЕННОГО ПРОШЛОГО ${ }^{40}$, НЕ ПЕРЕИЗДАВАЛИСЬ. Е. Н. ЩЕПКИНА ОКОНЧИЛА ВЫСШИЕ ЖЕНСКИЕ КУРСЫ ПРОФЕССОРА ГЕРЬЕ, РАБОТАЛА УЧИТЕЛЬНИЦЕЙ ИСТОРИИ В САРАТОВЕ И МОСКВЕ. ЕЕ НАУЧНЫМ НАСТАВНИКОМ БЫЛ В 1880-Е ГГ. САМ К. Н. БЕСТУЖЕВ-РЮМИН, РЕЗУЛЬТАТОМ ЭТОГО СОТРУДНИЧЕСТВА СТАЛА ЕЕ БЛИСТАТЕЛЬНАЯ РАБОТА О РУССКОМ ДВОРЯНСТВЕ ТЕХ ЧЕРТАХ ЕГО БЫТА, О КОТОРЫХ СОВРЕМЕННЫЕ ЕЙ ЧИТАТЕЛИ СКОРЕЕ УЗНАВАЛИ ИЗ ЛИТЕРАТУРНЫХ ПРОИЗВЕДЕНИЙ ${ }^{41}$. В СЕРЕДИНЕ 1890-Х ГГ. ОНА УЖЕ САМА ПРЕПОДАВАЛА РУССКУЮ ИСТОРИЮ ХVIII-ХІХ ВВ. НА С.-ПЕТЕРБУРГСКИХ ВЫСШИХ ЖЕНСКИХ КУРСАХ И НА КУРСАХ ДЛЯ РАБОЧИХ ИМПЕРАТОРСКОГО РУССКОГО ТЕХНИЧЕСКОГО ОБЩЕСТВА. КАК ПЫТЛИВЫЙ И ДОТОШНЫЙ БИБЛИОГРАФ ОНА ВЕЛА ОТДЕЛ РУССКОЙ ИСТОРИИ В «МАЛОМ ЭНЦИКЛОПЕДИЧЕСКОМ СЛОВАРЕ» Ф. А. БРОКГАУЗА - И. А. ЭФРОНА, МНОГО ПУБЛИКОВАЛАСЬ В ИЗВЕСТНЫХ ЖУРНАЛАХ ${ }^{42}$.

СОВРЕМЕННЫЕ СПЕЦИАЛИСТЫ ПО ЖЕНСКОЙ И ГЕНДЕРНОЙ ИСТОРИИ СПРАВЕДЛИВО ОТНОСЯТ Е.Н. ЩЕПКИНУ К ЧИСЛУ ПЕРВЫХ РОССИЙСКИХ ФЕМИНИСТОК. В ГОДЫ ПЕРВОЙ РУССКОЙ РЕВОЛЮЦИИ ОНА БЫЛА ЧЛЕНОМ ПЕТЕРБУРГСКОГО ОТДЕЛЕНИЯ СОЮЗА РАВНОПРАВНОСТИ ЖЕНЩИН, ЧЛЕНОМ ЦЕНТРАЛЬНОГО БЮРО СОЮЗА РАВНОПРАВНОСТИ ЖЕНЩИН ОТ ПЕТЕРБУРГА, А ПОЗЖЕ - АКТИВНОЙ УЧАСТНИЦЕЙ РОССИЙСКОЙ ЛИГИ РАВНОПРАВИЯ ЖЕНЩИН (СПБ). В ЛИГЕ ОНА ВОЗГЛАВЛЯЛА КОМИССИЮ ПО ПРОПАГАНДЕ - И ПРИ ЭТОМ УСПЕВАЛА МНОГО ПИСАТЬ, ИНТЕНСИВНО ПУБЛИКОВАТЬСЯ ${ }^{44}$. КАК СЛОЖИЛАСЬ ЖИЗНЬ ИССЛЕДОВАТЕЛЬНИЦЫ ПОСЛЕ ЗАПРЕТА ВСЕХ ЖЕНСКИХ И ФЕМИНИСТСКИХ ОРГАНИЗАЦИЙ, МОЖНО, СКОРЕЕ, ГАДАТЬ. НО 1921 Г. БЫЛА ОПУБЛИКОВАНА КНИГА Е.Н. ЩЕПКИНОЙ ПО ИСТОРИИ ЖЕНСКОГО ДВИЖЕНИЯ В ГОДЫ 
ФРАНЦУЗСКОЙ РЕВОЛЮЦИИ (С КРИТИЧЕСКИМ ОЧЕРКОМ А. КОЛЛОНТАЙ $)^{45}$, ЧУТЬ ПОЗЖЕ ОНА РАБОТАЛА НАД СТАТЬЕЙ, ПОСВЯЩЕННОЙ ИСТОРИИ СОЮЗА РАВНОПРАВНОСТИ ЖЕНЩИН ${ }^{46}$. ЕЕ ПУБЛИКАЦИИ БОЛЕЕ ПОЗДНЕГО ВРЕМЕНИ, КАК И СФЕРА ЗАНЯТИЙ НЕИЗВЕСТНЫ, А ГОД СМЕРТИ (ОКОЛО 1938) УКАЗЫВАЕТСЯ ОБЫЧНО УСЛОВНО.

\section{О. А. Добиаш-Рождественская}

НАЧАЛО ХХ ВЕКА ОТМЕЧЕНО ИМЕНАМИ СТРЕМИТЕЛЬНО ВОРВАВШИХСЯ В ИСТОРИЧЕСКУЮ НАУКУ РОССИЯНОК, КОТОРЫЕ ЗАЩИТИЛИ ДИССЕРТАЦИИ ЗА РУБЕЖОМ.

В СОРБОННЕ НАЧАЛА ХХ В. ПОЛУЧИЛИ ДОКТОРСКИЙ ДИПЛОМ Е. А. БЕЛЕВИЧ-СТАНКЕВИЧ ЗА ДИССЕРТАЦИЮ «ИНТЕРЕС К КИТАЙСКОМУ ИСКУССТВУ ВО ФРАНЦИИ ВО ВРЕМЕНА ЛЮДОВИКА ХІV» И, СЛЕДОМ ЗА НЕЙ, В 1909 Г. МИРРА ИВАНОВНА БОРОДИНА - ДОЧЬ ИЗВЕСТНОГО РУССКОГО БОТАНИКА И.П. БОРОДИНА, ВПОСЛЕДСТВИИ ЖЕНА ФРАНЦУЗСКОГО ИСТОРИКА Ф. ЛОТА. ДИССЕРТАЦИЯ МИРРЫ, ПОСВЯЩЕННАЯ ТВОРЧЕСТВУ ФРАНЦУЗСКОГО СРЕДНЕВЕКОВОГО ПОЭТА КРЕТЬЕНА ДЕ ТРУА, ПОЛУЧИЛА ОЦЕНКУ КАК «ОЧЕНЬ ДОСТОЙНАЯ» - ВЫСШАЯ СТЕПЕНЬ ПОХВАЛЫ ДЛЯ РАБОТ ПОДОБНОГО РОДА ПОСЛЕ РЕВОЛЮЦИИ М. И. ЛОТ-БОРОДИНА, ОСТАВШИСЬ ЖИТЬ В ЭМИГРАЦИИ, ВЫСТУПИЛА СОЗДАТЕЛЬНИЦЕЙ РУССКОЙ АКАДЕМИЧЕСКОЙ ГРУППЫ В ПАРИЖЕ И ВЕСЬМА ИНТЕНСИВНО РАБОТАЛА, ПУБЛИКОВАЛАСЬ ${ }^{48}$, ВПЛОТЬ ДО НАЧАЛА ВТОРОЙ МИРОВОЙ ВОЙНЫ.

ДВА ГОДА СПУСТЯ ПОСЛЕ М.И. ЛОТ-БОРОДИНОЙ И ТОЖЕ В СОРБОННЕ ЕЩЕ ОДНА РОССИЯНКА ПОЛУЧИЛА ДОКТОРСКУЮ СТЕПЕНЬ, И ВПЕРВЫЕ ПО СПЕЦИАЛЬНОСТИ «ВСЕОБЩАЯ ИСТОРИЯ». ЕЮ БЫЛА УДОСТОЕНА ОЛЬГА АНТОНОВНА ДОБИАШРОЖДЕСТВЕНСКАЯ. АВТОБИОГРАФИЯ ЭТОЙ УЧЕНОЙ, ОТЛОЖИВШАЯСЯ В ЕЕ ЛИЧНОМ ФОНДЕ В РО ГПБ ИМ. М.Е. САЛТЫКОВА-ЩЕДРИНА ${ }^{49}$, КАК И В СЛУЧАЕ С Е.Н. ЩЕПКИНОЙ, ПОРАЖАЕТ ЦЕЛЕУСТРЕМЛЕННОСТЬЮ, ИЗУМИТЕЛЬНОЙ ДЛЯ ЖЕНЩИНЫ.

РОДИВШАЯСЯ В 1874 Г. В ХАРЬКОВЕ, ОНА ПРОВЕЛА ДЕТСТВО В НЕЖИНЕ, ГДЕ ЕЕ ОТЕЦ, ПОТОМСТВЕННЫЙ ДВОРЯНИН, БЫЛ ПРОФЕССОРОМ ГРЕЧЕСКОЙ ФИЛОЛОГИИ ИСТОРИКОФИЛОЛОГИЧЕСКОГО ИНСТИТУТА. ОКОНЧИВ В 1891 Г. НЕЖИНСКУЮ ГИМНАЗИЮ С ЗОЛОТОЙ МЕДАЛЬЮ, А В 1899 Г. ВЫСШИЕ ЖЕНСКИЕ КУРСЫ В С-ПЕТЕРБУРГЕ, ОНА НЕКОТОРОЕ ВРЕМЯ ЗАРАБАТЫВАЛА НА ЖИЗНЬ ЧАСТНЫМИ УРОКАМИ. ПРАКТИКА ЭТА СЛОЖИЛАСЬ ЕЩЕ В ДНИ СТУДЕНЧЕСТВА, КОГДА ОНА ПРЕДСЕДАТЕЛЬСТВОВАЛА НЕРЕДКО НА СХОДКАХ, ЗА ЧТО И ИСКЛЮЧАЛАСЬ ВРЕМЕННО С КУРСОВ. С 1901 Г. ОНА УЖЕ АКТИВНО ПРЕПОДАВАЛА ИСТОРИЮ ВНАЧАЛЕ В ЖЕНСКИХ ГИМНАЗИЯХ, ДАЛЕЕ В ВЫБОРГСКОМ КОММЕРЧЕСКОМ УЧИЛИЩЕ, В ШКОЛЕ НА ПАТРОННОМ ЗАВОДЕ, ЧИТАЛА ЛЕКЦИИ В НАРОДНОМ ДОМЕ ПАНИНОЙ, В 1904-1906 СОСТОЯЛА СЕКРЕТАРЕМ ВСЕРОССИЙСКОГО УЧИТЕЛЬСКОГО СОЮЗА. УЖЕ В ЭТИ ГОДЫ ОНА СПЕЦИАЛИЗИРОВАЛАСЬ НА ИСТОРИИ ЗАПАДНОГО СРЕДНЕВЕКОВЬЯ И В 1908 Г. УЕХАЛА В ПАРИЖ ДЛЯ РАБОТЫ В АРХИВАХ, В 1911 Г. - КАК СКАЗАНО ВЫШЕ ПОЛУЧИЛА В СОРБОННЕ СТЕПЕНЬ ДОКТОРА НАУК. «Я ВСЕ БОЛЕЕ И ОПРЕДЕЛЕННЕЕ СТАВИЛА ЗАДАЧЕЙ СЛУЖИТЬ СВОЕЙ НАУКЕ И СВОЕЙ СТРАНЕ» - ПИСАЛА ОН А В СВОЕЙ АВТОБИОГРАФИИ, И ДЕЙСТВИТЕЛЬНО, ПОСЛЕ ЗАЩИТЫ УЕХАЛА ОБРАТНО В РОССИЮ И ПОСЛЕ РЕВОЛЮЦИИ, В 1918Г. БЫЛА ИЗБРАНА ПРОФЕССОРОМ ПЕТРОГРАДСКОГО УНИВЕРСИТЕТА. НЕСМОТРЯ НА СЛОЖНУЮ СУДЬБУ, ОНА ПОДГОТОВИЛА БЛЕСТЯЩУЮ НАУЧНУЮ ШКОЛУ ${ }^{50}$. ЕЕ ЗНАМЕНИТЫЕ СЛОВА «МОГУЧИМ СТИМУЛОМ ТВОРЧЕСТВА ЯВЛЯЕТСЯ ОГОНЬ ЧУЖИХ МЫСЛЕЙ И ЗВУКИ ЧУЖИХ ГОЛОСОВ» ПОДВИГЛИ К РАБОТЕ НЕ ОДНО ПОКОЛЕНИЕ МОЛОДЫХ МЕДИЕВИСТОВ, ДА И НЕ ТОЛЬКО НИХ 
РАБОТ О. А. ДОБИАШ-РОЖДЕСТВЕНСКОЙ ОХВАТЫВАЕТ 182 ПУБЛИКАЦИИ, В ТОМ ЧИСЛЕ 7 КниГ ${ }^{52}$.

ОДНО ТОЛЬКО ПЕРЕЧИСЛЕНИЕ ИМЕН УЧЕНИКОВ ОЛЬГИ АНТОНОВНЫ - В. В. БАХТИН, А. Д. ЛЮБЛИНСКАЯ, С. А. УШАКОВ, - ДОСТАТОЧНО КРАСНОРЕЧИВО. В ГОДЫ СОВЕТСКОЙ ВЛАСТИ О.А. ДОБИАШ-РОЖДЕСТВЕНСКАЯ БЫЛА ГЛАВНЫМ БИБЛИОТЕКАРЕМ ГОСУДАРСТВЕННОЙ ПУБЛИЧНОЙ БИБЛИОТЕКИ В ЛЕНИНГРАДЕ, ЗНАТОКОМ БОГАТСТВ ЕЕ РУКОПИСНОГО ОТДЕЛА, ОСОБЕННО ПО ЗАПАДНОЕВРОПЕЙСКОЙ ИСТОРИИ. БЕЗ ЕЕ РАБОТ ПО ИСТОРИИ КУЛЬТУРЫ И БЫТА СРЕДНЕВЕКОВОЙ ФРАНЦИИ ТРУДНО ПРЕДСТАВИТЬ РОЖДЕНИЕ НАПРАВЛЕНИЯ «ИСТОРИИ ПОВСЕДНЕВНОСТИ», ОНА БЫЛА ДОТОШНЫМ БЫТОПИСАТЕЛЕМ, ОБЛАДАТЕЛЬНИЦЕЙ УНИКАЛЬНОГО АВТОРСКОГО СТИЛЯ. РАБОТЫ О.А. ДОБИАШРОЖДЕСТВЕНСКОЙ ОСНОВАНЫ НА БЛЕСТЯЩЕМ ЗНАНИИ УШЕДШИХ РЕАЛИЙ, ПОСКОЛЬКУ ОНА СКРУПУЛЕЗНО ЧИТАЛА САМИ ИСТОЧНИКИ. ВСЕ ПРЕДСТАВИТЕЛИ ШКОЛЫ АННАЛОВ ВО ФРАНЦИИ, ВСЕХ ТРЕХ ЕЕ ПОКОЛЕНИЙ, ВСЕГДА ССЫЛАЛИСЬ НА ЕЕ РАБОТЫ. ВОЗМОЖНО, ЭТОТ ФАКТ И ПРИВЕЛ К ТОМУ, ЧТО ВКЛАД О.А. ДОБИАШ-РОЖДЕСТВЕНСКОЙ В МИРОВУЮ ИСТОРИОГРАФИЮ ПРИНИЖАЛСЯ, ЗАМАЛЧИВАЛСЯ В СОВЕТСКОЙ ИСТОРИЧЕСКОЙ НАУКЕ, А ЗАСЛУЖЕННОЕ ПРИЗНАНИЕ ПРИШЛО ОЧЕНЬ ПОЗДНО, НА РУБЕЖЕ ХХ И ХХІ ВВ., С ПРИЗНАНИЕМ ВКЛАДА ШКОЛЫ АННАЛОВ В МИРОВУЮ ИСТОРИОГРАФИЮ ${ }^{53}$.

\section{Н. В. Брюллова-Шаскольская}

ВСПОМИНАЯ НАЧАЛО ХХ В., СТОИТ НАПОМНИТЬ, ЧТО ОБЩЕСТВЕННОЕ МНЕНИЕ В ТО ВРЕМЯ НЕ ПОДДЕРЖИВАЛО ТЕХ ЖЕНЩИН, КОТОРЫЕ ЖЕЛАЛИ ПРОЯВИТЬ СЕБЯ НА НАУЧНОМ ПОПРИЩЕ. ЕСЛИ ПУБЛИЦИСТЫ ХІХ СТОЛЕТИЯ УПРЕКАЛИ УЧЕНЫХ ЖЕНЩИН В ТОМ, ЧТО «НАРЯДИЛИСЬ ОНИ ЧУТЬ НЕ В МУЖСКИЕ КОСТЮМЫ, ОСТРИГЛИ ВОЛОСЫ, ЗАКРЫЛИ ГЛАЗА СИНИМИ ОЧКАМИ, УСВОИЛИ УГЛОВАТОСТЬ МАНЕР, СТАЛИ ГОВОРИТЬ КАКОЙ-ТО ДЕЛАННОЙ РЕЧЬЮ, С НАПУСКНЫМ ЦИНИЗМОМ ${ }^{54} »$, ТО ЖУРНАЛИСТ НАЧАЛА ХХ-ГО ПОПРЕКАЛ УЧЕНЫХ ЖЕНЩИН ТЕМ, ЧТО ИХ КНИЖНЫЕ ЗНАНИЯ РАВНОСИЛЬНЫ БЕСПОЛЕЗНОЙ ИГРУШКЕ: «ЧТО ЖЕ КАСАЕТСЯ ДО УЧЕНЫХ ЖЕНЩИН, ТО У НИХ КНИГИ ИГРАЮТ ТАКУЮ ЖЕ РОЛЬ, КАК И ИХ ЧАСЫ; А ЧАСЫ ОНИ НОСЯТ ТОЛЬКО ДЛЯ ТОГО, ЧТОБЫ ПОКАЗАТЬ, ЧТО ЧАСЫ У НИХ ЕСТЬ, ХОТЯ СПЛОШЬ И РЯДОМ ЭТИ ЧАСЫ У НИХ НЕ ХОДЯТ ИЛИ ХОДЯТ СОВСЕМ НЕ ВЕРНО ${ }^{55}$.»

ЧТОБЫ ОКОНЧАТЕЛЬНО РАЗВЕСТИ И ПРОТИВОПОСТАВИТЬ ТЕХ, КТО ИЗ ЖЕНЩИН БЫЛ ОРИЕНТИРОВАН НА СЕМЬЮ И ТЕХ, КТО ЖЕЛАЛ ТВОРЧЕСКОЙ САМОРЕАЛИЗАЦИИ В НАУЧНОЙ РАБОТЕ, Е. ЛОЗИНСКИЙ - АВТОР СТАТЬИ О «НАСТОЯЩЕМ И БУДУЩЕМ ЖЕНСКОГО ДВИЖЕНИЯ» (1904 Г.), УБЕЖДАЛ ЧИТАТЕЛЕЙ, ЧТО ИНТЕРЕСЫ «АКАДЕМИКОВ В ЧЕПЦЕ»-ЭТО «ИНТЕРЕСЫ ОДНИХ ЛИШЬ НЕЗАМУЖНИХ И СТАРЫХ ДЕВ, ИЩУЩИХ ЗАПОЛНИТЬ ЧЕМ-ЛИБО СВОЕ ПУСТОЕ СУЩЕСТВОВАНИЕ ${ }^{56}$. ОН БЫЛ МАЛО ОЗАБОЧЕН О ТОМ, ЧТО «ПРИПЕЧАТЫВАЕТ» СВОИМИ ВЫСКАЗЫВАНИЯМИ ВСЕХ ТЕХ ЖЕНЩИН, КОТОРЫМ НЕ ПОСЧАСТЛИВИЛОСЬ В СЕМЕЙНОЙ ЖИЗНИ И ДЛЯ КОТОРЫХ НАУЧНАЯ РАБОТА МОГЛА БЫ СТАТЬ И ДЕЙСТВИТЕЛЬНО БЫЛА РЕАЛЬНОЙ ОТДУШИНОЙ. С ПОДОБНЫМИ ВОЗЗРЕНИЯМИ ПЕРЕКЛИКАЛИСЬ УСТАНОВКИ ВЛАСТИТЕЛЕЙ УМОВ РОССИЙСКОЙ ИНТЕЛЛИГЕНЦИИ НАЧАЛА ПРОШЛОГО СТОЛЕТИЯ, В ЧАСТНОСТИ, Н. А. БЕРДЯЕВА.

ВСЕ ЭТИ ДЕВИЦЫ, ПОТЕРЯВШИЕ ОБЛИК ЖЕНЩИНЫ, С ИСТЕРИЧЕСКОЙ ТОРОПЛИВОСТЬЮ БЕГУЩИЕ НА ВСЕ СХОДКИ И МИТИНГИ, ПРОИЗВОДЯТ ОТТАЛКИВАЮЩЕЕ ВПЕЧАТЛЕНИЕ. ЭТО СУЩЕСТВА, НЕ ИМЕЮЩИЕ СВОЕГОЯ, ОБЕЗЬЯНЫ, «МУЖЧИНЫ ТРЕТЬЕГО СОРТА ‘... [ОНИ] СЛИШКОМ БЫСТРО 
СТАНОВЯТСЯ ПОДСЛЕПОВАТЫМИ ОТ НЕСООТВЕТСТВУЮЩИХ ИХ НАЗНАЧЕНИЮ ЗАНЯТИЙ, И ОНИ НАДЕВАЮТ ОЧКИ, ПРЕВРАЩАЮЩИЕСЯ В СИМВОЛ ОБЕЗЬЯННИЧЕСТВА, ИСКАЖАЮЩИЙ ПРИРОДУ ЖЕНЩИНЫ ${ }^{57}$. КТО С ДЕТСТВА СЕБЯ ГОТОВИЛ К НАУЧНОМУ ТРУДУ. ТАКОВА ВНУЧКА АРХИТЕКТОРА И ХУДОЖНИКА А. П. БРЮЛЛОВА - НАДЕЖДА ВЛАДИМИРОВНА БРЮЛЛОВА, В ЗАМУЖЕСТВЕ БРЮЛЛОВА-ШАСКОЛЬСКАЯ (1889-1937). ВЫРОСШИ В ОБЕСПЕЧЕННОЙ ДВОРЯНСКОЙ СЕМЬЕ И ЗАКОНЧИВ, КАК И МНОГИЕ ТОГДА, ВЫСШИЕ ЖЕНСКИЕ КУРСЫ, ОНА ОТПРАВИЛАСЬ В 1908 Г. СЛУШАТЬ ЛЕКЦИИ В ГЕРМАНИИ, ГДЕ И ВЫШЛА ЗАМУЖ ЗА СООТЕЧЕСТВЕННИКА, П.Б. ШАСКОЛЬСКОГО.

ПО ПОЛИТИЧЕСКИМ УБЕЖДЕНИЯМ БЛИЗКАЯ ЭСЕРАМ, СЧИТАВШАЯСЯ В ЭТОЙ ПАРТИИ ГЛАВНЫМ СПЕЦОМ ПО НАЦИОНАЛЬНОМУ ВОПРОСУ, ОНА ПОСЛЕ РЕВОЛЮЦИИ БЫЛА ВЕСЬМА ДЕЯТЕЛЬНОЙ УЧАСТНИЦЕЙ ПОЛИТИЧЕСКОЙ РАБОТЫ, ЧТО НЕ МЕШАЛО ЕЙ ЗАНИМАТЬСЯ И ПРЕПОДАВАНИЕМ. В ГОДЫ ГРАЖДАНСКОЙ ВОЙНЫ ПРЕПОДАВАЛА В ХАРЬКОВСКОМ УНИВЕРСИТЕТЕ В КАЧЕСТВЕ ЭКСТРАОРДИНАРНОГО ПРОФЕССОРА ПО КАФЕДРЕ ИСТОРИИ РЕЛИГИИ. ИЗ ХАРЬКОВА ВМЕСТЕ С СЕМЬЕЙ Н.В. БРЮЛЛОВАШАСКОЛЬСКАЯ ВЫНУЖДЕНА БЫЛА УЕХАТЬ В 1920 Г. В ПЕТРОГРАД, ГДЕ ПРЕПОДАВАЛА ИСТОРИЮ РЕЛИГИИ В ГЕОГРАФИЧЕСКОМ ИНСТИТУТЕ, ЕВРОПЕЙСКОМ УНИВЕРСИТЕТЕ, ПРИНИМАЛА УЧАСТИЕ В РАБОТЕ ВОЛЬНОЙ ФИЛОСОФСКОЙ АССОЦИАЦИИ, КАК ВОСТОКОВЕД ВЫСОКОЙ КВАЛИФИКАЦИИ СОТРУДНИЧАЛА С МУЗЕЕМ АНТРОПОЛОГИИ И ЭТНОГРАФИИ. В 1922 Г. В СВЯЗИ С ПРОЦЕССОМ НАД ЭСЕРАМИ БЫЛА АРЕСТОВАНА, НО ДЕЛО Ее КАК ОСОБО ЦЕННОГО НАУЧНОГО СПЕЦИАЛИСТА БЫЛО ВЫДЕЛЕНО В ОТДЕЛЬНОЕ ПРОИЗВОДСТВО. ПРИГОВОРОМ УЧЕНОЙ БЫЛА ССЫЛКА В ТАШКЕНТ. ТАМ ОНА ПРИСТУПИЛА К СЕРЬЕЗНЫМ ЭТНОГРАФИЧЕСКИМ ИССЛЕДОВАНИЯМ. И ХОТЯ ВСЯ Ре ЖИЗНЬ ВПЛОТЬ ДО ГИБЕЛИ В 1937 Г. БЫЛА СВЯЗАНА С ПЕРЕЕЗДАМИ И АРЕСТАМИ, НЕ ПРЕКРАЩАЛА НАУЧНОЙ РАБОТЫ. В ЛЕНИНГРАДЕ В КОРОТКИЕ ПЕРЕРЫВЫ МЕЖДУ ВЫСЫЛКАМИ ОНА РАБОТАЛА В КАЧЕСТВЕ ЗАВЕДУЮЩЕЙ ОТДЕЛОМ КОЧЕВЫХ НАРОДОВ В СРЕДНЕАЗИАТСКОМ МУЗЕЕ И ПРЕПОДАВАЛА В СРЕДНЕАЗИАТСКОМ ФИНАНСОВО-ЭКОНОМИЧЕСКОМ ИНСТИТУТЕ, БУДУЧИ ДОЦЕНТОМ ПО КАФЕДРЕ ИНОСТРАННЫХ ЯЗЫКОВ. ЛИЧНАЯ ЖИЗНЬ УЧЕНОЙ ТОЖЕ БЫЛА НЕПРОСТА. ПОТЕРЯВ МУЖА ЕЩЕ МОЛОДОЙ ЖЕНЩИНОЙ (В 1918 Г. ОН УМЕР ОТ ИСПАНКИ), МНОГО ПЕРЕТЕРПЕВ ЗА СВОЮ, В СУЩНОСТИ НЕДОЛГУЮ (50-ЛЕТНЮЮ) ЖИЗНЬ, ОНА НЕ ТОЛЬКО СУМЕЛА ОПУБЛИКОВАТЬ РЯД ЦЕННЫХ НАУЧНО-ИССЛЕДОВАТЕЛЬСКИХ РАБОТ ${ }^{58}$, НО И ПОДНЯТЬ, ВОСПИТАТЬ ТРОИХ ДЕТЕЙ. ИЗДАТЬ, КОНЕЧНО, УДАЛОСЬ НЕ ВСЕ - В ЧАСТНОСТИ, ДО СИХ ПОР В ВИДЕ РУКОПИСИ СУЩЕСТВУЕТ ЕЕ КНИГА О ЗНАМЕНИТОМ КАРЛЕ БРЮЛЛОВЕ И ЕГО БРАТЕ АЛЕКСАНДРЕ ${ }^{59}$.

\section{Л. И. Олавская}

ОДНОЙ ИЗ МЛАДШИХ СОВРЕМЕННИЦ И УЧЕНИЦ ВЫШЕУПОМЯНУТОЙ О.А. ДОБИАШРОЖДЕСТВЕНСКОЙ, НАЧАВШЕЙ ОБУЧЕНИЕ ЕЩЕ НА ВЫСШИХ ЖЕНСКИХ КУРСАХ, БЫЛА ЕЩЕ ОДНА ВЫСОКООБРАЗОВАННАЯ ДВОРЯНКА - ДОЧЬ ИНЖЕНЕРА-ТЕХНОЛОГА, ВПОСЛЕДСТВИИ ТОВАРИЩА МИНИСТРА ФИНАНСОВ ЛИДИЯ ИОСИФОВНА ОЛАВСКАЯ (УРОЖД. НОВИЦКАЯ), ПРОЖИВШАЯ НА УДИВЛЕНИЕ ДОЛГУЮ ЖИЗНЬ (1889-1975) И ВСЕ ПОВИДАВШАЯ НА СВОЕМ ВЕКУ. НА КУРСАХ ОНА ПРОЯВИЛА СЕБЯ В ГРУППЕ ВСЕОБЩЕЙ ИСТОРИИ КАК УЧАСТНИЦА СЕМИНАРА ИВАНА МИХАЙЛОВИЧА ГРЕВСА, СТАВШАЯ ОДНИМ ИЗ САМЫХ БЛИЗКИХ ЕМУ ЛЮДЕЙ. ГРЕВС ПИСАЛ О НЕЙ: «Я ТАК СИЛЬНО ЛЮБЛЮ ЕЕ 
ПОЛНОЙ ОТЕЧЕСКОЮ ПРИВЯЗАННОСТЬЮ, ЧТО МНЕ, ПОЖАЛУЙ, НЕЛЕГКО ГОВОРИТЬ О НЕЙ ВСЮ ПРАВДУ: БУДУТ ДУМАТЬ, ЧТО Я ПРЕУВЕЛИЧИВАЮ ОТ ЛЮБВИ ${ }^{60} . »$ 1918 Г., а ТАКЖЕ БЫЛА СОТРУДНИЦЕЙ ОТДЕЛЕНИЯ ИСТОРИИ БИБЛИОТЕКИ, С 1922 ПО 1930 ГОД ВОЗГЛАВЛЯЛА УНИКАЛЬНЫЙ КАБИНЕТ ИНОСТРАННОЙ ЛИТЕРАТУРЫ, КОТОРЫЙ СТАЛ МЕСТОМ ВСТРЕЧ И ПРОФЕССИОНАЛЬНОГО ОБЩЕНИЯ ДЛЯ НАУЧНОЙ ЭЛИТЫ ЛЕНИНГРАДА. КОМПЛИМЕНТОМ РАБОТЕ ОЛАВСКОЙ ЗВУЧИТ СЕЙЧАС РЕЗКАЯ КРИТИКА, ВЫСКАЗАННАЯ В 1936 ГОДУ КОМИССИЕЙ ПО ПЕРЕДАЧЕ ДЕЛ КАБИНЕТА:

ПРЕОБЛАДАЮЩЕЕ МЕСТО ЗАНИМАЮТ ЧИСТО АКАДЕМИЧЕСКИЕ БИБЛИОГРАФИЧЕСКИЕ ТЕМЫ <... В ОТНОШЕНИИ МЕТОДОВ БИБЛИОГРАФИЧЕСКОЙ ОБРАБОТКИ ‘... НУЖНО ОТМЕТИТЬ ИХ ГОЛЫЙ ФОРМАЛИЗМ И ОТСУТСТВИЕ ДАЖЕ НАМЕКОВ НА ВНЕДРЕНИЕ В БИБЛИОГРАФИЧЕСКУЮ ПРАКТИКУ МАРКСИСТСКОЛЕНИНСКОЙ МЕТОДОЛОГИИ ${ }^{62}$.

УВОЛЕННАЯ ИЗ БИБЛИОТЕКИ И ОТСТРАНЕННАЯ ОТ НАУЧНОЙ ДЕЯТЕЛЬНОСТИ, Л.И. ОЛАВСКАЯ НАШЛА СЕБЕ ПРИМЕНЕНИЕ КАК ПЕРЕВОДЧИЦА ${ }^{63}$. ЗНАНИЕ ФРАНЦУЗСКОГО ПОЗВОЛИЛО ЕЙ СДЕЛАТЬ ЕДВА ЛИ НЕ САМЫЙ УДАЧНЫЙ ПЕРЕВОД РОМАНА А.ДЮМА «ГРАФ МОНТЕ-КРИСТО» ${ }^{64}$.

ЛИЧНОЕ ДЕЛО Л. И. ОЛАВСКОЙ (ХРАНИТСЯ В АРХИВЕ РАН В РУКОПИСНОМ ОТДЕЛЕ) ЕЩЕ ЖДЕТ СВОЕГО ПЫТЛИВОГО ИССЛЕДОВАТЕЛЯ ${ }^{65}$, КАК ТРУДЫ И БИОГРАФИИ ДРУГИХ ЕЕ СОВРЕМЕННИЦ, ТАКЖЕ, ПО ПРИЧИНЕ СОЦИАЛЬНОГО ПРОИСХОЖДЕНИЯ ИЛИ СОЧУВСТВИЯ В ЮНОСТИ НЕБОЛЬШЕВИСТСКИМ ПАРТИЯМ, ПОДВЕРГШИХСЯ НЕПРИЗНАНИЮ ИЛИ ЗАБВЕНИЮ.

\section{А. В. Пруссак}

ПОЧТИ РОВЕСНИЦЕЙ Л. И. ОЛАВСКОЙ БЫЛА ИННА ИВАНОВНА ИГНАТОВИЧ (1879-1967) ДОЧЬ ПРОВИНЦИАЛЬНОГО ВРАЧА И УЧЕНИЦА В. И. СЕМЕВСКОГО, НАПЕЧАТАВШАЯ НЕМАЛО ТРУДОВ ПО ИСТОРИИ КРЕСТЬЯНСТВА ${ }^{66}$, В ТОМ ЧИСЛЕ И ДО РЕВОЛЮЦИИ. НО ПРИ СОВЕТСКОЙ ВЛАСТИ, НЕСМОТРЯ НА ЗАЩИТУ ПЕРЕД ВОЙНОЙ КАНДИДАТСКОЙ ДИССЕРТАЦИИ, ЕЙ НЕ УДАЛОСЬ СТАТЬ ЗАМЕТНОЙ ФИГУРОЙ В НАУКЕ ${ }^{67}$. МОЖНО ВСПОМНИТЬ И ДВОРЯНКУ АННУ ВЛАДИМИРОВНУ БЕЛЯЕВУ, УРОЖДЕННУЮ ПРУССАК (1887-1956) ${ }^{68}$, СЕСТРУ ПОЭТА В. В. ПРУССАКА, ПОДПИСЫВАВШУЮ СВОИ НАУЧНЫЕ ТРУДЫ ДЕВИЧЬЕЙ ФАМИЛИЕЙ. ОНА ОКОНЧИЛА СЛОВЕСНО-ИСТОРИЧЕСКОЕ ОТДЕЛЕНИЕ ЖЕНСКОГО ПЕДИНСТИТУТА, СТАВ УЧЕНИЦЕЙ ПРОФЕССОРА Н. М. КАРИНСКОГО, СПЕЦИАЛИСТА ПО РУССКОЙ ДИАЛЕКТОЛОГИИ И ИСТОРИИ ЯЗЫКА. ПОЛУЧАЯ ВТОРОЕ ИСТОРИЧЕСКОЕ ОБРАЗОВАНИЕ В АРХЕОЛОГИЧЕСКОМ ИНСТИТУТЕ, А. В. ПРУССАК УЖЕ В 1907 НАЧАЛА ПЕЧАТАТЬСЯ. ЕЕ РАБОТЫ ПО СИБИРЕВЕДЕНИЮ ОПУБЛИКОВАНЫ В ЩОТЧЕТАХ ОТДЕЛЕНИЯ РУССКОГО ЯЗЫКА И СЛОВЕСНОСТИ» ЗА 1914 Г., ЖУРНАЛЕ «ЖИВАЯ СТАРИНА» В 1915 Г., ИЗВЕСТИЯХ ВОСТОЧНО-СИБИРСКОГО ОТДЕЛА РУССКОГО ГЕОГРАФИЧЕСКОГО ОБЩЕСТВА В 
1916 Г.... ИНЫМИ СЛОВА, В СВОИ 30 С НЕБОЛЬШИМ ЛЕТ, ТО ЕСТЬ 1910-Е ГГ., ОНА УЖЕ БЫЛА КАК ИССЛЕДОВАТЕЛЬНИЦА ХОРОШО ИЗВЕСТНА ${ }^{69}$.

В НАЧАЛЕ 1920-Х БЕЛЯЕВА (ПРУССАК) РАБОТАЛА В ПЕТРОГРАДСКОМ ДОМЕ УЧЕНЫХ, ГДЕ ВОШЛА В ОБЩИНУ РУССКО-КАТОЛИЧЕСКОЙ ЦЕРКВИ. В 1924 Г., АРЕСТОВАННАЯ ПО ДЕЛУ РУССКИХ КАТОЛИКОВ, ОНА ПРОВЕЛА 8 ЛЕТ В ТЮРЬМЕ ${ }^{70}$. И ХОТЯ К ЛЕТУ 1933 Г. ОНА БЫЛА ОСВОБОЖДЕНА И ВЕРНУЛАСЬ В ЛЕНИНГРАД, НАУЧНУЮ ДЕЯТЕЛЬНОСТЬ ПРОДОЛЖИЛА ЛИШЬ СПУСТЯ ГОДЫ, В СЕРЕДИНЕ 1930-Х ГГ. ${ }^{71}$. СТАВ СОТРУДНИКОМ ЛЕНИНГРАДСКОГО ОТДЕЛЕНИЯ ИНСТИТУТА ИСТОРИИ, ОНА ПОДГОТОВИЛА СТАТЬИ ПО ИСТОРИИ ПЕТРОВСКОГО ВРЕМЕНИ, ПУГАЧЕВСКОГО БУНТА, ЗАНИМАЛАСЬ - КАК ЗНАЮЩАЯ СВОБОДНО ДРЕВНЕРУССКУЮ СКОРОПИСЬ - ОПИСАНИЕМ МАТЕРИАЛОВ АСТРАХАНСКОЙ ПРИКАЗНОЙ ИЗБЫ. ПОСЛЕ ВОЙНЫ Ре ТЕМОЙ БЫЛА ИСТОРИЯ РУССКОЙ МЕДИЦИНЫ, АПТЕЧНОГО ДЕЛА, ГОСПИТАЛЕЙ И МЕДИЦИНСКИХ ШКОЛ. ОНА АКТИВНО ПЕЧАТАЛАСЬ В МЕДИЦИНСКИХ ЖУРНАЛАХ С ЭТИМИ ТЕМАМИ В 1952-1954 ГГ. ${ }^{72}$.

\section{И. И. Любименко}

НАУЧНЫЕ СУДЬБЫ Л. И. ОЛАВСКОЙ, И. И. ИГНАТОВИЧ, А. В. БЕЛЯЕВОЙ (ПРУССАК) БЫЛИ ТРАГИЧНЫ ИЛИ ПО КРАЙНЕЙ МЕРЕ КУДА МЕНЕЕ УСПЕШНЫ, ПО СРАВНЕНИЮ С СУДЬБАМИ ТЕХ ЖЕНЩИН, КТО БЫЛ «ПРИКРЫТ» ИМЕНЕМ И СТАТУСОМ СВОИХ МУЖЕЙ. ПРИМЕР ТОМУ - ЖИЗНЕННЫЙ ПУТЬ ИННЫ ИВАНОВНЫ ЛЮБИМЕНКО, УРОЖДЕННОЙ БОРОДИНОЙ (18781959), О КОТОРОЙ В СОВРЕМЕННОЙ НАУКЕ СОХРАНЕНА БЛАГОДАРНАЯ ПАМЯТЬ ${ }^{73}$. ЕЕ ТРУДАМ ПРИНАДЛЕЖИТ ВИДНОЕ МЕСТО В ИСТОРИОГРАФИИ РУССКО-АНГЛИЙСКИХ ОТНОШЕНИЙ ПОСЛЕ 1553 Г., ИСТОРИИ ВОЗНИКНОВЕНИЯ С.-ПЕТЕРБУРГСКОЙ АКАДЕМИИ НАУК И ЕЕ РАЗВИТИЯ ДО КОНЦА ХVIII В., НАЧАЛЬНОЙ ИСТОРИИ САНКТ-ПЕТЕРБУРГА, ЕГО ЭКОНОМИКИ И КУЛЬТУРЫ. КУДА МЕНЬШЕ ИСТОРИОГРАФЫ ИНТЕРЕСОВАЛИСЬ ЕЕ ЛИЧНЫМ ЖИЗНЕННЫМ МИРОМ, ХОТЯ О ЕЕ РАБОТАХ НАПИСАЛИ НЕМАЛО...

ДОЧЬ ИЗВЕСТНОГО УЧЕНОГО-БОТАНИКА, ПРОФЕССОРА ЛЕСНОГО ИНСТИТУТА И.П. БОРОДИНА, ИННА ПОЗНАКОМИЛАСЬ С БУДУЩИМ МУЖЕМ, БОТАНИКОМ В. Н. ЛЮБИМЕНКО (1873-1937) В ДОМЕ ОТЦА - ОН БЫЛ ЕГО УЧЕНИКОМ. ПОЛУЧИВ ВЫСШЕЕ ОБРАЗОВАНИЕ НА ВЫСШИХ ЖЕНСКИХ КУРСАХ В С.-ПЕТЕРБУРГЕ, ИННА ПРОДОЛЖИЛА ЕГО УЖЕ ПОСЛЕ ЗАМУЖЕСТВА В СОРБОННЕ. В 1903-1908 ГГ. ЖИЛА С МУЖЕМ ВО ФРАНЦИИ, ГДЕ И ЗАЩИТИЛА 1908 Г. ДИССЕРТАЦИЮ О ЖАНЕ БРЕТАНЬСКОМ (ОТДЕЛЬНОЙ КНИГОЙ ЭТА РАБОТА ВЫШЛА В ЛИЛЛЕ). ТЕМОЙ НАУЧНЫХ ИЗЫСКАНИЙ УЧЁНОЙ В 1910-ХГГ. БЫЛИ МЕЖДУНАРОДНЫЕ ОТНОШЕНИЯ, ИСТОРИЯ ДИПЛОМАТИИ ${ }^{74}$. КАК СКЛАДЫВАЛАСЬ ЖИЗНЬ И. И. ЛЮБИМЕНКО В БУРНЫЕ ГОДЫ РЕВОЛЮЦИИ И ГРАЖДАНСКОЙ ВОЙНЫ МОЖНО ДОГАДАТЬСЯ ПО ТОМУ, ЧТО ЕЕ МУЖ ПРИНЯЛ СОЦИАЛЬНО-ПОЛИТИЧЕСКИЕ ПЕРЕМЕНЫ В СТРАНЕ, ОСТАЛСЯ В РОССИИ И СТАЛ В 1922 ЧЛЕНОМ-КОРРЕСПОНДЕНТОМ, А В 1929 Г. ДЕЙСТВИТЕЛЬНЫМ ЧЛЕНОМ АКАДЕМИИ НАУК. ЕГО ЖЕНА ТАКЖЕ ПРОДОЛЖИЛА В СОВЕТСКОЙ РОССИИ КАРЬЕРУ УЧЕНОЙ ${ }^{75}$.

ВСКОРЕ ПОСЛЕ ОКТЯБРЬСКОЙ РЕВОЛЮЦИИ, И ЕДВА ЛИ НЕ НА ЦЕЛОЕ ДЕСЯТИЛЕТИЕ, ВЕДУЩИМ НАПРАВЛЕНИЕМ В ЕЕ ИЗЫСКАНИЯХ СТАНОВИТСЯ ТЕОРИЯ, ПРАКТИКА И ИСТОРИЯ АРХИВНОГО ДЕЛА. ОНА БЫВАЛА ЗА РУБЕЖОМ В СОСТАВЕ ДЕЛЕГАЦИЙ, ИЗУЧАВШИХ ПОСТАНОВКУ АРХИВНОГО ДЕЛА ВО ФРАНЦИИ И ГЕРМАНИИ ${ }^{76}$, ПРОДОЛЖАЛА АКТИВНО ПЕЧАТАТЬСЯ. В 1933 Г. ЕЙ БЫЛО ПРИСУЖДЕНО ЗВАНИЕ ЧЛЕНА ПАРИЖСКОЙ ШКОЛЫ ВЫСШИХ НАУК, КОТОРАЯ ПОДДЕРЖАЛА ИДЕЮ ПЕРЕВОДА НА ФРАНЦУЗСКИЙ Ее 
МОНОГРАФИИ «ТОРГОВЫЕ ПОЛИТИЧЕСКИЕ ОТНОШЕНИЯ АНГЛИИ И РОССИИ РАНЕЕ ПЕТРА ВЕЛИКОГО» (Paris, 1933). ВСКОРЕ ПОСЛЕ ЭТОГО СОБЫТИЯ, 1 НОЯБРЯ 1935 Г. И. И. ЛЮБИМОВА ЗАЩИТИЛА ВТОРУЮ, ДОКТОРСКУЮ ДИССЕРТАЦИЮ; СТЕПЕНЬ БЫЛА ПРИСУЖДЕНА ЕЙ ЗА ЦИКЛ ТРУДОВ ПО ИСТОРИИ ДИПЛОМАТИЧЕСКИХ И ТОРГОВЫХ СВЯЗЕЙ РОССИИ С ГОСУДАРСТВАМИ ЗАПАДНОЙ ЕВРОПЫ.

И. И. ЛЮБИМЕНКО БЛАГОПОЛУЧНО ПРОРАБОТАЛА КАК УЧЕНЫЙ И ПРЕПОДАВАТЕЛЬ ДО КОНЦА 1950-ХГГ., ПЕРЕЖИВ НА 20 ЛЕТ МУЖА. ОНА ВЫНЕСЛА И ЛЕНИНГРАДСКУЮ БЛОКАДУ, И МНОЖЕСТВО ИДЕОЛОГИЧЕСКИХ КАМПАНИЙ, ОТ КОТОРЫХ ПОСТРАДАЛИ ЕЕ КОЛЛЕГИ-УЧЕНЫЕ ${ }^{77}$. В ПИСЬМАХ УЧЕНОЙ ПОСЛЕВОЕННОГО ВРЕМЕНИ - СЕТОВАНИЯ НА ТО, ЧТО ЕЕ ГРУЗЯТ НЕИНТЕРЕСНЫМИ ЕЙ ТЕМАМИ, ЧТО ЕЕ «ЗАЕЛА РЕДАКТОРСКАЯ РАБОТА», «БЕСКОНЕЧНЫЙ РЯД МЕЛКИХ ПРИДИРОК ${ }^{78}$. В 1949 Г. И. И. ЛЮБИМЕНКО ПИСАЛА С. И. АРХАНГЕЛЬСКОМУ: «ОТНОСИТЕЛЬНО НАПАДОК НА ВАС СТАРАЙТЕСЬ ОТНОСИТЬСЯ ФИЛОСОФСКИ; ТУТ ВЕДЬ, УВЫ, МНОГО ЛИЧНОГО, ЗАВИСТИ К УСПЕХАМ, К БОЛЬШОМУ ЧИСЛУ РАБОТ», «ЧАСТО ‘..> КРИТИКУЮТ ЛЮДИ САМИ НЕ ТВОРЧЕСКИЕ ‘.. СОЖАЛЕНИЮ, ВО ВСЕМ ЭТОМ ЕЩЕ ОЧЕНЬ МНОГО ПЕРСОНАЛЬНОЙ ЗАВИСТИ К НАИБОЛЕЕ ПРЕУСПЕВШИМ ${ }^{79}$. СТАРОСТЬ ИННА ИВАНОВНА ПЕРЕЖИВАЛА ТЯЖЕЛО: ГЛАВНЫЙ ТРУД ЕЕ ЖИЗНИ ПО АНГЛО-РУССКИМ ОТНОШЕНИЯМ В СВЯЗИ С ЕЕ УХОДОМ НА ПЕНСИЮ ИИ АН СССР ОТКАЗАЛСЯ ПУБЛИКОВАТЬ, И О НЕМ СТАЛО ИЗВЕСТНО ЛИШЬ СПУСТЯ ПОЛВЕКА ${ }^{80}$.

\section{Н. В. Пигулевская}

ИМЯ МЛАДШЕЙ СОВРЕМЕННИЦЫ И. И. ЛЮБИМЕНКО, Л. И. ОЛАВСКОЙ И И. И. ИГНАТОВИЧ НИНЫ ВИКТОРОВНЫ ПИГУЛЕВСКОЙ (В ДЕВИЧЕСТВЕ - СТЕБНИЦКОЙ) (1894-1970) БЕРЕЖНО СОХРАНИЛИ РОССИЙСКИЕ ВОСТОКОВЕДЫ. ВНУЧКА ИЗВЕСТНОГО ГЕОГРАФА, ЧЛЕНА-КОРРЕСПОНДЕНТА АКАДЕМИИ НАУК, ДОЧЬ УСПЕШНОГО ЮРИСТА, ОНА ПОЛУЧИЛА НЕПЛОХОЕ ДОМАШНЕЕ И ГИМНАЗИЧЕСКОЕ ОБРАЗОВАНИЕ, ПРОДОЛЖИЛА ЕГО НА ВЖК В ПЕТЕРБУРГЕ, ГДЕ ЕЕ УЧИТЕЛЯМИ БЫЛИ О. А. ДОБИАШ-РОЖДЕСТВЕНСКАЯ, А. В. КАРТАШЕВ, И. М. ГРЕВС ${ }^{81}$. ВЫБРАВ СЕБЕ ИСТОРИЮ РАННЕХРИСТИАНСКОЙ ЦЕРКВИ В КАЧЕСТВЕ ТЕМЫ ДЛЯ ИССЛЕДОВАНИЙ, ОНА В 1917 Г. УЖЕ «ПРИУГОТОВЛЯЛАСЬ К ПРОФЕССОРСКОМУ ЗВАНИЮ В ПЕТЕРБУРГСКОМ УНИВЕРСИТЕТЕ». НО ЖИЗНЬ РАСПОРЯДИЛАСЬ ИНАЧЕ, ВОСТРЕБОВАВ ЕЕ ПРЕПОДАВАТЕЛЬСКИЕ НАВЫКИ В СОЗДАННЫХ НОВОЙ ВЛАСТЬЮ ВУЗАХ. В НАЧАЛЕ 1920-Х ОНА РАБОТАЛА В ГОСУДАРСТВЕННОЙ ПУБЛИЧНОЙ БИБЛИОТЕКЕ ИМ. М.Е. САЛТЫКОВА-ЩЕДРИНА, ОТКУДА ЕЕ (КАК ЧЛЕНА РЕЛИГИОЗНО-ФИЛОСОФСКОГО ОБЩЕСТВА «ВОСКРЕСЕНИЕ») ЗАБРАЛИ НА 5 ЛЕТ В ЛАГЕРЬ НА «РУССКУЮ ГОЛГОФУ», КАК ПОЗЖЕ НАЗВАЛИ ОСТРОВ СОЛОВКИ В БЕЛОМ МОРЕ. «АКТИРОВАННАЯ» ПО БОЛЕЗНИ, ОНА СНАЧАЛА БЫЛА ПЕРЕВЕДЕНА НА ПОСЕЛЕНИЕ, А ПОСЛЕ СНЯТИЯ ОБВИНЕНИЯ - ВЕРНУЛАСЬ В ЛЕНИНГРАД И С 1937 Г. ДО САМОЙ СМЕРТИ РАБОТАЛА В ЛЕНИНГРАДСКОМ ОТДЕЛЕНИИ ИНСТИТУТА ВОСТОКОВЕДЕНИЯ РАН (ЛО ИВ РАН). В ИЗВЕСТНОМ СМЫСЛЕ ЗАЩИТОЙ ЕЙ В ТЕ МРАЧНЫЕ ГОДЫ БЫЛ ЕЕ КОЛЛЕГА, ИЗБРАННЫЙ ДЕЙСТВИТЕЛЬНЫМ ЧЛЕНОМ АКАДЕМИИ НАУК И. А. ОРБЕЛИ, СОЗДАТЕЛЬ ОТДЕЛА ВОСТОКА В ЭРМИТАЖЕ.

В ВОЗРАСТЕ 45 ЛЕТ, ПЕРЕД САМОЙ ВОЙНОЙ, ЕЙ БЫЛО ПОЗВОЛЕНО ЗАЩИТИТЬ СРАЗУ ДОКТОРСКУЮ ДИССЕРТАЦИЮ (ПРАВИЛА ТОГО ВРЕМЕНИ ПОЗВОЛЯЛИ МИНОВАТЬ ЗАЩИТУ КАНДИДАТСКОЙ ДЛЯ ОСОБО ВЫДАЮЩИХСЯ УЧЕНЫХ $\left.{ }^{82}\right)$, И В ГОДЫ ВОЙНЫ ОНА БЫЛА ХРАНИТЕЛЕМ ВОСТОЧНЫХ РУКОПИСЕЙ В ПУБЛИЧНОЙ БИБЛИОТЕКЕ... ЗА ПРОШЕДШИЕ С ЕЕ ЮНОСТИ 20 ЛЕТ ОНА ТОЛЬКО ЕЩЕ БОЛЕЕ УБЕДИЛАСЬ В ИХ ЦЕННОСТИ И СУМЕЛА СОХРАНИТЬ ИХ, НЕСМОТРЯ НА РЕВОЛЮЦИИ И ВОЙНЫ, НА РАЗРУШЕНИЕ УСТОЕВ 
ОБЩЕСТВА, К КОТОРОМУ ОНА ПРИНАДЛЕЖАЛА ПО РОЖДЕНИЮ И ВОСПИТАНИЮ, КОГДА С БЕСПОЩАДНОЙ ЖЕСТОКОСТЬЮ ПОДАВЛЯЛОСЬ И ИСКОРЕНЯЛОСЬ МИРОСОЗЕРЦАНИЕ, КОТОРОЕ ОНА С ДЕТСТВА УСВОИЛА И КОТОРОМУ НЕ ИЗМЕНИЛА В ТЕЧЕНИЕ ВСЕЙ СВОЕЙ ЖИЗНИ... В ГОДЫ БЛОКАДЫ ЛЕНИНГРАДА ИНИЦИАТИВА ПИГУЛЕВСКОЙ, ГЛУБОКАЯ ПРЕДАННОСТЬ СВОЕМУ ДЕЛУ СЫГРАЛИ НЕМАЛУЮ РОЛЬ В ОРГАНИЗАЦИИ РАБОТ ПО СПАСЕНИЮ И СОХРАНЕНИЮ РУКОПИСНЫХ БОГАТСТВ ИНСТИТУТА. ПОСЛЕ ВОЙНЫ УЧЕНАЯ ПОЛУЧИЛА ЗВАНИЕ ПРОФЕССОРА, В 1946 Г. БЫЛА ИЗБРАНА ЧЛЕНОМ-КОРРЕСПОНДЕНТОМ $\mathrm{AH} \mathrm{CCCP}^{83}$.

ОДИН ИЗ КРУПНЕЙШИХ В РУССКОЙ ИСТОРИИ ВОСТОКОВЕДОВ-АРАБИСТОВ И СПЕЦИАЛИСТОМ ПО ИСТОРИИ ВИЗАНТИИ, ОНА БЫЛА АВТОРОМ 200 НАУЧНЫХ РАБОТ, В ТОМ ЧИСЛЕ 8 МОНОГРАФИЙ, ОСОБО ЦЕННЫМИ ИЗ КОТОРЫХ ОСТАЮТСЯ РЕ ИССЛЕДОВАНИЯ ПО ИСТОРИИ СИРИИ, ОНА ВОСПИТАЛА ПЛЕЯДУ УЧЕНИКОВ, БЫЛА БЛИСТАТЕЛЬНЫМ ОРГАНИЗАТОРОМ НАУКИ - СОЗДАТЕЛЬНИЦЕЙ КАБИНЕТА БЛИЖНЕГО ВОСТОКА В ИНСТИТУТЕ ВОСТОКОВЕДЕНИЯ РАН, ПРЕДСЕДАТЕЛЬНИЦЕЙ ПАЛЕСТИНСКОГО ОБЩЕСТВА ${ }^{84}$. ЖАЛЬ, ЧТО В НЕДАВНО ИЗДАННОМ СБОРНИКЕ ЕЕ ПАМЯТИ И В ЧЕСТЬ 100-ЛЕТИЯ СО ДНЯ ЕЕ РОЖДЕНИЯ, НЕТ ВОСПОМИНАНИЙ ТЕХ, КТО ПОМНИЛ ЕЕ В МОЛОДОСТИ ${ }^{85}$.

\section{С. И. Протасова}

СХОЖИЙ ПО УСПЕШНОСТИ НАУЧНЫЙ ПУТЬ ЖДАЛ ЕЩЕ ОДНУ ВЫПУСКНИЦУ ВЖК СОФЬЮ ИВАНОВНУ ПРОТАСОВУ (1878-1946) ${ }^{86}$. РОЖДЕННАЯ В СЕМЬЕ МОСКОВСКОГО ВРАЧА, ВЫПУСКНИЦА СТОЛИЧНЫХ ВЖК 1903 Г., ОНА БЫЛА УЧЕНИЦЕЙ М. И. РОСТОВЦЕВА И И. М. ГРЕВСА. ПОСЛЕ ЗНАКОМСТВА С ЗАПАДНЫМИ, ПРЕЖДЕ ВСЕГО ФРАНЦУЗСКИМИ БИБЛИОТЕКАМИ (В 1906 Г. С. И. ПРОТАСОВА БЫЛА КОМАНДИРОВАНА МИНИСТЕРСТВОМ НАРОДНОГО ПРОСВЕЩЕНИЯ ЗА ГРАНИЦУ С НАУЧНОЙ ЦЕЛЬЮ, ГДЕ УЧАСТВОВАЛА В СЕМИНАРАХ О.ГИРШФЕЛЬДА, Г. ДИЛЬСА, Э. МЕНЕРА И ИЗВЕСТНОГО ПАПИРОЛОГА Э. МЕЙЕРА), ОНА С 1909 Г. ПРЕПОДАВАЛА ИСТОРИЮ РИМА В ПЕТЕРБУРГЕ НА ВЖК, НАЧАЛА ПЕЧАТАТЬСЯ ${ }^{87} .1$ ИЮЛЯ 1917 Г., ВО ВРЕМЕНА РЕВОЛЮЦИОННОЙ НЕРАЗБЕРИХИ В СТОЛИЦЕ, ПЕРЕЕХАЛА В ТОМСК, ГДЕ КАК ИСТОРИК АНТИЧНОСТИ БЫЛА НАЗНАЧЕНА «ИСПРАВЛЯТЬ ДОЛЖНОСТЬ ЭКСТРАОРДИНАРНОГО ПРОФЕССОРА КАФЕДРЫ ВСЕОБЩЕЙ ИСТОРИИ ТОМСКОГО УНИВЕРСИТЕТА» И СТАЛА ПЕРВОЙ ЖЕНЩИНОЙ-ПРОФЕССОРОМ ТАМ В СОСТАВЕ ПРЕПОДАВАТЕЛЕЙ ${ }^{88}$. С 1921 Г. ОНА БЫЛА УЖЕ В САРАТОВЕ, ГДЕ ЕЕ ЛЕКЦИИ ПО ИСТОРИИ РИМА И ГРЕЦИИ ПОЛЬЗОВАЛИСЬ БОЛЬШОЙ ПОПУЛЯРНОСТЬЮ У СТУДЕНТОВ. С.И. ПРОТАСОВА БЫЛА И ЗАМЕЧАТЕЛЬНЫМ УЧЕНЫМ, И ЯРКОЙ ЛИЧНОСТЬЮ, ДА И ВЫБОР ЕЕ ТЕМ ПО СОЦИАЛЬНОЙ ИСТОРИИ АНТИЧНОСТИ ПРИВЛЕКАЛ УМЕНИЕМ ПРОСТО РАССКАЗАТЬ О сЛОЖНОМ.

ПРОФЕССОР С.И. ПРОТАСОВА ПРИНАДЛЕЖАЛА К СТАРШЕМУ ПОКОЛЕНИЮ СОВЕТСКИХ ИСТОРИКОВ, ПЕРЕХОДИВШИХ В 20-Х ГГ. НА ПОЗИЦИИ МАРКСИЗМА И РАЗДЕЛЯВШИХ ПРОГРЕССИВНЫЕ ВЗГЛЯДЫ, - ВСПОМИНАЛ ВПОСЛЕДСТВИИ ОДИН ИЗ ее МЛАДШИХ КОЛЛЕГ. - ЕЕ ЛЕКЦИИ И СЕМИНАРИИ ПО ИСТОРИИ ГРЕЦИИ И РИМА ВЫЗЫВАЛИ БОЛЬШОЙ ИНТЕРЕС У СТУДЕНТОВ. С. И. ПРОТАСОВА ПРИНИМАЛА АКТИВНОЕ УЧАСТИЕ В РУКОВОДСТВЕ СТУДЕНЧЕСКИМИ КРУЖКАМИ, В ЧАСТНОСТИ КРУЖКОМ ЛЮБИТЕЛЕЙ КЛАССИЧЕСКОЙ ФИЛОЛОГИИ, ОРГАНИЗОВАННЫМ ТОГДА ЕЩЕ МОЛОДЫМ ПРЕПОДАВАТЕЛЕМ М.Е. СЕРГЕЕНКО. ПОД РУКОВОДСТВОМ С.И. ПРОТАСОВОЙ, В ЧАСТНОСТИ, ЧИТАЛИСЬ И КОММЕНТИРОВАЛИСЬ ИЗВЕСТИЯ ГЕРОДОТА О ЮГЕ РОССИИ И ДРУГИЕ АНТИЧНЫЕ ИСТОЧНИКИ ${ }^{89}$. 
ПЕРЕД ВОЙНОЙ С. И. ПРОТАСОВА ПОЛУЧИЛА ЗВАНИЕ ПРОФЕССОРА В ЛЕНИНГРАДСКОМ ИНСТИТУТЕ ФИЛОЛОГИИ И ЛИТЕРАТУРЫ, ПОСЛЕ ВОЙНЫ РАБОТАЛА В СТОЛИЦЕ, В МГУ, А В ПОСЛЕДНИЕ ГОДЫ ЖИЗНИ БЫЛА НАУЧНЫМ СОТРУДНИКОМ ИНСТИТУТА ИСТОРИИ АН СССР. ЕЕ УЧЕНИКАМИ БЫЛИ ФИЛОСОФ И ПУБЛИЦИСТ, ПРОСЛАВИВШИЙСЯ ЗА РУБЕЖОМ, Г. П. ФЕДОТОВ, СОВЕТСКИЕ АНТИЧНИКИ А.И. ДОВАТУР, М.Е. СЕРГЕЕНКО - МЛАДШАЯ КОЛЛЕГА И ПОДРУГА СВОЕЙ ПРЕПОДАВАТЕЛЬНИЦЫ, НАЦЕЛИВШЕЙ ЕЕ НА НАПИСАНИЕ КНИГИ «ЖИЗНЬ ДРЕВНЕГО РИМА», ОПЯТЬ-ТАКИ СВЯЗАННОЙ С ЕЩЕ НЕ ОФОРМИВШИМСЯ ТОГДА НАПРАВЛЕНИЕМ ИСТОРИИ ПОВСЕДНЕВНОСТИ ${ }^{90}$.

\section{И другие...}

МЛАДШИМИ СОВРЕМЕННИЦАМИ О. А. ДОБИАШ-РОЖДЕСТВЕНСКОЙ, Л. И. ОЛАВСКОЙ И С. И. ПРОТАСОВОЙ БЫЛИ И ДВЕ РОДСТВЕННИЦЫ ОСТРОВСКИЕ - ПЛЕМЯННИЦА ДРАМАТУРГА А. Н. ОСТРОВСКОГО МАРИЯ АНДРЕЕВНА ${ }^{91}$ И ЕГО ДОЧЬ МАРИЯ АЛЕКСАНДРОВНА. ИХ ИМЕНА СЕЙЧАС МАЛОИЗВЕСТНЫ. ТЕМ НЕ МЕНЕЕ, СВОЙ ПОСИЛЬНЫЙ ВКЛАД ВНЕСЛИ В ИСТОРИОГРАФИЮ И ОНИ. УЧИВШИЕСЯ НА ВЖК В СТОЛИЦЕ ВМЕСТЕ С Е.А. БАЛЬМОНТ (УПОМЯНУВШЕЙ О НИХ В ВОСПОМИНАНИЯХ ${ }^{92}$ ), ОНИ ОБЕ, КАК И О.А. ДОБИАШ, Е.Н. ЩЕПКИНА И ДР., ПРИНАДЛЕЖАТ НЕ ТОЛЬКО РОССИЙСКОЙ ИСТОРИОГРАФИИ, НО И РОССИЙСКОМУ ЛИБЕРАЛЬНОМУ ЖЕНСКОМУ ДВИЖЕНИЮ ${ }^{93}$. ЭТО БЫЛИ ЖЕНЩИНЫ С АКТИВНОЙ ГРАЖДАНСКОЙ ПОЗИЦИЕЙ, НЕИСПРАВИМЫЕ СПОРЩИЦЫ. ОДНА, ПЛЕМЯННИЦА ПИСАТЕЛЯ, УЧЕНИЦА С.Ф. ПЛАТОНОВА, СТАЛА ПЕРВОЙ ЖЕНЩИНОЙ, ЗАЩИТИВШЕЙ МАГИСТЕРСКУЮ ДИССЕРТАЦИЮ НА ОТКРЫТОМ ДИСПУТЕ С УЧЕНЫМИ МУЖАМИ В РОССИИ 94. ЛИЧНЫЕ БУМАГИ ЭТИХ ЖЕНЩИН-ИСТОРИКОВ, НЕОПУБЛИКОВАННЫЕ РУКОПИСИ И ОРИГИНАЛЫ ОПУБЛИКОВАННЫХ ПРОИЗВЕДЕНИЙ ХРАНЯТСЯ В СОСТАВЕ ЛИЧНЫХ КОЛЛЕКЦИЙ СЕМЬИ ОСТРОВСКИХ 95 . ОБЕ ЖЕНЩИНЫ ПРОДОЛЖАЛИ РАБОТАТЬ И ПРИ СОВЕТСКОЙ ВЛАСТИ, ПЛЕМЯННИЦА ПИСАТЕЛЯ ОПУБЛИКОВАЛА СОЛИДНОЕ ИССЛЕДОВАНИЕ ПО ИСТОРИИ РУССКОЙ СМУТЫ ${ }^{96}$, А ДОЧЬ ВО ВТОРОЙ ПОЛОВИНЕ ЖИЗНИ СТАЛА ЖЕНОЙ ПЕРВОГО СОВЕТСКОГО ПРОФЕССОРА ЭЛЕКТРОТЕХНИКИ, АКАДЕМИКА М. А. ШАТЕЛЕНА И ОТОШЛА ОТ ЗАНЯТИЙ НАУКОЙ.

ЗАМЕТНОЙ ФИГУРОЙ НЕ СТОЛЬКО ДОРЕВОЛЮЦИОННОЙ РОССИЙСКОЙ, СКОЛЬКО ДОВОЕННОЙ СОВЕТСКОЙ ИСТОРИЧЕСКОЙ НАУКИ БЫЛА И НОННА ИВАНОВНА СПРЫГИНА (1880-1953) - АРХЕОЛОГ ${ }^{97}$, ЭТНОГРАФ (СПЕЦИАЛИСТ ПО ИСТОРИИ МАТЕРИАЛЬНОЙ КУЛЬТУРЫ МОРДВЫ), КРАЕВЕД ПЕНЗЕНСКОГО КРАЯ. РОДИВШАЯСЯ В ОДЕССЕ, В СЕМЬЕ СЛУЖАЩЕГО, ОНА ПОСЛЕ ЗАМУЖЕСТВА (Н. И. СПРЫГИН ТАК ЖЕ БЫЛ ЭТНОГРАФОМ) ОТДАЛА ВСЮ ЖИЗНЬ РАЗВИТИЮ ПЕНЗЕНСКОГО ОБЩЕСТВА ЛЮБИТЕЛЕЙ ЕСТЕСТВОЗНАНИЯ, СОЗДАНИЮ ПЕНЗЕНСКОГО КРАЕВЕДЧЕСКОГО МУЗЕЯ98 (В 2010 Г. МУЗЕЙ ШИРОКО ОТМЕТИЛ 160-ЛЕТНИЙ ЮБИЛЕЙ СВОЕЙ ОСНОВАТЕЛЬНИЦЫ). ОНА БЫЛА ИНИЦИАТОРОМ ИСТОРИЧЕСКОЙ ОРИЕНТАЦИИ МУЗЕЯ, ТЕМ САМЫМ ПОЛОЖИВ НАЧАЛО ЭТНОГРАФИЧЕСКИМ И АРХЕОЛОГИЧЕСКИМ ИССЛЕДОВАНИЯМ. С 1922 ПО 1930 ГОДЫ ОНА БЫЛА ЗАВЕДУЮЩЕЙ ОТДЕЛОМ АРХЕОЛОГИИ И ЭТНОГРАФИИ МУЗЕЯ, РУКОВОДИЛА ИССЛЕДОВАНИЯМИ АРХЕОЛОГИЧЕСКИХ ПАМЯТНИКОВ ПЕНЗЕНСКОГО КРАЯ, ЯВЛЯЕТСЯ АВТОРОМ АРХЕОЛОГИЧЕСКОЙ КАРТЫ ПЕНЗЕНСКОЙ ОБЛАСТИ, НАУЧНЫХ ИССЛЕДОВАНИЙ ПО АРХЕОЛОГИИ И ЭТНОГРАФИИ РЕГИОНА ${ }^{99}$. ПРАКТИЧЕСКИ РОВЕСНИЦА Н.И. СПРЫГИНОЙ - ВЕРА АЛЕКСАНДРОВНА КРАЧКОВСКАЯ (1884-1974) - ВОСТОКОВЕД, ЭПИГРАФИСТ, ПРОФЕССОР-АРАБИСТ - БЫЛА ЖЕНОЙ 
АКАДЕМИКА-ФИЛОЛОГА И. Ю. КРАЧКОВСКОГО. ОНА ОСТАВИЛА ОГРОМНОЕ НАУЧНОЕ НАСЛЕДИЕ, БЫЛА АВТОРОМ МНОГИХ МОНОГРАФИЙ, НО ИМЯ ЕЕ ЗАТЕРЯЛОСЬ НА ФОНЕ ЗАТМИВШЕЙ ЕЕ УСПЕХИ ФИГУРЫ МУЖА ${ }^{100}$. МЕЖДУ ТЕМ, В ФОНДЕ КРАЧКОВСКИХ (САНКТПЕТЕРБУРГСКОГО ФИЛИАЛА АРХИВА РАН) ХРАНЯТСЯ НЕ ТОЛЬКО ЕЕ НЕОПУБЛИКОВАННЫЕ РАБОТЫ, НО И МНОГОЧИСЛЕННЫЕ ПЕЙЗАЖИ, РИСУНКИ, СОБРАНИЯ ФОТОГРАФИЙ - ОНА БЫЛА ТАЛАНТЛИВА ВО ВСЕМ ${ }^{101}$. НО УСПЕХИ В НАУКЕ И ВКЛАД В НЕЕ МУЖА ЗАСТАВИЛИ ЗАТЕРЯТЬСЯ ДАЖЕ ДАТУ ЗАЩИТЫ В. А. КРАЧКОВСКОЙ ДОКТОРСКОЙ ДИССЕРТАЦИИ.

ФИГУРЫ Н. И. СПРЫГИНОЙ И В. А. КРАЧКОВСКОЙ ЗАКЛЮЧАЮТ ИСТОРИЮ ТОЙ ГЕНЕРАЦИИ РОССИЙСКИХ ЖЕНЩИН-ИСТОРИКОВ, КОТОРЫЕ БЫЛИ РОЖДЕНЫ ЕЩЕ В ХІХ В., ПОЛУЧИЛИ ОБРАЗОВАНИЕ В ЦАРСКОЙ РОССИИ И НАЧАЛИ СВОЮ ДЕЯТЕЛЬНОСТЬ ДО СОЗДАНИЯ НОВЫХ РОССИЙСКИХ НАУЧНЫХ СТРУКТУР. ПРАКТИЧЕСКИ ВСЕ ОНИ БЫЛИ ДВОРЯНКИ ИЛИ, ЕСЛИ И ПРИНАДЛЕЖАЛИ К СРЕДНИМ СЛОЯМ ГОРОДА, ПО РОЖДЕНИЮ ИМЕЛИ СРЕДСТВА И ВОЗМОЖНОСТИ ДЛЯ ПОЛУЧЕНИЯ ОБРАЗОВАНИЯ И ДАЛЬНЕЙШЕГО ПУТИ В НАУКУ. СИМВОЛИЧНО, ЧТО ИЗ ВСЕЙ СОВОКУПНОСТИ ИМЕН ИСТОРИКОВ ЭТОГО ПОКОЛЕНИЯ ТАКОВЫХ ОКАЗАЛОСЬ С НАЧАЛА 1800 Г. ВСЕГО ДЕСЯТЬ. ДЛЯ АБСОЛЮТНОГО БОЛЬШИНСТВА ЭТИХ ЖЕНЩИН-ИСТОРИКОВ НАУКА (ПО КРАЙНЕЙ МЕРЕ ДО 1917 ГОДА) НЕ БЫЛА СПОСОБОМ ЗАРАБАТЫВАТЬ НА ЖИЗНЬ, а БЫЛА ЧЕМ-ТО ДОПОЛНИТЕЛЬНЫМ К УЖЕ ИМЕЮЩИМСЯ В ИХ РАСПОРЯЖЕНИИ ДЕНЕЖНЫМ СРЕДСТВАМ.

\section{Советские женщины-историки, получившие звания членов-корреспондентов и академиков АН СССР и РАН по истории}

ЧТО КАСАЕТСЯ ВКЛАДА СОВЕТСКИХ ЖЕНЩИН-ИСТОРИКОВ, ПРОСЛАВИВШИХ СВОИ НАУЧНЫЕ НАПРАВЛЕНИЯ И ПОЛУЧИВШИХ ЗВАНИЯ ЧЛЕНОВ-КОРРЕСПОНДЕНТОВ И АКАДЕМИКОВ АН СССР И РАН ПО ИСТОРИИ, ТО ИХ БИОГРАФИИ - ОТДЕЛЬНАЯ СТРАНИЦА ИСТОРИИ НАУКИ. В НАСТОЯЩИЙ МОМЕНТ В РОССИИ НАСЧИТЫВАЕТСЯ ОКОЛО 400 ЖЕНЩИН-ДОКТОРОВ ИСТОРИЧЕСКИХ НАУК, ЧЬИ ИМЕНА ПОПАЛИ В СПРАВОЧНИКИ (368 СОГЛАСНО ДВУХТОМНИКУ А. А. ЧЕРНОБАЕВА $\left.{ }^{102}\right)$. ЗА ВСЕ ВРЕМЯ СУЩЕСТВОВАНИЯ АН СССР И ЕЕ ПРАВОПРЕЕМНИЦЫ РАН ПО ОТДЕЛЕНИЮ ИСТОРИИ ПОЛУЧИЛИ ЗВАНИЯ ЧЛЕНОВКОРРЕСПОНДЕНТОВ АКАДЕМИИ ИЛИ ЕЕ ДЕЙСТВИТЕЛЬНЫХ ЧЛЕНОВ ВСЕГО 5 ЖЕНЩИН. ПРИ ЭТОМ Т. И. АЛЕКСЕЕВА И А. П. БУЖИЛОВА, СТРОГО ГОВОРЯ, ЯВЛЯЮТСЯ НЕ ИСТОРИКАМИ, А АНТРОПОЛОГАМИ. НАПРОТИВ, В.П. АДРИАНОВА-ПЕРЕТЦ, ТАКЖЕ БЫВШАЯ ЧЛЕНОМКОРРЕСПОНДЕНТОМ АН СССР (НО ПО ЛИНИИ ЛИТЕРАТУРОВЕДЕНИЯ), ПРОСЛАВИВШАЯ ОТЕЧЕСТВЕННУЮ МЕДИЕВИСТИКУ, ИМЕЕТ ВСЕ ОСНОВАНИЯ СЧИТАТЬСЯ ЕЩЕ ОДНОЙ ЖЕНЩИНОЙ-ИСТОРИКОМ С МИРОВЫМ ИМЕНЕМ И ДОСТОЙНЫМ СТАТУСОМ.

ОСНОВНОЙ ЖЕ СОСТАВ ЖЕНСКОГО АКАДЕМИЧЕСКОГО ОЛИМПА - ЭТО А. М. ПАНКРАТОВА, М. В. НЕЧКИНА И З. В. УДАЛЬЦОВА - ЯВЛЯЮТСЯ НЕ ТОЛЬКО КРУПНЕЙШИМИ УЧЕНЫМИ С МИРОВЫМ ИМЕНЕМ, НО И ОРГАНИЗАТОРАМИ НАУКИ. БИОГРАФИИ А. М. ПАНКРАТОВОЙ И М.В. НЕЧКИНОЙ УЖЕ ИМЕЮТ СВОИХ ИССЛЕДОВАТЕЛЬНИЦ, ЧТО ЖЕ КАСАЕТСЯ З.В. УДАЛЬЦОВОЙ, ТО ЭТО, НАДО НАДЕЯТЬСЯ, ДЕЛО БЛИЖАЙШЕГО БУДУЩЕГО ${ }^{103}$. СОПОСТАВЛЯЯ ЖИЗНЕННЫЕ СТРАТЕГИИ СОВЕТСКИХ ЖЕНЩИН-ИСТОРИКОВ, ТРУДНО НЕ ОТМЕТИТЬ ТОГО, ЧТО МОТИВАЦИОННАЯ СОСТАВЛЯЮЩАЯ У СТАРШЕГО, СРЕДНЕГО И МЛАДШЕГО ПОКОЛЕНИЯ ИХ ОЧЕНЬ РАЗНИТСЯ. ДОСТАТОЧНО ОБРАТИТЬСЯ К МЕМУАРАМ САМЫХ СТАРШИХ, ЧТОБЫ ПОНЯТЬ, НАСКОЛЬКО ОНИ БЫЛИ АНГАЖИРОВАНЫ ИДЕОЛОГИЕЙ 
СВОЕГО ВРЕМЕНИ. ТЕКСТЫ ЭТИ ВРЯД ЛИ СОДЕРЖАТ ПОТАЕННЫЕ МЫСЛИ, ИХ НЕ ЗАПИСЫВАЛИ, ОСОБЕННО В ТЕ ВРЕМЕНА. ИДЕОЛОГИЯ ПЕРВОГО И ВТОРОГО СОВЕТСКОГО ДЕСЯТИЛЕТИЯ, ДА И ПОСЛЕВОЕННЫХ ЛЕТ ЗАСТАВЛЯЛА НАПРАВЛЯТЬ ВСЕ СИЛЫ, ЗНАНИЯ, ТАЛАНТЫ НЕ НА СОБСТВЕННОЕ БЛАГО, А НА «СЧАСТЛИВОЕ ЗАВТРА». КОНЕЧНО, ПОНИМАЛОСЬ ОНО ПО-РАЗНОМУ. НО БЫЛО У ТЕХ МОЛОДЫХ И ЮНЫХ ЖЕНЩИН, КТО ВЛАСТНО ВОРВАЛСЯ В МОЛОДУЮ СОВЕТСКУЮ НАУКУ, НЕЧТО ОБЩЕЕ: НЕПОНЯТНАЯ СОВРЕМЕННОМУ ЧЕЛОВЕКУ СТРАСТЬ К ЗНАНИЯМ У ТЕХ, КТО ПРОИСХОДИЛ ИЗ СЕМЕЙ, ГДЕ РОДИТЕЛИ НЕ ИМЕЛИ НЕ ТО, ЧТО ВЫСШЕГО, НО ЗАЧАСТУЮ ВООБЩЕ КАКОГО БЫ ТО НИ БЫЛО ОБРАЗОВАНИЯ.

\section{Р. А. Авербух и Г. М. Васильевич}

ЕСЛИ ПЕРВЫЕ РОССИЙСКИЕ ЖЕНЩИНЫ-ИСТОРИКИ БЫЛИ ЧАЩЕ ВСЕГО ИЗ ДВОРЯНСТВА, ТО ИХ ПРОДОЛЖАТЕЛЬНИЦЫ ПРОИСХОДИЛИ ИЗ «РАЗНЫХ ЧИНОВ», А ТЕ, ЧТО СТАЛИ УЧЕНЫМИ В 1920-Е ГОДЫ ОЧЕНЬ ЧАСТО БЫЛИ ИЗ САМЫХ БЕДНЫХ СЛОЕВ ГОРОДА И ИЗ РАБОЧЕЙ СРЕДЫ. ТАКОВОЙ БЫЛА БУДУЩАЯ ПРОФЕССОР ВСЕОБЩЕЙ ИСТОРИИ Р.А. АВЕРБУХ (1891-1978) ${ }^{104}$, ПРОИСХОДИВШАЯ ИЗ БЕДНОЙ ЕВРЕЙСКОЙ СЕМЬИ. ОКОНЧИВ КАЗАНСКИЕ ВЖК, ОНА БЫЛА ВСЕ ГОДЫ ГРАЖДАНСКОЙ ВОЙНЫ НА ПЕДАГОГИЧЕСКОЙ РАБОТЕ, А В КОНЦЕ 1920-ХГГ. ПОСТУПИЛА НАУЧНОЙ СОТРУДНИЦЕЙ В ИНСТИТУТ ИСТОРИИ КОМАКАДЕМИИ (ВПОСЛЕДСТВИИ - ИНСТИТУТ ИСТОРИИ АН СССР). ПРОФЕССОРСКОЕ ЗВАНИЕ ОНА ПОЛУЧИЛА ЕЩЕ В 1938 Г. И С 1944 Г. БЫЛА ПРОФЕССОРОМ МГУ. В ВОСПОМИНАНИЯХ О НЕЙ ОНА РИСУЕТСЯ «ТАКОЙ МИЛОЙ БАБУШКОЙ, НАПОМИНАВШЕЙ ПО ВНЕШНОСТИ МАРИЕТТУ ШАГИНЯН». ОДНАКО ОНА ПРИНАДЛЕЖАЛА К ПОКОЛЕНИЮ ТЕХ ИССЛЕДОВАТЕЛЬНИЦ, КТО ТЕРПЕЛИВО ПРИУЧАЛ «ЗАНИМАТЬСЯ РЕАЛЬНОЙ ИСТОРИЕЙ, УВАЖАТЬ ФАКТЫ» ${ }^{105}$.

ТАКОВОЙ БЫЛА Ее СОВРЕМЕННИЦА, ВЫДАЮЩИЙСЯ СОВЕТСКИЙ УЧЕНЫЙ-ТУНГУСОВЕД ГЛАФИРА МАКАРЬЕВНА ВАСИЛЕВИЧ (1895-1971). КАК И Р. А. АВЕРБУХ, ОНА ВЫРОСЛА В ПРОСТОЙ НЕБОГАТОЙ СЕМЬЕ, ОТЕЦ ЕЕ РАБОТАЛ НА ЗАВОДЕ, МАТЬ БЫЛА ДОМАШНЕЙ пОРТНИХОЙ.

БЛАГОДАРЯ ОТЛИЧНОЙ УЧЕБЕ ДЕВУШКУ ОСВОБОДИЛИ ОТ ПЛАТЫ ЗА ОБУЧЕНИЕ В ГИМНАЗИИ, ГДЕ ОНА СУМЕЛА ИЗУЧИТЬ В СОВЕРШЕНСТВЕ ИНОСТРАННЫЕ ЯЗЫКИ. ПОСЛЕ СМЕРТИ ОТЦА И БРАТА 22-Х ЛЕТНЯЯ ГЛАФИРА В ТЯЖЕЛЕЙШЕЕ ВРЕМЯ РЕВОЛЮЦИИ И ГРАЖДАНСКОЙ ВОЙНЫ, ГОЛОДА И РАЗРУХИ СТАЛА ОПОРОЙ ДЛЯ МАТЕРИ И БЛИЗКИХ. ВЫПУСКНИЦА ПЕРВОГО ВЫПУСКА ГЕОГРАФИЧЕСКОГО ИНСТИТУТА (ПЕРВОГО ВУЗА В РОССИИ, В КОТОРОМ ЭТНОГРАФИЯ ПРЕПОДАВАЛАСЬ КАК САМОСТОЯТЕЛЬНАЯ ДИСЦИПЛИНА) ОНА СТАЛА ОСНОВАТЕЛЬНИЦЕЙ ТУНГУСОВЕДЕНИЯ, ОСУЩЕСТВИЛА 13 ЭКСПЕДИЦИЙ НА СЕВЕР, НАПИСАЛА МНОЖЕСТВО ФУНДАМЕНТАЛЬНЫХ НАУЧНЫХ ТРУДОВ, СОСТАВИЛА АЗБУКУ И БУКВАРЬ ДЛЯ НАЧАЛЬНОЙ ШКОЛЫ НА ЭВЕНКИЙСКОМ, РАНЕЕ БЕСПИСЬМЕННОМ ЯЗЫКЕ ${ }^{106}$. ПО ВОСПОМИНАНИЯМ ЛЮДЕЙ, ХОРОШО ЗНАВШИХ ГЛАФИРУ МАКАРЬЕВНУ, ОНА ВСЕГДА ОТЛИЧАЛАСЬ ИСКЛЮЧИТЕЛЬНЫМ ТРУДОЛЮБИЕМ И РАБОТОСПОСОБНОСТЬЮ, ПРОВОДЯ ЗА ПИСЬМЕННЫМ СТОЛОМ ЕЖЕДНЕВНО НЕ МЕНЕЕ 12ТИ, А В СЛУЧАЕ СРОЧНОЙ РАБОТЫ И ПО 18 ЧАСОВ $^{107}$. КАК И ПО МНОГИМ ДРУГИМ ЖЕНСКИМ И МУЖСКИМ СУДЬБАМ, ПО ЕЕ ЖИЗНЕННОМУ ПУТИ БЕСПОЩАДНЫМ КОЛЕСОМ ПРОКАТИЛАСЬ ИСТОРИЯ: В ГОДЫ ЛЕНИНГРАДСКОЙ БЛОКАДЫ Г.М. ВАСИЛЕВИЧ ПОХОРОНИЛА ЕДИНСТВЕННОГО БЛИЗКОГО ЧЕЛОВЕКА - МАТЬ; В ПОСЛЕВОЕННЫЕ ГОДЫ 
БЫЛА ПО НАДУМАННОМУ ОБВИНЕНИЮ РЕПРЕССИРОВАНА, 3 ГОДА ПРОВЕЛА В ЛАГЕРЯХ, НО ВЫЙДЯ ОТТУДА ЕЩЕ 15 ЛЕТ ИНТЕНСИВНО ЗАНИМАЛАСЬ НАУЧНОЙ РАБОТОЙ.

\section{А. М. Панкратова}

ИЗ СЕМЬИ ПРОСТОГО РАБОЧЕГО ПРОИСХОДИЛА И БУДУЩИЙ АКАДЕМИК АНСССР (И ПЕРВАЯ ЖЕНЩИНА-АКАДЕМИК СРЕДИ ИСТОРИКОВ) АННА МИХАЙЛОВНА ПАНКРАТОВА. ВДОХНОВЛЕННАЯ ВИТАВШИМИ В ТОГДАШНЕМ ВОЗДУХЕ ИДЕЯМИ, ОНА ПИСАЛА, БУДУЧИ 24-ЛЕТНЕЙ ВЫПУСКНИЦЕЙ ИСТОРИКО-ФИЛОЛОГИЧЕСКОГО ФАКУЛЬТЕТА НОВОРОССИЙСКОГО УНИВЕРСИТЕТА: «ОСНОВНОЙ СМЫСЛ НАШИХ ЖИЗНЕЙ ‘... РЕВОЛЮЦИЯ, РАБОТА ДЛЯ НЕЕ, РКП, ПОСКОЛЬКУ ОНА ВЕДЕТ В РЕВОЛЮЦИЮ И НАС, ОТДАВШИХ ЕЙ СИЛЫ ${ }^{108}$.» ОНА ОКАЗАЛАСЬ ПЕРВОЙ ИЗ РОССИЙСКИХ ЖЕНЩИН-УЧЕНЫХ, ПОЛУЧИВШИХ ВЫСШЕЕ ОБРАЗОВАНИЕ НЕ НА ВЖК, А В РОССИЙСКОМ УНИВЕРСИТЕТЕ (В ОДЕССЕ), ХОТЯ ПО СВОЕМУ СОЦИАЛЬНОМУ ПРОИСХОЖДЕНИЮ - ИЗ СЕМЬИ РАБОЧЕГО ОНА ПОЧТИ НЕ ИМЕЛА НА ТО ШАНСОВ. СРАВНЕНИЕ ЕЕ ЖИЗНЕННОГО ПУТИ И ВСЕХ ЕЕ ПРЕДШЕСТВЕННИЦ ПРЕДСТАВЛЯЕТ ЕЕ СУДЬБУ БЕСКОНЕЧНОЙ БОРЬБОЙ, ИСТОРИЕЙ ВЫЖИВАНИЯ, КАК, ВПРОЧЕМ, И ВСЕЙ СТРАНЫ, В КОТОРОЙ ЕЙ ПРИШЛОСЬ СТРОИТЬ СВОЮ НАУЧНУЮ КАРЬЕРУ.

ЧАВ ОБРАЗОВАНИЕ В НАРОДНОЙ ШКОЛЕ, ОНА ПРОДОЛЖИЛА ЕГО В ГИМНАЗИИ, А В 1914

Г. И ПОСТУПИЛА НА ИСТОРИКО-ФИЛОЛОГИЧЕСКИЙ ФАКУЛЬТЕТ ВЖК. В ФЕВРАЛЕ 1917 Г. КУРСЫ БЫЛИ СЛИТЫ С ОДЕССКИМ (НОВОРОССИЙСКИМ) УНИВЕРСИТЕТОМ, И АННА МИХАЙЛОВНА ОКАЗАЛАСЬ В ЧИСЛЕ КУРСИСТОК, КОТОРЫЕ В 1917 Г. ЗАВЕРШИЛИ СВОЕ ОБРАЗОВАНИЕ УЖЕ В КАЧЕСТВЕ СТУДЕНТОК УНИВЕРСИТЕТА. ВГОДЫ ГРАЖДАНСКОЙ ВОЙНЫ УЧАСТВОВАЛА В ПАРТИЗАНСКОМ ДВИЖЕНИИ В ОДЕССКОЙ ГУБЕРНИИ, ДАЛЕЕ ДВА ГОДА ПРОВЕЛА НА ПАРТИЙНОЙ РАБОТЕ В УКРАИНЕ И НА УРАЛЕ.

А. М. ПАНКРАТОВА ИСПЫТЫВАЛА УДОВЛЕТВОРЕНИЕ ОТ ОБЩЕСТВЕННОГО ЗВУЧАНИЯ СВОЕЙ ДЕЯТЕЛЬНОСТИ, ОТ ПРИЧАСТНОСТИ СОБЫТИЯМ ВСЕРОССИЙСКОГО МАСШТАБА. ЛИЧНАЯ ЖИЗНЬ С ЕЕ ТРАДИЦИОННЫМИ ЦЕННОСТЯМИ БЫЛА ОТОДВИНУТА НА ЗАДНИЙ ПЛАН, КАЗАЛАСЬ «СЕРОЙ ОБЫВАТЕЛЬЩИНОЙ И МЕЩАНСТВОМ ${ }^{109}$ » - УЧЕНАЯ ПО ДУХУ И ЗОВУ ДУШИ ВСЕ СВОБОДНОЕ ОТ ОБЩЕСТВЕННОЙ РАБОТЫ ВРЕМЯ ПРОВОДИЛА В АРХИВАХ, СОБИРАЯ МАТЕРИАЛЫ К СВОЕЙ ПЕРВОЙ МОНОГРАФИИ ${ }^{110}$. В КОНЕЧНОМ СЧЕТЕ, ОНА СТАЛАТАКИ ВЫДАЮЩИМСЯ УЧЕНЫМ, КАК РАНЕЕ ПРЕДЧУВСТВОВАЛА: « ‘.. КОГДА Я БУДУ “ВЕЛИКИМ” ЧЕЛОВЕКОМ... ОЧЕНЬ ПРИГОДЯТСЯ МОИ ТЕТРАДИ ‘ ... ${ }^{\text {”11. } . » ~ В ~ 1922-1925 ~ Г О Д А Х ~}$ А. М. ПАНКРАТОВА ПРОДОЛЖИЛА ОБРАЗОВАНИЕ В ИНСТИТУТЕ КРАСНОЙ ПРОФЕССУРЫ (ИКП), ЧТО ТАКЖЕ ПРЕДОПРЕДЕЛИЛО СФЕРУ ЕЕ БУДУЩИХ НАУЧНЫХ ИНТЕРЕСОВ: ИМЯ ЕЕ НАВЕКИ СВЯЗАНО В НАШЕЙ ИСТОРИОГРАФИИ С ИСТОРИЕЙ РОССИЙСКОГО РАБОЧЕГО КЛАССА, ЕГО ДВИЖЕНИЕМ, ЕГО ОРГАНИЗАЦИЯМИ ${ }^{112}$. В ИКП, ПО ЕЕ СЛОВАМ, ГОТОВИЛИ «МАРКСИСТСКИ ВЫДЕРЖАННУЮ ПРОФЕССУРУ, ДЛЯ НАШИХ СОВЕТСКИХ ВУЗОВ, ГДЕ ОРУДОВАЛИ ВРАЖДЕБНЫЕ НАШЕМУ ДЕЛУ СТАРЫЕ БУРЖУАЗНЫЕ ПРОФЕССОРА, ЛИБО САБОТИРОВАВШИЕ, ЛИБО ВРЕДИВШИЕ В ТО ВРЕМЯ НАМ, НЕ ЖЕЛАЮЩИЕ ПРИНИМАТЬ НИ НАШЕГО СТРОЯ, НИ НАШЕЙ ИДЕОЛОГИИ ${ }^{113} 》$. ЯСНО, ЧТО ЭТОЙ ЖЕНЩИНЕ СУЖДЕНО БЫЛО СТАТЬ НЕ ПРОСТО «УЧЕНЫМ, А БОЙЦОМ ИСТОРИЧЕСКОГО ФРОНТА».

В ЛИЧНОМ АРХИВЕ А. М. ПАНКРАТОВОЙ ЕСТЬ ВОСПОМИНАНИЕ О ТОМ, КАК ОНА, 28ЛЕТНЯЯ, ЖДАЛА ПОЕЗДА НА ПЕРРОНЕ МОСКОВСКОГО ВОКЗАЛА - ТОГО, ЧТО ДОЛЖЕН БЫЛ ОТВЕЗТИ ЕЕ В ПЕРВУЮ НАУЧНУЮ КОМАНДИРОВКУ ЗА РУБЕЖ: 
ВЗВОЛНОВАННАЯ ПРЕДСТОЯЩЕЙ ПОЕЗДКОЙ, ПРЕДШЕСТВОВАВШИМИ ЕЙ СБОРАМИ, АННА МИХАЙЛОВНА РАСТЕРЯННО СТОЯЛА НА ПЕРРОНЕ С ПЛАЧУЩЕЙ МАЙЕЙ НА РУКАХ. РЕБЕНОК НИКАК НЕ УНИМАЛСЯ, ПОКА ПРОВОЖАВШИЕ НЕ ЗАМЕТИЛИ, ЧТО ПАНКРАТОВА ДЕРЖИТ ЗАВЕРНУТУЮ В ОДЕЯЛО ДОЧЬ ВНИЗ ГОЛОВОЙ ${ }^{114}$.

СТОИТ ДОБАВИТЬ, ЧТО А.М. ПАНКРАТОВА ЕХАЛА В КОМАНДИРОВКУ ОДНА С ГРУДНОЙ ДОЧКОЙ, НЕ РАССЧИТЫВАЯ НИ НА ЧЬЮ ПОМОЩЬ.

ГОДИЧНАЯ КОМАНДИРОВКА, КОТОРАЯ ТАК РАДОВАЛА УЧЕНУЮ, ПРЕВРАТИЛАСЬ В ПОЛУГОДОВУЮ. К ВЕЛИЧАЙШЕМУ ЕЕ СОЖАЛЕНИЮ, А. М. ПАНКРАТОВУ ОТОЗВАЛИ ИЗ ГЕРМАНИИ ТЕЛЕГРАММОЙ ИЗ ЦК: В ЧИСЛЕ ДРУГИХ КРАСНЫХ ПРОФЕССОРОВ ОНА БЫЛА МОБИЛИЗОВАНА НА ИДЕОЛОГИЧЕСКИЙ ФРОНТ, КАКОВЫМ СТАЛ ГОРОД НА НЕВЕ. СОСТОЯНИЕ ЗДОРОВЬЯ, ЛИЧНЫЕ НАУЧНЫЕ ПЛАНЫ И СЕМЕЙНЫЕ ПРОБЛЕМЫ В РАСЧЕТ ТОГДА НЕ ПРИНИМАЛИСЬ. ВПЕРЕДИ БУДУЩЕГО АКАДЕМИКА ЖДАЛИ ИСКЛЮЧЕНИЕ ИЗ ПАРТИИ, ССЫЛКА, ВОЙНА (РАЗМЕТАВШАЯ СЕМЬЮ), ТАК ЧТО ЗАНЯТИЕ НАУЧНОЙ РАБОТОЙ БЫЛО ДЛЯ АННЫ МИХАЙЛОВНЫ ДОЛГИЕ ГОДЫ И СМЫСЛОМ ЖИЗНИ, И ЕЕ НАПОЛНЕНИЕМ. НЕСМОТРЯ НА ТО, ЧТО А. М. ПАНКРАТОВА ИНОГДА СЕТОВАЛА НА СВОЮ ЗАГРУЖЕННОСТЬ, ТОЛЬКО ТАКАЯ ЖИЗНЬ БЫЛА ЕЙ И ПОСЛЕ, КОГДА ВСЕ НАЛАДИЛОСЬ, ПОНЯТНА, ТОЛЬКО ОНА ПРИНОСИЛА УДОВЛЕТВОРЕНИЕ: «СТРАННО У МЕНЯ ПОЛУЧАЕТСЯ ВСЮ МОЮ ЖИЗНЬ: НИКОГДА НЕ МОГУ НЕМНОЖКО ПОЖИТЬ ДЛЯ СЕБЯ. ТАК В НЕВЕРОЯТНОМ, ТОРОПЛИВОМ

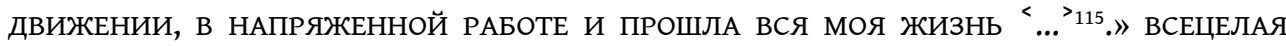
ОТДАННОСТЬ И ПРЕДАННОСТЬ ПРОФЕССИИ, ВЫБРАННОМУ ДЕЛУ - КОНЕЧНО, УДЕЛ ИЗБРАННЫХ. ОБЩАЯ ВОСПИТАТЕЛЬНАЯ УСТАНОВКА НА ТО, ЧТО ДЕВОЧКЕ ПРИДЕТСЯ БЫТЬ БОЛЕЕ ОБРЕМЕНЕННОЙ ЗАБОТАМИ О СЕМЬЕ И ДЕТЯХ, ЧЕМ ЕЕ СПУТНИКУ ЖИЗНИ, ЗАСТАВЛЯЛА ДЕЛАТЬ ЭТОТ ВЫБОР. И УБЕЖДЕНИЕ В ТОМ, ЧТО «ТАК БЫЛО ВСЕГДА И ТАК БУДЕТ» ВЛИЯЛО НА НАУЧНУЮ КАРЬЕРУ ЖЕНЩИН, НА ПРИНИМАЕМЫЕ ИМИ РЕШЕНИЯ И НА ОТНОШЕНИЕ К НИМ ${ }^{116}$.

САМА ПРОИСХОДИВШАЯ ИЗ РАБОЧЕЙ СРЕДЫ, А. М. ПАНКРАТОВА БЫЛА УВЕРЕНА, ЧТО НАУКЕ «НУЖНА МОЛОДЕЖЬ, ГЛУБОКО ПРОНИКШАЯСЯ ПРИНЦИПАМИ РЕВОЛЮЦИОННОГО МАРКСИЗМА» И ПОДДЕРЖИВАЛА В НАУКЕ ПРЕЖДЕ ВСЕГО ТЕХ, КТО ХОТЕЛ ИЗУЧАТЬ ИСТОРИЮ РАБОЧЕГО КЛАССА, ИСТОРИЮ РЕВОЛЮЦИЙ И ОСВОБОДИТЕЛЬНОГО ДВИЖЕНИЯ, СОБИРАТЬ МАТЕРИАЛЫ ДЛЯ «ИСТОРИИ ФАБРИК И ЗАВОДОВ ${ }^{117} »$. В ПОСЛЕВОЕННЫЕ ГОДЫ ОНА БЫЛА НАЗНАЧЕНА ГЛАВНЫМ РЕДАКТОРОМ ЦЕНТРАЛЬНОГО ИСТОРИЧЕСКОГО ЖУРНАЛА - «ВОПРОСЫ ИСТОРИИ». ОНА СТРЕМИЛАСЬ К ДЕЙСТВИТЕЛЬНОМУ РАЗВИТИЮ ИСТОРИЧЕСКОЙ НАУКИ, А НЕ К ОЧЕРЕДНОМУ ПРИСПОСОБЛЕНИЮ К НОВАЦИЯМ СВЕРХУ. ЭТО ОБСТОЯТЕЛЬСТВО ПРИВЕЛО К ТОМУ, ЧТО ПАНКРАТОВА И РУКОВОДИМЫЙ ЕЮ ЖУРНАЛ НАРУШИЛИ ПРИВЫЧНУЮ «СУБОРДИНАЦИЮ» ИСТОРИИ И ПОЛИТИКИ, ПОСТАВИВ ВО ГЛАВУ УГЛА НЕ «ВСЕСПАСИТЕЛЬНЫЕ» ПАРТИЙНЫЕ УКАЗАНИЯ ИЛИ «ДИРЕКТИВНЫЕ» СТАТЬИ, А «СВОБОДНЫЙ ОБМЕН МНЕНИЯМИ, ТВОРЧЕСКИЕ ДИСКУССИИ И СЕРЬЕЗНЫЕ НАУЧНЫЕ ИССЛЕДОВАНИЯ» ${ }^{118}$. ПОЭТОМУ, КОГДА ЗА НЕСГИБАЕМОСТЬ В СТРЕМЛЕНИИ К ЛИБЕРАЛИЗАЦИИ ИСТОРИЧЕСКОЙ НАУКИ УЧЕНУЮ ПОДВЕРГЛИ ТРАВЛЕ, ОНА Ее ПРОСТО НЕ ВЫДЕРЖАЛА. ПАНКРАТОВА ОТНОСИЛАСЬ К ТОМУ ПОКОЛЕНИЮ ПАРТИЙЦЕВ, КОТОРЫЕ ТВЕРДО СЛЕДОВАЛИ ЗА «ГЕНЕРАЛЬНОЙ ЛИНИЕЙ» ПАРТИИ. ОНА ПРИЗНАЛА НЕСОВЕРШЕННЫЕ РЕДКОЛЛЕГИЕЙ ЖУРНАЛА «ВОПРОСЫ ИСТОРИИ» ОШИБКИ, ПОДПИСАЛА К ПЕЧАТИ ОЧЕРЕДНОЙ НОМЕР ЖУРНАЛА, В КОТОРОМ СОЗНАВАЛАСЬ В СЛИШКОМ «ЛИБЕРАЛЬНОМ ТОЛКОВАНИИ ПОЛИТИКИ ПАРТИИ», «ОБЕЛЕНИИ ПОЗИЦИИ МЕНЬШЕВИКОВ» И ЧЕРЕЗ ЧЕТЫРЕ ДНЯ УМЕРЛА, 25 МАЯ 1957 Г. ВСЯ Ее СУДЬБА - СУДЬБА 
ЖЕНЩИНЫ-УЧЕНОЙ ТОЙ ЭПОХИ, ОТРАЗИВШАЯ МНОГИЕ ХАРАКТЕРНЫЕ ЧЕРТЫ ПЕРВОГО ПОКОЛЕНИЯ СОВЕТСКИХ ИСТОРИКОВ-ПРОФЕССИОНАЛОВ.

\section{Заключение}

ВПЕРВЫЕ ПРЕДПРИНЯТАЯ В ДАННОЙ СТАТЬЕ ПОПЫТКА ОЗВУЧИТЬ КРАТКИЙ ПЕРЕЧЕНЬ ТЕХ, КТО БЫЛ ЧАСТЬЮ НАШЕГО РОССИЙСКОГО ИСТОРИОПИСАНИЯ, НО ОКАЗАЛСЯ В БОЛЬШЕЙ ИЛИ МЕНЬШЕЙ СТЕПЕНИ ЗАБЫТ ИЛИ ОТОДВИНУТ НА ВТОРОЙ И ТРЕТИЙ ПЛАН, СТАНЕТ, НАДО НАДЕЯТЬСЯ, НАЧАЛОМ БОЛЬШОЙ РАБОТЫ ПО ВЫЯВЛЕНИЮ ВСЕХ НЕЗАСЛУЖЕННО ЗАБЫТЫХ ЖЕНСКИХ ИМЕН, «ЖЕНСКОГО ЛИЦА» РОССИЙСКОГО ИСТОРИОПИСАНИЯ. ХОЧЕТСЯ ВСЛЕД ЗА ПОЭТЕССОЙ АННОЙ АХМАТОВОЙ ВОСКЛИКНУТЬ:

ХОТЕЛОСЬ БЫ ВСЕХ ПОИМЕННО НАЗВАТЬ,

ДА ОТНЯЛИ СПИСОК, И НЕГДЕ УЗНАТЬ...

ДЛЯ НИХ СОТКАЛА Я ШИРОКИЙ ПОКРОВ

ИЗ БЕДНЫХ, У НИХ ЖЕ ПОДСЛУШАННЫХ СЛОВ...

В ОТЛИЧИЕ ОТ УЗНИЦ СТАЛИНСКИХ ЛАГЕРЕЙ, О КОТОРЫХ ПОЭТЕССА НАПИСАЛА ЭТИ СЛОВА, СПИСОК ЖЕНЩИН-УЧЕНЫХ (В ТОМ ЧИСЛЕ - ЖЕНЩИН-ИСТОРИКОВ) НИКЕМ И НИ У КОГО НЕ ОТНИМАЛСЯ. ЕГО ПРОСТО НЕ СОСТАВЛЯЛИ. НО ОН, ТЕМ НЕ МЕНЕЕ, НУЖЕН - ЭТО И ДАНЬ ПАМЯТИ ИМ, УЖЕ УШЕДШИМ, И ОРИЕНТИР ДЛЯ НАС, ЖИВУЩИХ И РАЗРАБАТЫВАЮЩИХ ТЕМЫ, КОТОРЫЕ БЫЛИ ИМИ ПОДНЯТЫ. В ТОМ ЧИСЛЕ И ПРЕЖДЕ ВСЕГО - ПО ЖЕНСКОЙ И ГЕНДЕРНОЙ ИСТОРИИ.

\section{NOTES}

1. ЦИТ. ПО: ВИДЕНСКИЙ В. С., «БЭРА БЕРИ, БАРИ» (К 100-ЛЕТИЮ СО ДНЯ РОЖДЕНЬЯ Н. К. БАРИ) // ИСТОРИКО-МАТЕМАТИЧЕСКИЕ ИССЛЕДОВАНИЯ, ВТОРАЯ СЕРИЯ, ВЫП.7(42), М., 2002, с. 241. ПОДГОТОВЛЕНО В РАМКАХ ПФИ РАН «ИСТОРИЧЕСКАЯ ПАМЯТЬ И РОССИЙСКАЯ ИДЕНТИЧНОСТЬ».

2. БЕЛИНСКИЙ В.Г., «ИСТОРИЯ РОССИИ В РАССКАЗАХ ДЛЯ ДЕТЕЙ. СОЧИНЕНИЕ АЛЕКСАНДРЫ ИШИМОВОЙ» // БЕЛИНСКИЙ В.Г., СОБРАНИЕ СОчИНЕНИЙ В ДЕВЯТИ ТОМАХ, Т. 4, М.: ХУДОЖЕСТВЕННАЯ ЛИТЕРАТУРА, 1979, <http://az.lib.ru/b/belinskij_w_g/text_0640.shtml>.

3. БЕЛИНСКИЙ В. Г., ИСТОРИЯ РОССИИ В РАССКАЗАХ ДЛЯ ДЕТЕЙ. СОЧ. АЛЕКСАНДРЫ ИШИМОВОЙ, СПБ.: ТИПОГРАФИЯ Е. ФИШЕРА, 1841, <http://dugward.ru/library/belinsky/belinskiy_rus_ist_ ishimovoy.html>.

4. АВЕРЬЯНОВА Л. Н., «АЛЕКСАНДРА ОСИПОВНА ИШИМОВА - ИЗВЕСТНАЯ РУССКАЯ ПИСАТЕЛЬНИЦА ХІХ ВЕКА, ПЕДАГОГ И ПЕРЕВОДЧИК» // ШКОЛЬНАЯ БИБЛИОТЕКА, 2004, № 5, с. 3137.

5. ЛИХАЧЕВА Е. И., МАТЕРИАЛЫ ДЛЯ ИСТОРИИ ЖЕНСКОГО ОБРАЗОВАНИЯ В РОССИИ, Т. 1-4, СПБ., 18901901.

6. ПОДРОБНЕЕ СМ.: НЕКРАСОВА Е., ИЗ ПРОШЛОГО ЖЕНСКИХ КУРСОВ, М., 1886.

7. ЦИТ. ПО: ДНЕПРОВ Э. Д. \& УСАЧЕВА Р. Ф., ЖЕНСКОЕ ОБРАЗОВАНИЕ В РОССИИ, М.: ДРОФА, 2009. 
8. ВСЕГО ЖЕ - СОГЛАСНО ДВУХТОМНИКУ (ЧЕРНОБАЕВ А. А., ИСТОРИКИ РОССИИ ХХ ВЕКА: БИОБИБЛИОГРАФИЧЕСКИЙ СЛОВАРЬ, Т. 1-2, САРАТОВ, 2005) - ЖЕНЩИН-ДОКТОРОВ ИСТОРИЧЕСКИХ НАУК МЕНЕЕ 400 (УПОМЯНУТО 368) ЧЕЛ.

9. БЕЛОЗЕРСКАЯ Н. А., «АВТОБИОГРАФИЯ» // ИСТОРИЧЕСКИЙ ВЕСТНИК, 1913, Т. 132, № 6, с. 925936.

10. БЕЛОЗЕРСКАЯ Н.А. (НАДЕЖДА АЛЕКСАНДРОВНА БЕЛОЗЕРСКАЯ, УРОЖДЕННАЯ ГЕНЪ), «АВТОБИОГРАФИЯ.» // ИСТОРИЧЕСКИЙ ВЕСТНИК, 1913, ИЮНЬ, С. 930; БЕЛОЗЕРСКАЯ Н. А., «РОССИЯ СТО ЛЕТ НАЗАД» // РУССКАЯ СТАРИНА, 1877; ЕЕ ЖЕ, «ПРОИСХОЖДЕНИЕ ЕКАТЕРИНЫ І» // РУССКАЯ СТАРИНА, СПБ., 1902; ЕЕ ЖЕ, «ПЕРВЫЕ ГОДЫ СБЛИЖЕНИЯ ПЕТРА С ЕКАТЕРИНОЙ» // РУССКАЯ СТАРИНА, СПБ., 1903; ЕЕ ЖЕ, «КНЯГИНЯ З. А. ВОЛКОНСКАЯ» // РУССКАЯ СТАРИНА, СПБ., 1897. СМ ТАКЖЕ: «НАДЕЖДА АЛЕКСАНДРОВНА БЕЛОЗЕРСКАЯ. НЕКРОЛОГ» // ИСТОРИЧЕСКИЙ ВЕСТНИК, СПБ., 1912, ВЫП. 4 (АПРЕЛЬ).

11. ШКОЛЬНЫЙ ИСТОРИЧЕСКИЙ СЛОВАРЬ, ПОД РЕД. Н. И. КАРЕЕВА, СПБ., 1906 (ОБ УЧАСТИИ С. КАРЕЕВОЙ СМ. РЕЦ. НА СЛОВАРЬ: ВЕСТНИК ВОСПИТАНИЯ, 1907, № 8, С. 63).

12. КОРЕЛИНА Н. П., ВОСПОМИНАНИЯ // ОТДЕЛ РУКОПИСЕЙ РГБ, Ф. 70, Д. 32.16.

13. КУНИЦКИЙ В., «НАУКА И ЖЕНЩИНА» // ЖЕНСКОЕ ОБРАЗОВАНИЕ, 1883, № 7.

14. ТИШКИН Г. А., ЖЕНСКИЙ ВОПРОС В РОССИИ. 50-60-Е ГГ. ХІХ В., Л., 1984.

15. АППЕЛЬРОД Г., «ОБРАЗОВАНИЕ ЖЕНЩИН СРЕДНЕГО И ВЫСШЕГО СОСТОЯНИЙ» // ОТЕЧЕСТВЕННЫЕ ЗАПИСКИ, 1858, № 2.

16. ДНЕПРОВ Э.Д., «ЖЕНСКОЕ ОБРАЗОВАНИЕ В ПОРЕФОРМЕННОЙ РОССИИ» // ФЕДОСОВА Э. П., БЕСТУЖЕВСКИЕ КУРСЫ - ПЕРВЫЙ ЖЕНСКИЙ УНИВЕРСИТЕТ В РОССИИ, М., 1980, с. 5-24.

17. СОБОЛЕВСКИЙ А. И., «П. С. УВАРОВА. 1840-1924. НЕКРОЛОГ» // ИЗВБСТІЯ РОССіЙСКОЙ АКАДЕМІИ НАУКЪ, VI СЕР., Т. 19 (ЧАСТИ 6-8), 1925, c. 141-144, <http://mi.mathnet.ru/izv4480>.

18. УВАРОВА П. С., БЫЛОЕ. ДАВНО ПРОШЕДШИЕ СЧАСТЛИВЫЕ ДНИ, М., 2005, с. 160.

19. ТАМ ЖЕ, С. 197, 206, 208.

20. БРЮЛЛОВА С. К., «ОБЩЕСТВЕННЫЕ ИДЕАЛЫ В ЕКАТЕРИНИНСКУЮ ЭПОХУ» // ВЕСТНИК ЕВРОПЫ, 1876, № 1 (В НЕЙ АВТОР ЗАДАЛАСЬ ЦЕЛЬЮ «ОТВЕТИТЬ НА ВОПРОСЫ, КАК У НАС ЖИЛИ, ДУМАЛИ, ЧЕГО ХОТЕЛИ ЕЩЕ НЕ ТАК ДАВНО»); БРЮЛЛОВА С.К., «НОВАЯ ТЕОРИЯ О ПРОИСХОЖДЕНИИ ФРАНЦИИ» // ВЕСТНИК ЕВРОПЫ, 1877, № 2 (ПО ПОВОДУ ИССЛЕДОВАНИЙ ФЮСТЕЛЬ ДЕ КУЛАНЖА О ВОЗНИКНОВЕНИИ ПОЛИТИЧЕСКИХ УЧРЕЖДЕНИЙ ДРЕВНЕЙ ФРАНЦИИ). НЕКРОЛОГ: СТАСЮЛЕВИЧ М., «СОФЬЯ БРЮЛЛОВА» // ВЕСТНИК ЕВРОПЫ, 1877, № 11.

21. ТУРГЕНЕВ И.С., «ИЗ ПИСЬМА В РЕДАКЦИЮ “ВЕСТНИКА ЕВРОПЫ” ПО ПОВОДУ СМЕРТИ С.К. БРЮЛЛОВОЙ» // ТУРГЕНЕВ И. С., СОБРАНИЕ СОЧИНЕНИЙ, В 12Т., Т. 12, М., 1979, с. 44.

22. ЦЕТКИН К., ИНТЕЛЛИГЕНТНЫЙ ПРОЛЕТАРИАТ, ЖЕНСКИЙ ВОПРОС И СОЦИАЛИЗМ, ОДЕССА, 1905, с. 6.

23. ГРОДЦЕК Г., ПРОБЛЕМА ЖЕНЩИНЫ, СПБ., 1904, с. 8.

24. ЛИХАЧЕВА Е. О., МАТЕРИАЛЫ ДЛЯ ИСТОРИИ ЖЕНСКОГО ОБРАЗОВАНИЯ В 1856-1880, СПБ., 1901, С. 459.

25. БЕЗ АВТОРА, МУЖЧИНА И ЖЕНЩИНА ВРОЗЬ И ВМЕСТЕ В РАЗЛИЧНЫЕ ЭПОХИ ИХ ЖИЗНИ, СПБ., 1859, С. 43.

26. ПОДРОБНЕЕ О ВРЕМЕННЫХ ПРАВИЛАХ, ВВЕДЕННЫХ ВЫСОЧАЙШИМ ПОВЕЛЕНИЕМ 31 МАЯ 1861

Г. СМ.: ГРИГОРЬЕВ В. В., «ИМПЕРАТОРСКИЙ С.-ПЕТЕРБУРГСКИЙ УНИВЕРСИТЕТ В ТЕЧЕНИЕ ПЕРВЫХ ПЯТИДЕСЯТИ ЛЕТ ЕГО СУЩЕСТВОВАНИЯ: ИСТОРИЧЕСКАЯ ЗАПИСКА», СПБ., 1870, с. 313.

27. ИВАНОВ А. Е., ВЫСШАЯ ШКОЛА РОССИИ В КОНЦЕ ХІХ - НАЧАЛЕ ХХ ВЕКА, М., 1991.

28. МЕЩЕРСКИЙ В., КН. «ЕЩЕ О ЖЕНСКОМ ВОПРОСЕ. ОТВЕТ БАРОНЕССЕ КОРФ»// ГРАЖДАНИН, 1872, № 19.

29. ЛИТВИНОВА П. Я., РУССКИЕ НАРОДНЫЕ УЗОРЫ, КИЕВ, 1872; ЕЕ ЖЕ, АЗБУКА ДЛЯ НАРОДНЫХ ШКОЛ, КИЕВ, 1877; ЕЕ ЖЕ, ЛИТВИНОВА П. Я., УЗОРЫ ВЫШИВАНЬЯ, ТКАНЬЯ И РИСОВАНИЯ / СОБРАЛА И СОСТ. ПЕЛАГЕЯ ЯКОВЛЕВНА ЛИТВИНОВА. КИЕВ, 1878; ЕЕ ЖЕ, ЮЖНОРУССКИЙ НАРОДНЫЙ ОРНАМЕНТ, КИЕВ, 
1878; ЕЕ ЖЕ, СБОРНИК НАРОДНЫХ РУССКИХ УЗОРОВ, КИЕВ, 1879. СМ. ТАКЖЕ ЕЕ СОЧ.: ЛИТВИНОВА П. Я., «ОЧЕРКИ ИЗ ЖИЗНИ СТАРОСВЕТСКИХ ПОМЕЩИКОВ» // КИЕВСКАЯ СТАРИНА, 1904, № 7/8, с. 176212 - ПРЕКРАСНОЕ ОПИСАНИЕ ДВОРЯНСКОГО ПРОВИНЦИАЛЬНОГО БЫТА.

30. М. И. МАКСИМОВА БЫЛА НАУЧНЫМ СОТРУДНИКОМ ОТДЕЛА АНТИЧНОГО МИРА ЛЕНИНГРАДСКОГО ГОСУДАРСТВЕННОГО ЭРМИТАЖА, ВРЕМЯ ПОЛУЧЕНИЯ ЕЮ ПРОФЕССОРСКОГО ЗВАНИЯ УСТАНОВИТЬ НЕ УДАЛОСЬ. ОДНАКО ПУБЛИКОВАТЬСЯ ОНА НАЧАЛА ЕЩЕ ДО 1917 ГОДА (СМ.: МАКСИМОВА М. И., АНТИЧНЫЕ ФИГУРНЫЕ ВАЗЫ, Т. 1. М., 1916; ЕЕ ЖЕ, АНТИЧНАЯ ГЕММА С ИЗОБРАЖЕНИЕМ ЛИКУРГА, ПГ., 1917).

31. ПРИСВЯчУЇТьСЯ ПАМ'ЯТі О. Я. ЄФИМЕНКОВОї, Харkів, 1930; МАРКОВ П. Г., А. Я. ЕФИМЕНКО ИСТОРИК УКРАИНЫ, КИЕВ: ИЗД-ВО КГУ, 1966.

32. МИНЕЕВА Т.А., «НАУКА ДЛЯ ВСЕХ ОДНА...» (ЖЕНЩИНЫ - ИСТОРИКИ В РОССИИ ВТОРОЙ ПОЛОВИНЫ ХІХ В.) // ЖЕНСКАЯ ИСТОРИЯ И СОВРЕМЕННЫЕ ГЕНДЕРНЫЕ РОЛИ/ ПОД РЕД. Н.Л. ПУШКАРЕВОЙ И ДР., М., 2010, С. 328.

33. МИРСКАЯ Е. 3. \& МАРТЫНОВА Е.А., «ЖЕНЩИНЫ-УЧЕНЫЕ: ПРОБЛЕМЫ И ПЕРСПЕКТИВЫ» // СОЦИАЛЬНАЯ ДИНАМИКА СОВРЕМЕННОЙ НАУКИ, М., 1995, С. 60-61.

34. МАРКОВ П. Г., А. Я. ЕФИМЕНКО - ИСТОРИК УКРАИНЫ, КИЕВ: ИЗД-ВО КГУ, 1966, с. 14, 18, 22. ГРУСТНО ДУМАТЬ О ТОМ, ЧТО И САМА А. Я. ЕФИМЕНКО, И ОДНА ИЗ ЕЕ ДОЧЕРЕЙ ПОГИБЛИ ОТ РУК «БАНДИТОВ» В ДЕКАБРЕ 1918 Г. (ХОТЯ НЫНЕ ТРУДНО ОПРЕДЕЛИТЬ, КАКОГО «ЦВЕТА» БЫЛИ ТЕ БАНДИТЫ, ЧТО УБИЛИ ДВОРЯНОК ЕФИМЕНКО).

35. СКАКУН О. Ф., «ХАРКІВСЬКИЙ ПЕРІОД ГРОМАДСЬКОЇ ДІЯЛЬНОСТІ О. Я. ЄФИМЕНКО» // ПИТАННЯ ІСТОРІЇ НАРОДІВ СРСР, ХАРЬКОВ, 1966, ВИП. 3, с. 117-124.

36. ЕФИМЕНКО А. Я. // <http://krotov.info/history/19/1890_10_2/1848_efimenko.htm>.

37. ЕФИМЕНКО А. Я., СЛОВАРЬ МЕСТНЫХ НАРЕЧИЙ АРХАНГЕЛЬСКОЙ ГУБЕРНИИ, СПБ., 1870; ЕФИМЕНКО А. Я., СБОРНИК МАТЕРИАЛОВ ОБ АРТЕЛЯХ РОССИИ, СПБ., 1873; ЕФИМЕНКО А.Я., «КРЕСТЬЯНСКОЕ ЗЕМЛЕВЛАДЕНИЕ НА КРАЙНЕМ СЕВЕРЕ» // ЕФИМЕНКО А. Я., ИССЛЕДОВАНИЯ НАРОДНОЙ ЖИЗНИ, М., 1884; ЕФИМЕНКО А. Я., ЮЖНАЯ РУСЬ, Т. 1-2, ХАРЬКОВ, 1905; ЕФИМЕНКО А. Я., ИСТОРИЯ УКРАИНСКОГО НАРОДА, СПБ., 1906.

38. СМОЛИЙ В.А., «А. Я. ЕФИМЕНКО: ОЧЕРК ЖИЗНИ И НАУЧНОГО ТВОРЧЕСТВА» // ЕФИМЕНКО А. Я., ИСТОРИЯ УКРАИНСКОГО НАРОДА, КИЕВ, 1990, С. 403-426.

39. ДАНИЛЕВИЧ В.Є., «НЕКРОЛОГ: О. Я. ЕФИМЕНКОВА» // НАШЕ МИНУЛЕ, КИЕВ, 1918, КН. 3, с. 105-111.

40. ПУШКАРЕВА Н. Л., ОСНОВНЫЕ ЦЕНТРЫ ИССЛЕДОВАНИЙ «ЖЕНСКОЙ ИСТОРИИ» НА ПОСТСОВЕТСКОМ ПРОСТРАНСТВЕ // СВАКД. (РЕД.), РЕГИОНАЛЬНЫЕ ШКОЛЫ РОССИЙСКОЙ ИСТОРИОГРАФИИ. ИССЛЕДОВАНИЯ БУДАПЕШТСКОГО ЦЕНТРА РУСИСТИКИ, Т. 18, БУДАПЕШТ, 2007, c. $45-55$.

41. ЩЕПКИНА Е. Н., СТАРИННЫЕ ПОМЕЩИКИ НА СЛУЖБЕ И ДОМА, СПБ., 1890.

42. СМ., НАПР.: ЩЕПКИНА Е.Н., «ВОСПОМИНАНИЯ И ДНЕВНИКИ РУССКИХ ЖЕНЩИН»// ИСТОРИЧЕСКИЙ ВЕСТНИК, 1914, № 8, с. 15-39; ЕЕ ЖЕ, «ЖЕНЩИНЫ В РУССКИХ УНИВЕРСИТЕТАХ» // ВЕСТНИК ЕВРОПЫ, 1912, № 9, с. 362-377; «ПЕРВЫЕ ГОДЫ ВЫСШИХ ЖЕНСКИХ КУРСОВ» // РУССКОЕ ПРОШЛОЕ, Т. V, ПЕТРОГРАД-М., 1923, С. 134-145. ПОЛНЫЙ ПЕРЕЧЕНЬ СМ.: ПУШКАРЕВА Н.Л., РУССКАЯ ЖЕНЩИНА: ИСТОРИЯ И СОВРЕМЕННОСТЬ, М., 2002 («Е. Н. ЩЕПКИНА»).

43. ЩЕПКИНА Е.Н., ЖЕНСКОЕ ДВИЖЕНИЕ, СПЬ., 1906; ЕЕ ЖЕ, ЖЕНСКОЕ ДВИЖЕНИЕ 1905 ГОДА В ОТЗЫВАХ СОВРЕМЕННЫХ ДЕЯТЕЛЕЙ, СПБ., 1906; ЕЕ ЖЕ, ИЗ ИСТОРИИ ЖЕНСКОЙ ЛИЧНОСТИ В РОССИИ. ЛЕКЦИИ И СТАТЬИ, СПБ., 1914; ЕЕ ЖЕ, ЩЕПКИНА Е. Н., К ИСТОРИИ РАЗВИТИЯ ЛИЧНОСТИ ЖЕНЩИНЫ, СПБ., 1914.

44. Edmondson L., Feminism in Russia 1900-1917, London, 1984.

45. ЩЕПКИНА Е. Н., ЖЕНСКОЕ ДВИЖЕНИЕ В ГОДЫ ФРАНЦУЗСКОЙ РЕВОЛЮЦИИ, ПБ., 1921. 
46. ЩЕПКИНА Е.Н., «ПЕРВЫЕ ГОДЫ ВЫСШИХ ЖЕНСКИХ КУРСОВ»// РУССКОЕ ПРОШЛОЕ, Т. V, ПЕТРОГРАД-М., 1923, С. 134-145.

47. ЛЮБИНА Г. И., РОССИЯ И ФРАНЦИЯ, ТАМ ЖЕ, С. 42.

48. СМ., НАПР.: ЛОТ-БОРОДИНА М., Unam sanctam: М.-J. Congar, О. P., Chrétiens désunis Principes d'un " Eccumenisme catholique ", Les Éditions du Cerf: [РЕЦЕНЗИЯ] / ПУТЬ, 1939, № 59 (2-4), с. 74-76.

49. РО ГОПБ, Ф. 254. (АРХИВ О. А. ДОБИАШ-РОЖДЕСТВЕНСКОЙ) 381 ЕД. ХР., 1874-1939. СМ. ТАКЖЕ: ВОРОНОВА Т.П., АРХИВ О.А. ДОБИАШ-РОЖДЕСТВЕНСКОЙ В ГПБ ИМ. М.Е. САЛТЫКОВАЩЕДРИНА // СРЕД. ВЕКА. ВЫП. 1, Л., 1942, С. 7-18.

50. ЛЮБЛИНСКАЯ А. Д., «О. А. ДОБИАШ-РОЖДЕСТВЕНСКАЯ КАК УЧЕНЫЙ» // УЧЕНЫЕ ЗАПИСКИ ЛГУ, СЕР. ИСТ. НАУК, ВЫП. 12, 1941; ЕЕ ЖЕ, «О. А. ДОБИАШ-РОЖДЕСТВЕНСКАЯ КАК ИСТОРИК» // СРЕД. ВЕКА, ВЫП. 1, 1942; ЕЕ ЖЕ, «ЗНАЧЕНИЕ ТРУДОВ О. А. ДОБИАШ-РОЖДЕСТВЕНСКОЙ ДЛЯ РАЗВИТИЯ ЛАТИНСКОЙ ПАЛЕОГРАФИИ В СССР» // ТАМ ЖЕ, ВЫП. 29, 1966; ВОРОНОВА Т. П., «АРХИВ О.А. ДОБИАШ-РОЖДЕСТВЕНСКОЙ В ГПБ ИМ. М.Е. САЛТЫКОВА-ЩЕДРИНА» // ТАМ ЖЕ; ЧЕХОВА Е. П., «ОЛЬГА АНТОНОВНА ДОБИАШ-РОЖДЕСТВЕНСКАЯ»// САНКТ-ПЕТЕРБУРГСКИЕ ВЫСШИЕ ЖЕНСКИЕ (БЕСТУЖЕВСКИЕ) КУРСЫ (1878-1918), Л., 1973; ВОРОНОВА Т. П., «ЗАСЕДАНИЕ, ПОСВЯЩЕННОЕ 100ЛЕТИЮ СО ДНЯ РОЖДЕНИЯ О.А. ДОБИАШ-РОЖДЕСТВЕНСКОЙ» // АРХЕОГРАФИЧЕСКИЙ ЕЖЕГОДНИК ЗА 1974 Г., М., 1975; КАГАНОВИЧ Б. С., «О. А. ДОБИАШ-РОЖДЕСТВЕНСКАЯ И ЕЕ НАУЧНОЕ НАСЛЕДИЕ» // ФРАНЦУЗСКИЙ ЕЖЕГОДНИК 1982, М., 1984; РУТЕНБУРГ В. И., «ВЫДАЮЩИЙСЯ МЕДИЕВИСТ И ПАЛЕОГРАФ» // ДОБИАШ-РОЖДЕСТВЕНСКАЯ О.А. КУЛЬТУРА ЗАПАДНОЕВРОПЕЙСКОГО СРЕДНЕВЕКОВЬЯ: НАУЧНОЕ НАСЛЕДИЕ / ОТВ. РЕД. В. И. РУТЕНБУРГ, М., 1987, С. 3-5.

51. ВИДЕНСКИЙ В.С., «БЭРА БЕРИ, БАРИ (К 100-ЛЕТИЮ СО ДНЯ РОЖДЕНЬЯ Н. К. БАРИ)»// ИСТОРИКО-МАТЕМАТИЧЕСКИЕ ИССЛЕДОВАНИЯ, ВТОРАЯ СЕРИЯ, ВЫП. 7 (42), М., 2002.

52. ЕРШОВА В. М., О. А. ДОБИАШ-РОЖДЕСТВЕНСКАЯ, Л., 1988 (БИБЛИОГР.).

53. ВРАСКАЯ О. Б., «ИЗ ВОСПОМИНАНИЙ ОБ О.А. ДОБИАШ-РОЖДЕСТВЕНСКОЙ» // О. А. ДОБИАШРОЖДЕСТВЕНСКАЯ. КУЛЬТУРА ЗАПАДНОГО СРЕДНЕВЕКОВЬЯ, М., 1987, С. 310-313; ЕРШОВА В. М., О. А. ДОБИАШ-РОЖДЕСТВЕНСКАЯ, Л., 1988.

54. СИПОВСКИЙ В., «ПОЛОЖЕНИЕ У НАС ВОПРОСА О ВЫСШЕМ ЖЕНСКОМ ОБРАЗОВАНИИ» // ЖЕНСКОЕ ОБРАЗОВАНИЕ. 1876, № 6, с. 260.

55. АНТРОПОЛОГИЯ // НАУЧНОЕ ОБОЗРЕНИЕ, 1900, № 3, с. 167 (167-174).

56. ЛОЗИНСКИЙ Е., «О НАСТОЯЩЕМ И БУДУЩЕМ ЖЕНСКОГО ДВИЖЕНИЯ (В СВЯЗИ С ПРОБЛЕМАМИ ЦЕЛОМУДРИЯ И ЗАДАЧАМИ МАТЕРИНСТВА)» // К СВЕТУ, СПБ., 1904, С. 38.

57. БЕРДЯЕВ Н. А., НОВОЕ РЕЛИГИОЗНОЕ СОЗНАНИЕ И ОБЩЕСТВЕННОСТЬ, СПБ., 1907, с. 174.

58. МОНОГРАФИИ: БРЮЛЛОВА-ШАСКОЛЬСКАЯ Н. В., КРЕСТЬЯНСКИЕ ВОССТАНИЯ В ГОДЫ НАПОЛЕОНОВСКИХ ВОЙН, М., 1931; ЕЕ ЖЕ, ОТКЛИКИ ПУГАЧЕВЩИНЫ. КРЕСТЬЯНСКОЕ ДВИЖЕНИЕ ПРИ ПАВЛЕ I, М., 1932. СМ. ТАКЖЕ: <wWw.prlib.ru/Lib/pages/item.aspx?itemid=69945>.

59. ФАМИЛЬНЫЙ САЙТ ШАСКОЛЬСКИХ // <http://shaskolsky.far.ru>.

60. ЦИТ. ПО: АНЦИФЕРОВ Н. П., ИЗ ДУМ О БЫЛОМ: ВОСПОМИНАНИЯ / ВСТУП. СТ., СОСТ., ПРИМЕЧ. И АННОТ. УКАЗ. ИМЕН А. И. ДОБКИНА, М.: ФЕНИКС: КУЛЬТУР. ИНИЦИАТИВА, 1992, с. 490.

61. ПОДРОБНЕЕ О ЖИЗНИ И СУДЬБЕ Л. И. ОЛАВСКОЙ СМ.: АНЦИФЕРОВ Н. П., ИЗ ДУМ О БЫЛОМ, М., 1992.

62. АНТОНОВ В.В., КЕРЗУМ А.П. \& ХМЕЛЕВСКАЯ Н.А., «ИЗ ИСТОРИИ ИНФОРМАЦИОННОБИБЛИОГРАФИЧЕСКОГО ОТДЕЛА РНБ» // ИНФОРМАЦИОННО-БИБЛИОГРАФИЧЕСКОЕ ОБСЛУЖИВАНИЕ, ВЫП. 1: ИСТОРИЯ И СОВРЕМЕННОЕ СОСТОЯНИЕ, СПБ., 2003, С. 14.

63. СМ., НАПРИМЕР: СВОДНЫЙ КАТАЛОГ ИНОСТРАННЫХ ПЕРИОДИЧЕСКИХ ИЗДАНИЙ 1914-1928ГГ., ИМЕЮЩИХСЯ В Б-КАХ ЛЕНИНГРАДА / СОСТ. КОЛЛЕКТИВ ПОД РУКОВОДСТВОМ Л. И. ОЛАВСКОЙ, Л., 1928.

64. ДЮМА А., ГРАФ МОНТЕ-КРИСТО / ПЕР. Л. И. ОЛАВСКОЙ, Л., 1931. 
65. ОЛАВСКАЯ Л. И. // РО РНБ, Ф. 10/1, ЛИЧНОЕ ДЕЛО; АРХИВ РОССИЙСКОЙ АКАДЕМИИ НАУК, САНКТ-ПЕТЕРБУРГСКИЙ ФИЛИАЛ, Ф. 726, ОП. 1, Д. 188.

66. ИГНАТОВИЧ И. И., ПОМЕЩИЧЬИ КРЕСТЬЯНЕ НАКАНУНЕ ОСВОБОЖДЕНИЯ, ИЗД. 3-Е., М., 1925; еЕ ЖЕ, «ВОЛНЕНИЯ ПОМЕЩИЧЬИХ КРЕСТЬЯН ОТ 1854 ДО 1863» // МИНУВШИЕ ГОДЫ, 1908, № 5-11; ЕЕ ЖЕ, БОРЬБА КРЕСТЬЯН ЗА ОСВОБОЖДЕНИЕ, Л.-М., 1924.

67. САНКТ-ПЕТЕРБУРГСКИЙ ФИЛИАЛ АРХИВА РАН (ФОНД 1023) ХРАНИТ НАУЧНЫЕ ТРУДЫ И. И. ИГНАТОВИЧ; ДОКУМЕНТЫ О НАУЧНОЙ И ПРЕПОДАВАТЕЛЬСКОЙ ЕЁ ДЕЯТЕЛЬНОСТИ, БИОГРАФИЧЕСКИЕ ДОКУМЕНТЫ, ФОТОГРАФИИ С СОРАТНИКАМИ ПО РЕВОЛЮЦИОННОЙ И ОБЩЕСТВЕННОЙ ДЕЯТЕЛЬНОСТИ (С А.Ф. КОНИ, А.В. ЛУНАЧАРСКИМ, В.Н. ФИГНЕР). И. И. ИГНАТОВИЧ ПЕРЕПИСЫВАЛАСЬ С Е. К. БРЕШКО-БРЕШКОВСКОЙ, С ИСТОРИКАМИ Б. Д. ГРЕКОВЫМ, Н. М. ДРУЖИНИНЫМ, С. И. ЗИЛЬБЕРШТЕЙНОМ, М. В. НЕЧКИНОЙ, В. Т. ПАШУТО.

68. ГАРФ. Ф. 8409, ОН-1, Д. 26, Л. 219-220; Д. 42, Л. 147.

69. ПРУССАК А.В., ОГОВОРЕ СЕСТРОРЕЦКА, СПБ., 1907; ЕЕ ЖЕ, ОПИСАНИЕ АЗБУКОВНИКОВ, ХРАНЯЩИХСЯ В РУКОПИСНОМ ОТДЕЛЕНИИ ИМП. ПУБЛИЧНОЙ БИБ-КИ, СПБ., 1915.

70. ЧЕРЕПЕНИНА Н. Ю., ШИКЕР А. К. \& ШКАРОВСКИЙ М. В., РИМСКО-КАТОЛИЧЕСКАЯ ЦЕРКОВЬ НА СЕВЕРО-ЗАПАДЕ РОССИИ В 1917-1945 ГГ., СПБ., 1998, С. 278.

71. БЕЛЯЕВА (ПРУССАК) А. В., «КРАСНОЯРСКИЙ СЕЛИТРЯНОЙ ЗАВОД» // ИСТОРИЧЕСКИЕ ЗАПИСКИ ИНСТИТУТА ИСТОРИИ АН СССР, 1940, с. 258-263.

72. ФОНД А. В. ПРУССАК // САНКТ-ПЕТЕРБУРГСКИЙ ФИЛИАЛ АРХИВА РАН, Ф. 133, ОП. 3, Д. 7, 46.

73. ВАЛК С.Н., «ИННА ИВАНОВНА ЛЮБИМЕНКО»// ТРУДЫ ЛЕНИНГРАДСКОГО ОТДЕЛЕНИЯ ИНСТИТУТА ИСТОРИИ АН СССР, Л., ВЫП. 2, 1961, с. 483-493; СОЛОДКИН Р. Я., «ОСНОВНЫЕ НАПРАВЛЕНИЯ НАУЧНОЙ ДЕЯТЕЛЬНОСТИ И.И.ЛЮБИМЕНКО И МЕСТО ЕЕ РАБОТ В ОТЕЧЕСТВЕННОЙ ИСТОРИОГРАФИИ ПЕРВОЙ ПОЛОВИНЫ - СЕРЕДИНЫ ХХ В.» АВТОРЕФ.ДИСС.... К.И.Н. СПЕЦИАЛЬНОСТЬ 07.00.09. НИЖНИЙ НОВГОРОД, 2009.

74. Lubimenko I., «Trois lettres inédites d'Élisabeth d'Angleterre à la cour de Russie» // Mélanges d'histoire offerts à M. Charles Bémont, Paris, 1913, c. 551-552; eE ЖЕ, «Les relations diplomatiques de l'Angleterre avec la Russie au Xvi ${ }^{\mathrm{e}}$ siècle» // Revue historique, 1916, т. 121, с. 4-12; люьимЕнко и., ИСТОРИЯ ТОРГОВЫХ СНОШЕНИЙ РОССИИ С АНГЛИЕЙ, ЮРЬЕВ, 1912.

75. ДУБРОВСКИЙ А. М. \& НАУМЕНКО С. И., «И. И. ЛЮБИМЕНКО: НОВЫЕ МАТЕРИАЛЫ О ЖИЗНИ И ДЕЯТЕЛЬНОСТИ» // ГОСУДАРСТВО И ОБЩЕСТВО В РОССИИ ХV-НАЧАЛА ХХ ВЕКА: СБОРНИК СТАТЕЙ ПАМЯТИ Н. Е. НОСОВА, СПБ., 2007, с. 489-503.

76. СОЛОДКИН Р.Я., «АРХИВНОЕ ДЕЛО В СССР И ЗА РУБЕЖОМ В СТАТЬЯХ ИСТОРИКА И. И. ЛЮБИМЕНКО В 1920-Е ГГ.» // ОТЕЧЕСТВЕННЫЕ АРХИВЫ, 2007, № 6, с. 12-21; ЛЮБИМЕНКО И. И., АРХИВНЫЕ КУРСЫ: ЛЕКЦИИ, ЧИТАННЫЕ В 1918 ГОДУ, ПГ., 1920, КН. 1-2.

77. ЛИЧНЫЕ ФОНДЫ И ДЕЛА И. И. ЛЮБИМЕНКО СМ.: САНКТ-ПЕТЕРБУРГСКИЙ ФИЛИАЛ АРХИВА РАН, Ф. 133, ОП. 3, Д. 170; Ф. 4, ОП. 4, Д. 3829; Ф. 7, оП. 3, Д. 61 и ДР.

78. «ИЗ ПЕРЕПИСКИ И.И. ЛЮБИМЕНКО С С.И. АРХАНГЕЛЬСКИМ»// ЦЕНТРАЛЬНЫЙ АРХИВ НИЖЕГОРОДСКОЙ ОБЛАСТИ (ДАЛЕЕ - ЦАНО), Ф. 6299 (С. И. АРХАНГЕЛЬСКОГО), ОП. 1, Д. 215, Л. 30, 113ов-114.

79. ЦАНО, Ф. 6299 (С. И. АРХАНГЕЛЬСКОГО), ОП. 1, Д. 215, Л. 66ОБ-67.

80. ГРИГОРЬЕВА Е.А., «К ИСТОРИИ КНИГИ И. И. ЛЮБИМЕНКО О РУССКО-АНГЛИЙСКИХ ОТНОШЕНИЯХ В XVIII В.»// ВЕСТНИК НИЖЕГОРОДСКОГО УНИВЕРСИТЕТА ИМ. Н. И. ЛОБАЧЕВСКОГО, 2010, № 4 (1), с. 198-201.

81. МЕЩЕРСКАЯ Е.Н., «К 100-ЛЕТИЮ СО ДНЯ РОЖДЕНИЯ Н.В. ПИГУЛЕВСКОЙ (1894-1970)»// ПРАВОСЛАВНЫЙ ПАЛЕСТИНСКИЙ СБОРНИК, ВЫПУСК 98 (35): СБОРНИК ПАМЯТИ Н.В. ПИГУЛЕВСКОЙ. ОТВЕТСТВЕННЫЙ РЕДАКТОР О. Г. ПЕРЕСЫПКИН, СПБ., 1998, С. 5-8.

82. ПУШКАРЕВА Н. Л., «КОГДА ЗАРПЛАТЫ БЫЛИ БОЛЬШИМИ» // РОССИЙСКАЯ ИСТОРИЯ, 2016, № 6, c. 69-83. 
83. ПАЙКОВА В.А. \& ЛЕБЕДЕВА И. Н., «Н. В. ПИГУЛЕВСКАЯ: К 75-ЛЕТИЮ СО ДНЯ РОЖДЕНИЯ» // НАРОДЫ АЗИИ И АФРИКИ, 1969, № 1, с. 64-66.

84. ЛУНДИН А.Г., СПИСОК ПЕЧАТНЫХ РАБОТ ЧЛ.КОРР. АНСССР Н.В. ПИГУЛЕВСКОЙ, М., 1965; УДАЛЬЦОВА 3. В., СОВЕТСКОЕ ВИЗАНТИНОВЕДЕНИЕ ЗА 50 ЛЕТ, М., 1969, С. 229-253.

85. СБОРНИК ПАМЯТИ Н. В. ПИГУЛЕВСКОЙ, ОТВЕТСТВЕННЫЙ РЕДАКТОР О. Г. ПЕРЕСЫПКИН, СПБ., 1998.

86. СМ.: «ПРОФ. С. И. ПРОТАСОВА. НЕКРОЛОГ» // ВЕСТНИК ДРЕВНЕЙ ИСТОРИИ, 1946, № 3, с. 239.

87. ПРОТАСОВА С. И., «К ВОПРОСУ ОБ ИСТОЧНИКАХ ПЛУТАРХА В БИОГРАФИИ ЛИКУРГА»// ЖУРНАЛ МИНИСТЕРСТВА НАРОДНОГО ПРОСВЕЩЕНИЯ, НОВАЯ СЕРИЯ, Ч. LIX, 1915, ОКТЯБРЬ, С. 430-436. 88. ГОСУДАРСТВЕННЫЙ АРХИВ ТОМСКОЙ ОБЛАСТИ, Ф. 102, ОП. 1, Д. 875, Л. 117-118; ОП. 9, Д. 399. 89. СОЛОМОНОВ В.А., «НАЧАЛО ПУТИ. ИСТОРИЯ ИНСТИТУТА»// САРАТОВСКИЙ ГОСУДАРСТВЕННЫЙ УНИВЕРСИТЕТ, <www.sgu.ru/faculties/historical/history/step2.php>.

90. ГАЛЯМИЧЕВА А., «ДВА НЕИЗВЕСТНЫХ АВТОГРАФА Г. П. ФЕДОТОВА» // ВЕК АЛЬМА-МАТЕР. СГУ, 2008, № 6 (2062).

91. ОСТРОВСКАЯ М.А., ВАЛААМ, СПБ., 1907; ОСТРОВСКАЯ М.А., ОПИСАНИЕ ДОКУМЕНТОВ, ПОСТУПИВШИХ В АРХЕОГРАФИЧ. КОМИССИЮ ИЗ ВЯТСКОЙ КАЗЕННОЙ ПАЛАТЫ, СПБ., 1907; ОСТРОВСКАЯ М.А., ЧЕТЫРЕ ДРЕВНИЕ ЧАСТНЫЕ ГРАМОТЫ, СПБ., 1908; ОСТРОВСКАЯ М.А., О ДРЕВНЕРУССКОМ ОДИНОЧЕСТВЕ, АРХАНГЕЛЬСК, 1911; ЕЕ ЖЕ, СУДНОЕ ДЕЛО ХVII В. ПО ПОВОДУ СКЛАДНОЙ ЗАПИСИ, КАЗАНЬ, 1911; ЕЕ ЖЕ, ИЗ ИСТОРИИ ВЯТСКИХ ИНОРОДЦЕВ. КАЗАНЬ, 1912; ЕЕ ЖЕ, ДРЕВНЕРУССКИЙ СЕВЕРНЫЙ МИР, АРХАНГЕЛЬСК, 1912. ГЛАВНЫЙ ТРУД - ОСТРОВСКАЯ М. А., ЗЕМЕЛЬНЫЙ БЫТ СЕЛЬСКОГО НАСЕЛЕНИЯ РУССКОГО СЕВЕРА В ХVI-XVIII ВЕКАХ, СПБ., 1913 (РЕЦ.: ГОЛОС МИН., 1914, № 5, C. 264-268).

92. АНДРЕЕВА-БАЛЬМОНТ Е. А., ВОСПОМИНАНИЯ, М.: ИЗДАТЕЛЬСТВО ИМ. САБАШНИКОВЫХ, 1997, С. 41.

93. ТИХОНОВ И. Л. \& СЕМЕНОВА Е.С., «ПЕРВАЯ ЖЕНЩИНА ПРЕПОДАВАТЕЛЬ САНКТПЕТЕРБУРГСКОГО УНИВЕРСИТЕТА » // САНКТ-ПЕТЕРБУРГСКИЙ УНИВЕРСИТЕТ, 2004, № 6 (5 МАРТА), С. 11-14.

94. СЕМЕВСКИЙ В. И., «ДИСПУТ М.А.осТРОВСКОЙ» // ГОЛОС МИНУВШЕГО, 1914, № 4, с. 17-26.

95. ОСТРОВСКИЕ // ГОСУДАРСТВЕННЫЙ МЕМОРИАЛЬНЫЙ И ПРИРОДНЫЙ МУЗЕЙ-ЗАПОВЕДНИК А. Н. ОСТРОВСКОГО «ЩЕЛЫКОВО». КОСТРОМСКАЯ ОБЛАСТЬ. 154 ЕД. ХР., 1846-1968 ГГ.

96. ОСТРОВСКАЯ М. А., ИЗ ИСТОРИИ СОЦИАЛЬНОЙ БОРЬБЫ В НОВГОРОДЕ ХVII ВЕКА, ВОЛОГДА, 1924.

97. «АРХЕОЛОГИЧЕСКОЕ НАСЛЕДИЕ Н. И. СПРЫГИНОЙ »// ОФИЦИАЛЬНЫЙ ПОРТАЛ ПРАВИТЕЛЬСТВА ПЕНЗЕНСКОЙ ОБЛАСТИ. КУЛЬТУРА. НОВОСТИ КУЛЬТУРЫ, <http://archive.pnzreg $. r u / c u l t u r e / n e w s / s p r i g i n a>$.

98. ЗОБНИНА Н., «КРАЕВЕД Н. И. СПРЫГИНА» // ЮБИЛЕЙНЫЙ СБОРНИК. К 50-ЛЕТИЮ ПЕНЗЕНСКОГО ОБЛАСТНОГО КРАЕВЕДЧЕСКОГО МУЗЕЯ (1905-1955), ПЕНЗА, 1957, С. 37-43.

99. СМ., НАПРИМЕР: СПРЫГИНА Н.И., ОДЕЖДА МОРДВЫ-МОКШИ КРАСНОСЛОБОДСКОГО И БЕДНОДЕМЬЯНОВСКОГО УЕЗДОВ ПЕНЗЕНСКОЙ ГУБЕРНИИ, ПЕНЗА, 1928.

100. КРАЧКОВСКАЯ В.А., МУСУЛЬМАНСКОЕ ИСКУССТВО В СОБРАНИИ ХАНЕНКО, Л., 1926; ЕЕ ЖЕ, ИЗРАЗЦЫ МАВЗОЛЕЯ ПИР-ХУСЕЙНА, ТБИЛИСИ, 1946; ЕЕ ЖЕ, ЭПИГРАФИКА ВОСТОКА, М.-Л., 1947; ЕЕ ЖЕ, ЭВОЛЮЦИЯ КУФИЧЕСКОГО ШРИФТА В СРЕДНЕЙ АЗИИ, М., 1949; ЕЕ ЖЕ, ПАМЯТНИКИ АРАБСКОГО ПИСЬМА В СРЕДНЕЙ АЗИИ И ЗАКАВКАЗЬЕ ДО ІХ В., М.-Л., 1952; ЕЕ ЖЕ, В. В. БАРТОЛЬД - НУМИЗМАТ И ЭПИГРАФИСТ, М.-Л., 1953; ЕЕ ЖЕ, АРАБСКОЕ ПИСЬМО НА ПАМЯТНИКАХ СРЕДНЕЙ АЗИИ И ЗАКАВКАЗЬЯ, М.-Л., 1955; ЕЕ ЖЕ, АРАБСКАЯ ЭПИГРАФИКА НА КАВКАЗЕ, М.-Л., 1958; ЕЕ ЖЕ, РЕДКАЯ РУКОПИСЬ КОРАНА ХVІ ВЕКА, М., 1960; ЕЕ ЖЕ, ЖЕНСКАЯ ОДЕЖДА ХАДРАМАУТА, Л., 1964.

101. СПБФ АРХИВА РАН, Ф. 1026 (КРАЧКОВСКИЕ), ОП. 9, Д. 37, Л. 1-23; Д. 47, л. 1-33; Д. 65, л. 1-46. 102. В ТОМ ЖЕ СПРАВОЧНИКЕ А.А. ЧЕРНОБАЕВА УПОМЯНУТО ЕЩЕ ОКОЛО ПОЛУТОРА СОТЕН ЖЕНЩИН-ИСТОРИКОВ КАНДИДАТОВ НАУК, ЧЬИ РАБОТЫ ОКАЗАЛИ СУЩЕСТВЕННОЕ ВЛИЯНИЕ НА РАЗВИТИЕ РАЗЛИЧНЫХ НАПРАВЛЕНИЙ. 
103. АКАДЕМИК А. М. ПАНКРАТОВА, В СБОРНИКЕ: ИЗ ИСТОРИИ РАБОЧЕГО КЛАССА И РЕВОЛЮЦИОННОГО ДВИЖЕНИЯ, М., 1958; СИДОРОВА Л.А., «АННА МИХАЙЛОВНА ПАНКРАТОВА (1897-1957)»// ИСТОРИКИ РОССИИ. БИОГРАФИИ, М., 2001, с. 685-690; БАДЯ Л. В., АКАДЕМИК А. М. ПАНКРАТОВА ИСТОРИК РАБОЧЕГО КЛАССА СССР, М., 1979.

104. АВЕРБУХ Р. А., ЦАРСКАЯ ИНТЕРВЕНЦИЯ В БОРЬБЕ С ВЕНГ. РЕВОЛЮЦИЕЙ 1848-1849 ГГ., М., 1935; ЕЕ ЖЕ, ИТАЛИЯ В ПЕРВОЙ И ВТОРОЙ МИР. ВОЙНАХ, М., 1946; ЕЕ ЖЕ, РЕВОЛЮЦИЯ И НАЦИОНАЛЬНООСВОБОДИТЕЛЬНАЯ БОРЬБА В ВЕНГРИИ 1848-1849 ГГ., М. 1965; ЕЕ ЖЕ, РЕВОЛЮЦИЯ В АВСТРИИ (1848-1849 ГГ.), М., 1970.

105. ЧЕРНЯЕВ А. С., «ДВА СЛОВА О КАФЕДРЕ НОВОЙ И НОВЕЙШЕЙ ИСТОРИИ МГУ» // МГУ ИМ. М. В. ЛОМОНОСОВА. ИСТОРИЧЕСКИЙ ФАКУЛЬТЕТ (<www.hist.msu.ru/Departments/ModernHist/node $/ 34>)$.

106. ВАСИЛЕВИЧ Г. М., ТИПЫ ОЛЕНЕВОДСТВА У ТУНГУСОЯЗЫЧНЫХ НАРОДОВ, М., 1964; ЕЕ ЖЕ, ИСТОРИЧЕСКИЙ ФОЛЬКЛОР ЭВЕНКОВ, М.-Л., 1966 И ДР.

107. ЕРМОЛОВА Н.В., «Г. М. ВАСИЛЕВИЧ КАК ЭТНОГРАФ-ТУНГУСОВЕД»// РЕПРЕССИРОВАННЫЕ ЭТНОГРАФЫ, ВЫП. 2, М., 2003, с. 10-46.

108. А. М. ПАНКРАТОВА - В.А. ДОМБРОВСКОМУ, 28 ДЕКАБРЯ 1921 Г. ЛИЧНЫЙ АРХИВ М. Г. ПАНКРАТОВОЙ // ИСТОРИК И ВРЕМЯ. 20-50-Е ГОДЫ ХХ ВЕКА, А. М. ПАНКРАТОВА, М., 2000, с. 262.

109. А. М. ПАНКРАТОВА - В.А. ДОМБРОВСКОМУ, 12 ФЕВРАЛЯ 1922 Г. ЛИЧНЫЙ АРХИВ М. Г. ПАНКРАТОВОЙ // ИСТОРИК И ВРЕМЯ. 20-50-Е ГОДЫ ХХ ВЕКА, А. М. ПАНКРАТОВА, М., 2000, с. 264.

110. ПАНКРАТОВА А. М., ФАБРИЧНО-ЗАВОДСКИЕ КОМИТЕТЫ В РОССИИ В БОРЬБЕ ЗА СОЦИАЛИСТИЧЕСКУЮ ФАБРИКУ, М., 1923. ЕЙ БЫЛО В ТО ВРЕМЯ ВСЕГО 27 ЛЕТ!

111. «ИЗ ЛИЧНЫХ ДНЕВНИКОВ АКАДЕМИКА М.В. НЕЧКИНОЙ», ПУБЛ. Е. Р. КУРАПОВОЙ // ОТЕЧЕСТВЕННЫЕ АРХИВЫ, 1997, № 5, с. 55-92; № 6, с. 42-93.

112. ПАНКРАТОВА А. М., ФАБЗАВКОМЫ В БОРЬБЕ ЗА СОЦИАЛИСТИЧЕСКУЮ ФАБРИКУ, М., 1923; ЕЕ ЖЕ, ФАБЗАВКОМЫ И ПРОФСОЮЗЫ. РОССИЯ, ГЕРМАНИЯ, ИТАЛИЯ И ФРАНЦИЯ, М., 1924; еЕ ЖЕ, ФОРМИРОВАНИЕ ПРОЛЕТАРИАТА В РОССИИ (ХVII-XVIII ВВ.), М., 1963; ЕЕ ЖЕ, РАБОЧИЙ КЛАСС РОССИИ. ИЗБРАННЫЕ ТРУДЫ , M., 1983.

113. ПАНКРАТОВА А. М., ВОСПОМИНАНИЯ // АРХИВ РАН, Ф. 697, ОП. 2, Д. 186, Л. 29.

114. АРХИВ РАН. Ф. 697 (А. М. ПАНКРАТОВА), ОП. 2, Д. 186, Л. 17; СИДОРОВА Л. А., «ОБЩИЕ ПРОБЛЕМЫ ИСТОРИЧЕСКОЙ НАУКИ: ПРОБЛЕМЫ “ОТЦОВ” И “ДЕТЕЙ” В ИСТОРИЧЕСКОМ СООБЩЕСТВЕ» // ИСТОРИЯ И ИСТОРИКИ, 2002, № 1, с. 34.

115. ПИСЬМО А. М. ПАНКРАТОВОЙ С. В. БАХРУШИНУ, 26 ИЮЛЯ 1936 Г. // ИСТОРИК И ВРЕМЯ. 20-50-Е ГОДЫ ХХ ВЕКА: А М.ПАНКРАТОВА, М., 2000, с. 305.

116. ИСТОРИК И ВРЕМЯ. 20-50-Е ГОДЫ ХХ ВЕКА: А. М. ПАНКРАТОВА, М., 2000.

117. БАДЯ Л. В., А. М. ПАНКРАТОВА - ИСТОРИК РАБОЧЕГО КЛАССА СССР, М., 1979.

118. «РЕДАКЦИОННАЯ СТАТЬЯ» // ВОПРОСЫ ИСТОРИИ, 1956, №3, с. 12.

\section{RÉSUMÉS}

ИМЕНА ПЕРВЫХ РОССИЙСКИХ ЖЕНЩИН-ИСТОРИКОВ ПОЧТИ ЗАБЫТЫ. ДАННЫЙ ТЕКСТ СТАВИТ ЦЕЛЬЮ НАПОМНИТЬ ИХ, ЗАДУМАТЬСЯ НАД СВОЕОБРАЗИЕМ СПОСОБОВ СОЦИАЛЬНОГО ВЫЖИВАНИЯ, ЖИЗНЕННЫХ СТРАТЕГИЙ, ОБРАЗОВ ЖИЗНИ МУЖЧИН И ЖЕНЩИН В ИСТОРИЧЕСКОЙ НАУКЕ, ИХ СОЦИАЛЬНЫХ НАСТРОЕНИЙ, АКСИОСФЕРЫ, БЮДЖЕТА ВРЕМЕНИ, МОДЕЛЕЙ 
МЕЖЛИЧНОСТНОГО И МЕЖГРУППОВОГО ВЗАИМОДЕЙСТВИЯ. РАБОЧАЯ ГИПОТЕЗА СОСТОИТ В ФИКСАЦИИ ПРОБЛЕМЫ ИСТОКОВ ГЕНДЕРНЫХ ДИСКРИМИНАЦИЙ В НАУКЕ (КАК РОССИЙСКОЙ, ТАК И ЕВРОПЕЙСКОЙ). ОТСУТСТВИЕ ДО СЕЙ ПОРЫ ДАЖЕ ФОРМАЛЬНОГО СПИСКА РОССИЙСКИХ ЖЕНЩИН-УЧЕНЫХ (В ТОМ ЧИСЛЕ - ЖЕНЩИН-ИСТОРИКОВ) - ПОКАЗАТЕЛЬ ОТСУТСТВИЯ ИНТЕРЕСА К ЖИЗНИ ЖЕНЩИН В НАУКЕ, К ТЕМАТИКЕ, КОТОРАЯ ИМИ ВЫБИРАЛАСЬ,- ЭТО НЕПРИЗНАНИЕ «ОСОБОСТИ» СУЩЕСТВОВАНИЯ ЖЕНЩИН В НАУЧНОМ СООБЩЕСТВЕ. ИСТОРИЧЕСКАЯ СПРАВЕДЛИВОСТЬ ВОССТАНАВЛИВАЕТСЯ ЭТИМ ТЕКСТОМ, В КОТОРОМ ПРЕДСТАВЛЕНЫ КРАТКИЕ ЖИЗНЕОПИСАНИЯ ДВАДЦАТИ ПЕРВЫХ РУССКИХ ЖЕНЩИН-ИСТОРИКОВ.

The names of the first Russian women historians are almost forgotten. This text aims to reflect on the specific ways of social survival, life strategies, ways of life of men and women in historical sciences, their social attitudes, system of values, time, budget, models of interpersonal and intergroup interactions among academicians. The main goal was to investigate the problem of the origins of gender discrimination in Russian Academia. The absence of even a formal list of Russian women scholars (including female historians) seems to be an indicator of the lack of interest in the lives of women in Academia. Historical justice is restored with this text, which presents brief biographies of some number of Russian women historians who were the first ones in the field.

\section{INDEX}

Keywords : woman, women's history, women scientists, Russian women historians, gender history, women's daily life

motsclesru ЖЕНЩИНА, ЖЕНСКАЯ ИСТОРИЯ, ЖЕНЩИНЫ-УЧЕНЫЕ, РОССИЙСКИЕ ЖЕНЩИНЫИСТОРИКИ, ГЕНДЕРНАЯ ИСТОРИЯ, ЖЕНСКАЯ ПОВСЕДНЕВНОСТЬ

\section{AUTEUR}

\section{НАТАЛЬЯ ЛЬВОВНА ПУШКАРЁВА}

Institut d'ethnologie et anthropologie, Académie des sciences de Russie 